\title{
Propellant Expulsion in Unmanned Spacecraft
}

\author{
R. N. Porter
}

H. B. Stanford

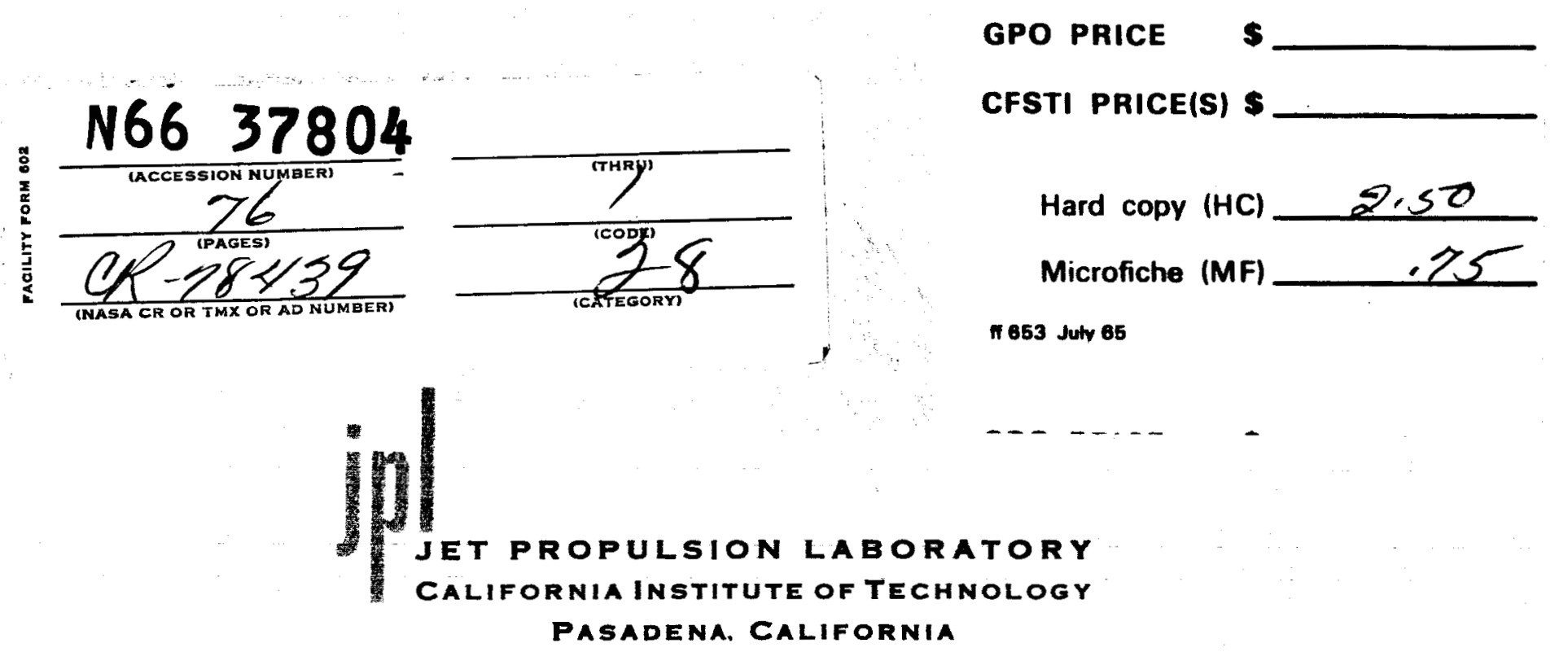

July 1, 1966 


\title{
Propellant Expulsion in Unmanned Spacecraft
}

\author{
R. N. Porter
}

H. B. Stanford
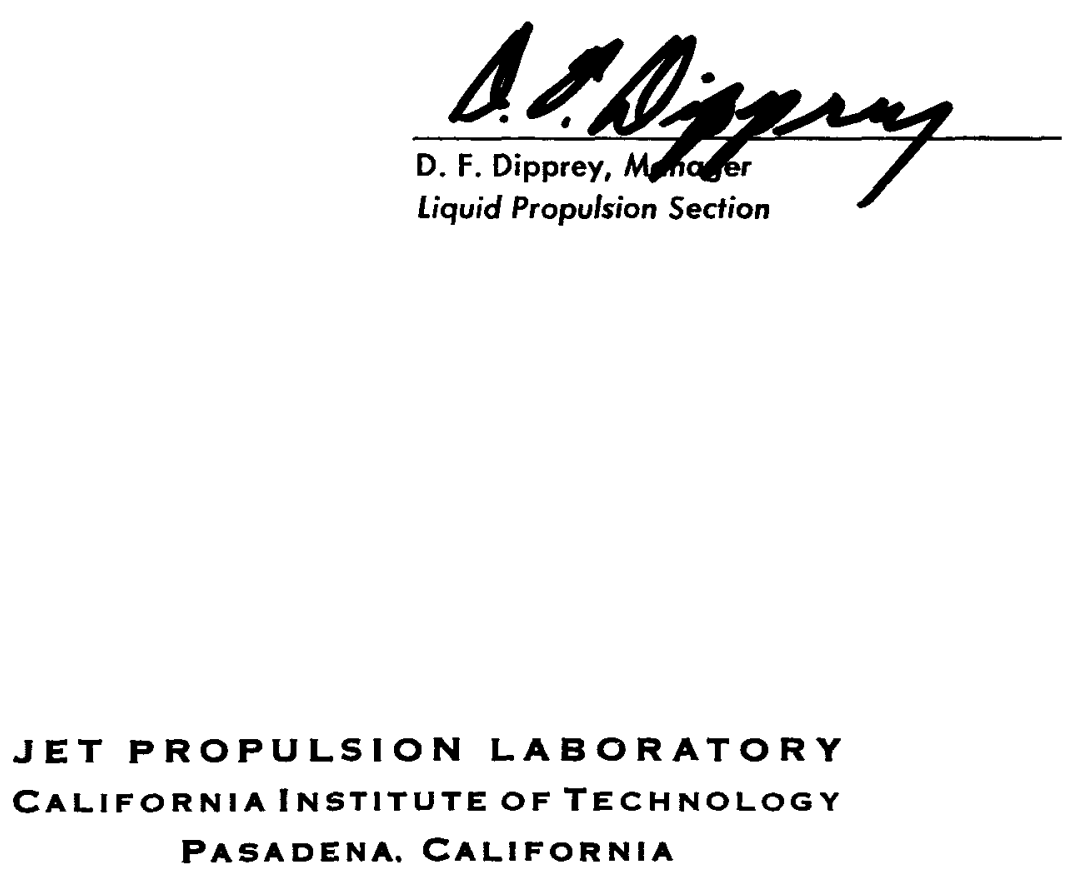
Copyright $(C) 1966$

Jet Propulsion Laboratory

California Institute of Technology

Prepared Under Contract No. NAS 7-100

National Aeronautics \& Space Administration 


\section{CONTENTS}

I. Introduction

II. Selection of Expulsion Devices . . . . . . . . . . . 2

III. Bladders . . . . . . . . . . . . . . . . . 4
A. Definition
B. Shape
C. Installation and Removal
D. Neck Attachment
E. Port
F. Filling
G. Bladder Folding
H. Properties of Bladder Materials
I. Fabrication
J. Inspection
K. Cleaning
L. Testing .

IV. Diaphragms . . . . . . . . . . . . . . . . 22
A. Definition
B. Shape
C. Installation and Removal
D. Anchor and Seal Design . . . . . . . . . . . . . 22
E. Ports . . . . . . . . . . . . . . . . . . 25

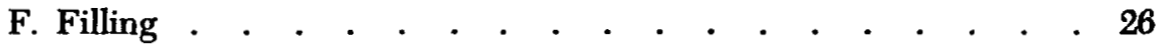
G. Folding . . . . . . . . . . . . . . . . . . 26
H. Materials . . . . . . . . . . . . . . . . . 28
I. Fabrication . . . . . . . . . . . . . . . . . 28
J. Inspection . . . . . . . . . . . . . . . . . . . . . 29
K. Cleaning . . . . . . . . . . . . . . . . . 29
L. Testing . . . . . . . . . . . . . . . . . 29

V. Pistons . . . . . . . . . . . . . . . . . . . . .
A. Definition
30
B. Shape
C. Seals
D. Guide
E. Installation and Remova
31
F. Filling
G. Expulsion
31
H. Materials
31
I. Fabrication
31 


\section{CONTENTS (Cont'd)}

J. Inspection . . . . . . . . . . . . . . . . . . . 31

K. Cleaning . . . . . . . . . . . . . . . . . . . . 31

L. Testing . . . . . . . . . . . . . . . . . . . 31

VI. Historical Background . . . . . . . . . . . . . . . . 32

VII. Current Applications in Unmanned Spacecraft . . . . . . 37

VIII. Advanced Developments . . . . . . . . . . . . . 43

A. Bladder Materials . . . . . . . . . . . . . . . 45

B. Bladder Development. . . . . . . . . . . . . . 48

C. Convoluted Diaphragms . . . . . . . . . . . . . . . 51

D. ALPS Generant Tank and Cell . . . . . . . . . . . . 54

E. ALPS Start Tank . . . . . . . . . . . . . . . 57

F. Additional Information . . . . . . . . . . . . . . . . 59

IX. Summary and Conclusions

References . . . . . . . . . . . . . . . . . . . 60

\section{TABLES}

1. Results of permeability and compatibility tests of polymeric materials and hydrazine .

2. Average permeability to nitrogen tetroxide of potential bladder materials

3. Results of crease resistance testing . . . . . . . . . . . . . . . 15

\section{FIGURES}

1. Typical bladder folding patterns . . . . . . . . . . . . . . . . 5

2. Bladder neck attachment designs . . . . . . . . . . . . . . . . . 6

3. Possible methods of filling bladders . . . . . . . . . . . . . . . $\quad$. 7

4. Double and three-corner folds in a bladder . . . . . . . . . . . . . . 9

5. Damage to Teflon caused by simultaneous contact with fuel 


\section{FIGURES (Con''d)}

6. A battery of permeation testers measuring the permeation of $\mathrm{N}_{2} \mathrm{O}_{4}$ through potential bladder materials . . . . . . . . . 13

7. JPL crease tester for evaluating bladder materials . . . . . . . 14

8. Some results obtained on the JPL crease fest machine . . . . . . 14

9. Sonic welder used at JPL to make seams in thin aluminum foil $\quad$. $\quad$. 18

10. Test setup used to measure expulsion efficiency of small

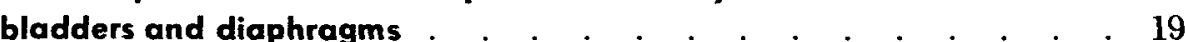

11. Expulsion characteristic of a hemispherical Teflon bladder $\quad . \quad$. $\quad 20$

12. Facility used to slosh test and measure expulsion efficiency of bladders and diaphragms . . . . . . . . . . . . . 21

13. Some convolution geometries suitable for hemispherical expulsion diaphragms . . . . . . . . . . . . . . 23

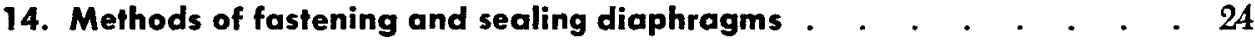

15. Effect of ribs on the expulsion efficiency of a rubber diaphragm . . . 25

16. Possible methods of filling tanks fitted with convoluted diaphragms . . 27

17. Typical buckling (cornering) pattern occuring in convoluted diaphragms during expulsion, and the resulting creases . . . . . 28

18. Metal convoluted diaphragms showing appearance before expulsion, after expulsion, and after aftempt to refill . . . . . . 29

19. Experimental WAC Corporal piston tank . . . . . . . . . . . . 33

20. Three piston tank designs used in the Corporal program . . . . . 34

21. Sergeant APU hydrazine tank with piston expulsion . . . . . . 36

22. Butyl bladder used in Ranger Block II spacecraft _ . . . . . . . 37

23. Section through wall of Butyl bladder of the type used in Mariner Mars spacecraft showing blistering that occurred during a ten-month storage test $\quad . \quad$. . . . . . . . . . . . . . . 39

24. Evolution of the Ranger stant slug expulsion assembly _ . . . . . . 41

25. Mariner A start slug expulsion assembly . . . . . . . . . . . . . 42

26. Schematic diagram of the Advanced Liquid Propulsion System (ALPS)

27. Seamless hemispherical bladder of the conventional spayed and sintered Teflon construction . . . . . . . . . . . . . . . . 48

28. Hemispherical bladder fabricated of Teflon-aluminum foil laminate . $\quad . \quad 50$

29. Seamless hemispherical Teflon bladder fabricated with the top half folded down inside the bottom half . . . . . . . . . . . 50

30. Folding scheme for a hemispherical bladder involving hinging the flat side at the equator. 


\section{FIGURES ICont'd}

31. Calculated permeation rate of $\mathrm{NO}_{2}$ from $\mathrm{N}_{2} \mathrm{O}_{4}$ bladder into water-filled bladder.

32. Envelope containing the expulsion characteristics of seven convoluted metal diaphragms . . . . . . . . . . . . . . 52

33. Rubber hemispherical expulsion diaphragm with external ribs . . . 55

34. Cross-section of the ALPS generant tank and expulsion diaphragm assembly

35. ALPS start tank configuration and operating sequence . . . . . . 58 


\begin{abstract}
Bladders, diaphragms, and pistons can be used for the positive expulsion of earth-storable liquid rocket propellants in free-fall (zero-g). Work at JPL on these devices since the 1940's provided a technological background that aided in the development of reliable bladders for use in Ranger and Mariner spacecraft. Current advanced development programs are aimed at providing expulsion technology for future spacecraft.
\end{abstract}

\title{
I. INTRODUCTION
}

This report ${ }^{1}$ outlines the work done by the Jet Propulsion Laboratory (JPL) on mechanical positive expulsion devices up to mid-1965. A review seems to be in order at this time because of the increasing dependence upon such devices for propellant expulsion in spacecraft. These most recent applications have received the most publicity but, actually, the investigation of positive expulsion was started during the mid-1940's as part of the early sounding rocket programs and continued through the missile era. After JPL's Explorer satellite became the nation's first successful entry in the space exploration program and the objective of the Laboratory changed from developing weapons to exploring space, JPL activity in this field of technology was greatly increased.

Currently the Laboratory is under contract to NASA to conduct the exploration of extraterrestrial space using unmanned spacecraft. Some of the more sophisticated spacecraft have liquid rocket systems on board which are used for trajectory adjustment maneuvers. These rocket systems must start under free-fall (zero-g) conditions. To assure smooth and reliable starts, the rocket

\footnotetext{
${ }^{1} \mathrm{~A}$ preliminary version of this report was given as paper $868 \mathrm{~B}$, same title, at the SAE-ASME Air Transport and Space Meeting, New York, New York, April 1964. A corrected version of the paper was published in the SAE Transactions, Vol. 73, 1965.
}

engines must be fed continuous streams of propellants free of gas bubbles. A problem arises because all of the feed systems under development use gas pressure as the energy source for pumping the propellants out of the tanks and into the engines. Ingestion of bubbles of gas becomes likely under zero-g in an ordinary tank since no strong forces exist to keep the propellants positioned around the tank outlet ports. This difficulty can be overceme by using positive expulsion devices to prevent the ingestion of bubbles.

A great number of methods for obtaining bubble-free propellant flow in zero-g have been proposed. Bell Aerosystems Company has published several reports (see Ref. 1, 2, and 3) which catalog most of the proposed and existing devices. The ideas range from exploitation of surface tension forces to the application of electrostatic fields. Only a few methods have been employed to date in the U.S. space program. The most common approach is to use a sequenced start during which auxiliary thrust devices (usually solid propellant or liquid monopropellant rockets) temporarily accelerate the vehicle so that inertial forces settle the propellants to the rear of the tanks over the outlet ports, and then the main engine is started. Another general solution which has been successfully used in flight is to mechanically separate the 
pressurizing gas from the propellants with a barrier which can be collapsed, flexed, folded, or moved by the gas pressure to pump the propellants out of the tanks and into the engine. The work at JPL has been concentrated on solving the problems associated with such barriers.

When liquid propulsion systems are in the conceptual stage, the advantages of using barrier-type positive expulsion devices appear to be quite attractive. An idealized positive expulsion device might provide several advantages in addition to feeding bubble-free propellant to the engine. Among these possible advantages are:

1. Elimination of chemical reactions between the pressurizing gas and liquid propellant by physically preventing contact between the two fluids. (Also, the barrier may act as a heat insulator.) This would, for example, allow the use of fuel-rich gases from a gas generator to pressurize an oxidizer.

2. Elimination of absorption of the pressurizing gas in the liquid propellant by physically preventing contact between the two fluids. A typical problem is the absorption of nitrogen gas in nitrogen tetroxide.

3. Elimination of propellant loss due to propellant vaporization in the tank. As an example, the vapor remaining in the tank after nitrogen tetroxide has been expelled at $100^{\circ} \mathrm{F}$ is equal to $0.45 \%$ of the initial liquid load. In a system designed for $1 \%$ holdup, almost half of the residual propellant is vapor in the tank.

4. Elimination of corrosion in the propellant tank and components of the tank pressurization system by completely containing the propellant and its vapor in the positive expulsion device. This would allow the use of noncompatible materials which might result in a weight decrease and thus an improvement in performance.

5. Elimination of propellant sloshing and better control of the center-of-gravity of the propellant load.

6. Provision of a means of detecting the volume of propellant filled in or remaining in the tank.

Obtaining some of these additional advantages requires considerable ingenuity since, at the present state of the art, it is difficult to satisfy even the primary requirement of reliable positive expulsion. The positive expulsion system designer must use great care in deciding which type of device to use and what he can expect of a given design.

\section{SELECTION OF EXPULSION DEVICES}

To assess the suitability of the various types of barriers for a given propulsion system, the designer must be aware of the operations to be performed, the operating conditions, and the nature of the development program allowed. Careful consideration of these factors may eliminate some of the concepts from the competition. Further evaluation on the basis of expulsion performance, reliability, weight, and ease of fabrication may then be necessary to make a choice.

There are several operations which barrier-type positive expulsion can perform. Usually, these devices are associated with expelling propellant from the main tankage into the engine. Actual and proposed usage has also included the injection of hypergolic start slugs for starting monopropellant engines and gas generators, the expulsion of small quantities of propellant from auxiliary tankage for starting engines under zero- $g$ to effect propellant settling in the main tankage, and the expulsion of propellant into gas generators powering turbines to drive turbopumps or auxiliary (electric) power units. Obviously some of these uses demand only a single expulsion stroke while others may require repeated partial strokes or even throttled flow.

Detailed analysis and definition of the operational requirements lead to the formulation of a "duty cycle" which is a function of the mission profile and the system into which the positive expulsion device is incorporated. The duty cycle is a chronological outline of the storage periods the unit must survive and operational cycles it must perform in order to accomplish its function during 
a mission. But the duty cycle is only part of the "life cycle" of any single device; to describe the life cycle, the designer must also consider how many and what kinds of operations or cycles are required for inspection, cleaning, installation, checkout, filling, storage prior to flight, and the possibility of aborts with attendant draining, recheckout, and refilling.

Next, the designer must know under what conditions the device goes through its life cycle. The ground handling procedures, mission, and the spacecraft design determine the external environment which will be imposed upon the propulsion system, such as:

1. Temperature range. Storage temperatures on Earth can be estimated rather easily. In addition, temperature cycling may be required for heat sterilization (e.g., three cycles of ambient to $293^{\circ} \mathrm{F}$ ). Any temperature rise caused by aerodynamic heating during boost into trajectory must be considered. The system will be stored over a range of temperatures in space which is a result of a complex relationship between equilibrium solar radiation (a function of distance from the Sun), shadows cast by the spacecraft or large astronomical bodies, reflections from surfaces on the spacecraft or large astronomical bodies, radiation from hot parts on the spacecraft, and heat conduction through the spacecraft structure. Often, the electronics equipment on board requires temperature conditioning. The heat balance of the spacecraft, when optimized for the electronics, may narrow the range of temperatures occurring in the tankage.

2. Pressure range. The external pressure will range from one atmosphere to zero unless pressurized compartments are used.

3. Acceleration range. While stored on Earth, the most severe shock loads come from dropping the container. During boost, peak accelerations seldom will be less than $5 \mathrm{~g}$ and may reach 10 or more. During coast or free-fall, the so-called zero- $g$ field will exist. Occasional small accelerations will be felt when the spacecraft attitude control system operates. Midcourse and approach trajectory corrections will seldom exceed $1 \mathrm{~g}$. Retrograde maneuvers into orbit or for soft landing may require up to $8 \mathrm{~g}$. Orbit corrections will impose accelerations of the same magnitude as midcourse corrections.

4. Vibration. The subject of vibration and its effects on the propulsion system is very complex and specific (i.e., conditions applying to one case may be quite different from the next). Hopefully the designer will be able to obtain reasonably detailed information on the vibration characteristics of the booster to be used; if not, it is better to be conservative and expect a severe environment. Reference 4 contains the vibration test levels to which the Ranger spacecraft was subjected in an attempt to deliberately exceed the expected levels to be encountered in flight.

5. Radiation. No information received to date indicates that corpuscular radiation away from the immediate vicinity of the Earth will be a serious problem. The tankage will take the brunt of the particles and, with most designs, the positive expulsion device will be subjected only to secondary emission.

6. Micrometeoroids. The same comments apply here as for radiation, but the regions of high intensity may be different. For long durations in space the tankage may require bumpers.

Because most positive expulsion devices will be located inside tanks the internal environment may be more important than the external conditions. These factors include not only the accelerations and vibrations but also the chemical reactivity, temperature, and pressure of the propellants and the pressurant.

Geometrical restraints must also be considered. The volume to be expelled can be calculated when the designer knows the total impulse or gas volume needed, the propellants to be used and their minimum density, the performance of the combustor and nozzle, and the margins for error to be allowed. This volume plus the volume of the expulsion device and ullage must be fitted inside the tank. Vehicle considerations often determine the shape of the tank and the location of inlet and outlet ports. Finally, the variation in the center of gravity of the tankage system must not exceed some maximum amount of travel about a predetermined point.

Program restraints on development schedule, manpower, funding, and facilities may be controlling factors in deciding which devices should be given further consideration.

Performance can be judged by the answers to these three questions:

1. How well does the device keep the propellant fed to the engine free of gas and contamination? To do this well, the device must contain no residual air 
or gas after filling, suppress vaporization of the propellant, be impermeable to the pressurant, be inert to the propellant, be clean, and not outgas.

2. How efficiently does the device make use of the tank volume? To be highly efficient, the device must occupy little space itself, require a minimum ullage, permit no leakage or absorption of propellant, and leave a minimum of residual propellant after expulsion.

3. How passive is the device? To be highly passive and to permit a maximum of control over the flow rate by the active control elements in the system, the device should produce expulsion with a low, constant, and repeatable differential pressure (which in turn means it is also flexible, non-"oil-canning," and nonresonant), produce no flow disturbances such as vortexing, produce smooth, instant starts and stops, and should operate equally well at any flow rate.

Reliability can be judged by the answers to these two questions:

1. Will the device maintain its structural integrity? To preserve its structural integrity, the device must not be degraded or damaged by the chemical and thermal environment, by the acts of insertion, testing, filling, and expulsion, by propellant sloshing, or by fatigue due to vibration.

2. Will the device permit checkout and replacement? To be fully sure of the condition of a service unit, the device must be capable of being inspected for structural integrity, checked for dimensional accuracy, tested for leaks, actuated to measure expulsion efficiency, and replaced if unacceptable.

Light weight can be expected if the device itself is light, if it can be installed without the need for large or heavy tank openings or reinforcements, if it has a shape which fits lightweight tanks, and if it has a high volumetric efficiency.

Ease of fabrication can only be judged by experience and current information on the state of the art.

Using these standards of judgment the designer should be able to select a likely candidate for development. The following sections discuss three types of barriers the designer might choose: bladders, diaphragms, and pistons.

\section{BLADDERS}

\section{A. Definition}

The term "bladder" will be restricted in this report to balloon-like membranes which completely enclose either the propellant or the ullage. ${ }^{2}$ The former is collapsed by external gas pressure to expel the propellant, whereas the latter is inflated by the gas until it conforms to the tank shape and thus expels the propellant.

\section{B. Shape}

Usually the shape of the tank determines the shape of the fully expanded bladder. This is true because, to achieve the most efficient use of the tank volume, it must be filled as completely as possible and emptied

\footnotetext{
${ }^{2}$ This clarification is felt to be necessary because many different names such as "expulsion bag," "fuel cell," etc., have been used to denote this general category of devices.
}

completely. Bladders which are made smaller than the tank face the danger of excessive stretching if extended until reaching the support of the tank wall. This hazard occurs during filling for the bladders which store propellant inside and during expulsion for the bladders which occupy the ullage. Making the bladders larger than the tank requires the excess surface area to be folded which may cause damaging creases. Aside from the problem of overfilling, the bladder which holds the propellant inside will be forced to conform to the shape of the bottom of the tank by hydrostatic pressure. A still more serious problem exists because of the relationship between the bladder shape and the folding pattern. Figure 1 shows how three different shapes were folded by expulsion. Additional factors which affect the folding, such as collapse about internal masts and the location of the outlet are illustrated by the spherical bladders (Fig. Ic and 1d). With many materials now available the 
(a) CYLINDER OF ELASTOMER

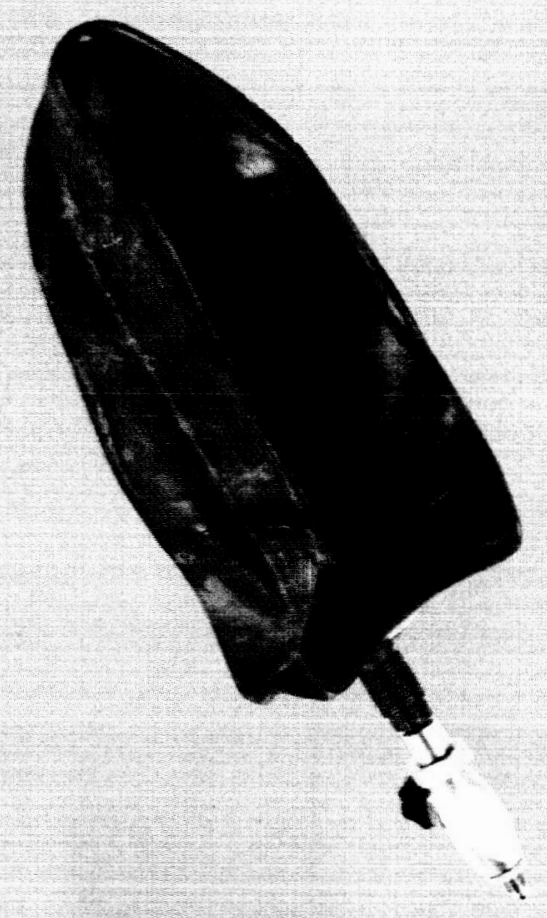

(c) SPHERE OF ELASTOMER WITH OUTLET UPWARD

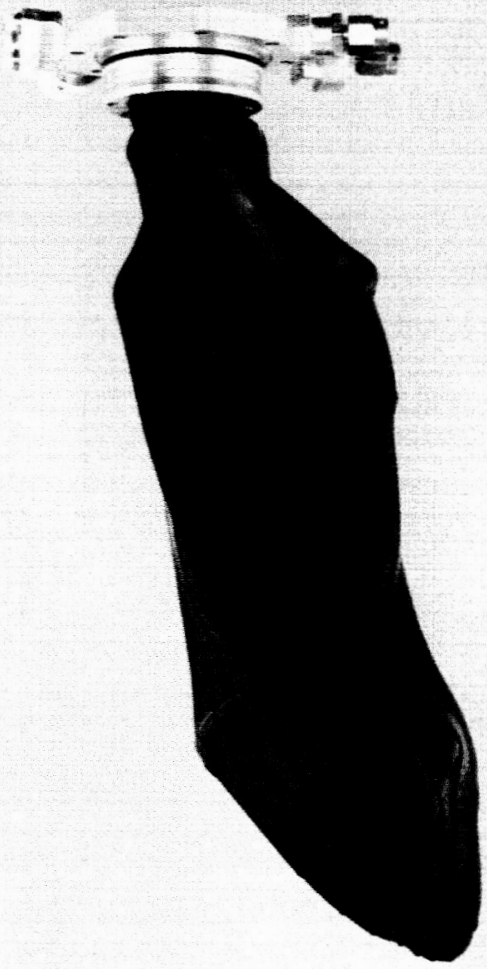

(b) HEMISPHERE OF TEFLON
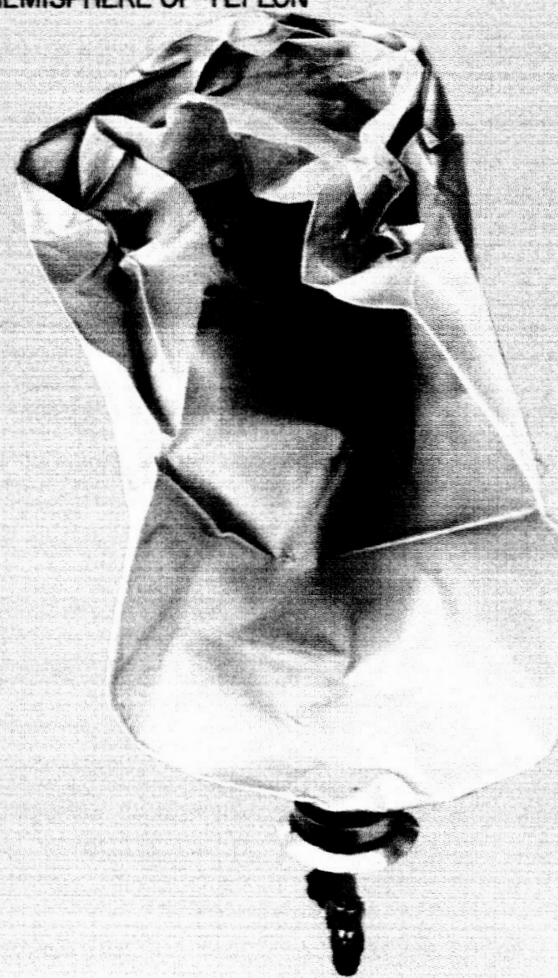

(d) SPHERE OF ELASTOMER WITH OUTLET DOWNWARD, FOLDED ABOUT A CENTRAL MAST

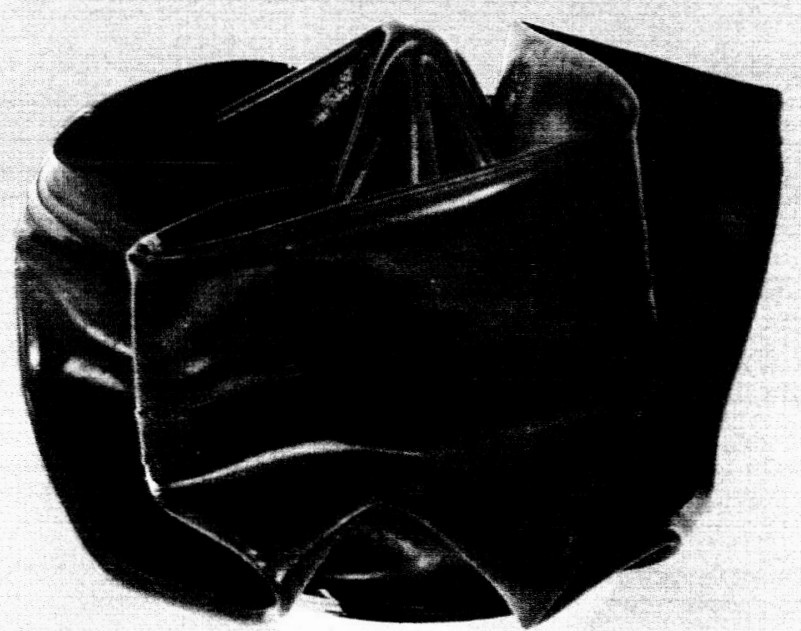

Fig. 1. Typical bladder folding patterns 
durability of the bladder is grossly affected by the folding. This subject is discussed below. At this point, it is sufficient to say that the tank and bladder shape should be chosen with full recognition given to the interactions between these two parts. The practice of simply designing bladders to fit arbitrary tankage shapes may create more problems for the bladder than it solves for the tankage.

\section{Installation and Removal}

A problem closely allied with the folding pattern is bladder installation and removal. An opening in the tank

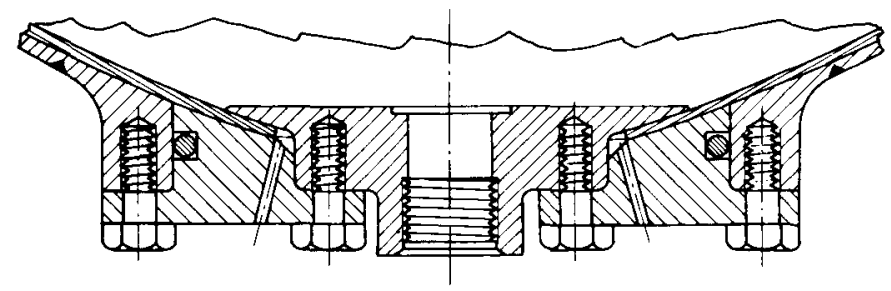

(a) CORPORAL DUAL GAS GENERATOR SYSTEM HYDRAZINE BLADDER (1954) (SERGEANT APU [I956] WAS SIMILAR)

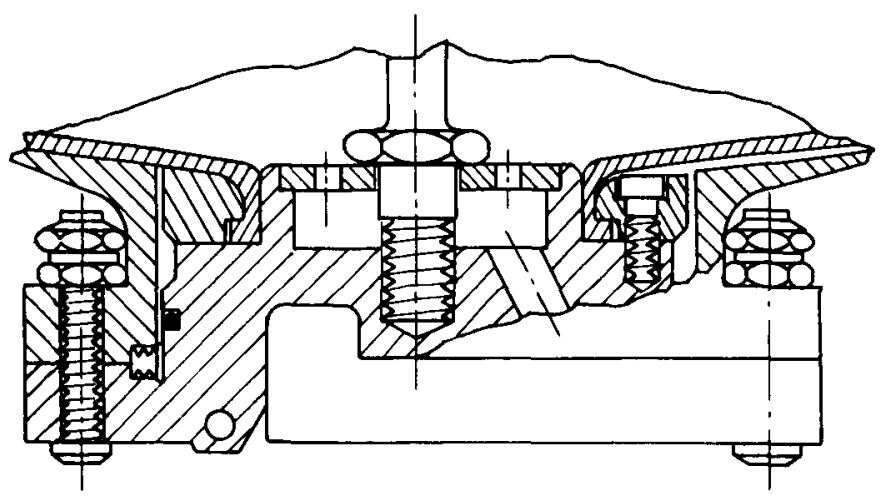

(c) RANGER BLOCK 3 AND MARINER C MIDCOURSE PROPULSION SYSTEM BLADDER (1962) must be provided unless the bladder is to be permanently installed as the tank is welded together. The size of the opening must be kept as small as possible if the tank weight is to be minimized. Opposed to this consideration is the fact that the bladders may be damaged if folded or rolled up too tightly in order to install them through a very small opening. The problem will be compounded if the bladder needs stiffening ribs or stays to control folding (unless these stiffeners also can be used to collapse the bladder into a compact bundle). Sometimes the application of an inert lubricant or warming the bladder to make it more flexible may ease the installation problem.

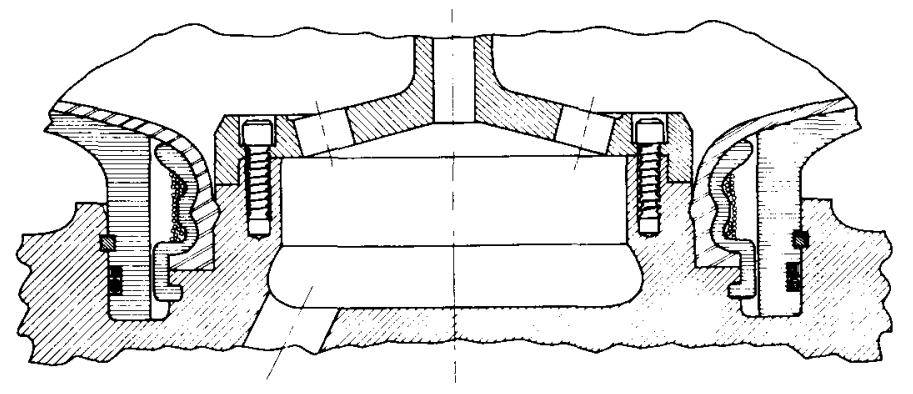

(b) RANGER BLOCK 2 MIDCOURSE PROPULSION SYSTEM (1960) (MARINERA MIDCOURSE PROPULSION SYSTEM [I961] WAS SIMILAR)

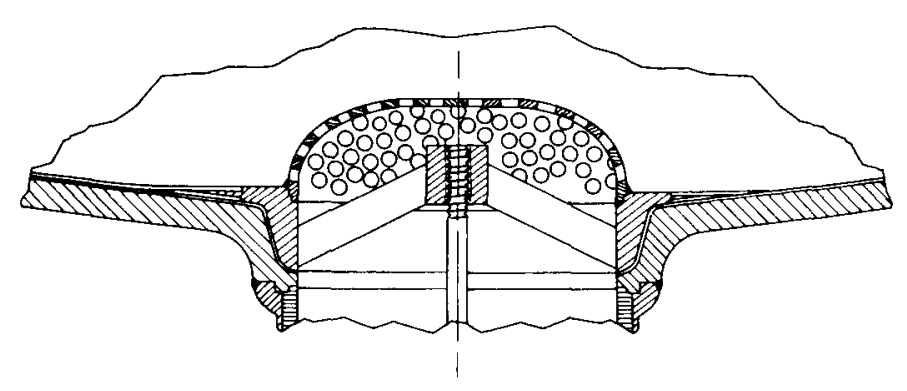

(d) ALPS FUEL AND OXIDIZER BLADDERS (PROPOSED 1963)

Fig. 2. Bladder neck attachment designs 


\section{Neck Attachment}

With few exceptions, bladders have necks which are fastened to the separable tank flange that closes the opening through which the bladder is installed. The bladder neck may serve as a seal between flange and tank if it is sufficiently elastic. A good seal must be secured between the neck and the outlet connection to avoid leakage of the liquid into the ullage. Since this is an anchor point for the bladder, the neck must be securely connected to the bladder to withstand loads due to bladder movement (as in sloshing) and changes in shape (when adjacent areas are being stretched or folded). Figure 2 shows several designs which have been used or proposed at JPL.

\section{E. Port}

The neck also acts as the port through which either the propellant or pressurant flows into and out of the bladder. It must remain uncovered to avoid choking off this flow. Some protection against extrusion of the bladder into the port must be provided. Sometimes perforated standpipes or strainers are pushed through the port to a position even with or beyond the inside contour of the bladder. (If these measures are insufficient safeguard against sealing off the port, ribs may be molded or cemented onto the surface of the bladder or tank.) These various devices and the flange must be designed to accommodate the filling and draining scheme to be used. Particular attention must be paid to the avoidance of places where gas bubbles can be trapped during filling.

\section{F. Filling}

Figure 3 indicates several possible methods of attaining bubble-free liquid loading. A common means of removing the air (or other gases) from the bladder is to vent it off from the top of the bladder through a standpipe as the liquid level rises (Fig. 3a). The method shown in Fig. $3 \mathrm{~b}$ is essentially the same, except that the tank has been inverted and the propellant is poured in while the air is bled off from the top. When using standpipes or inverting the tankage is not possible, the bladder can be collapsed by evacuating the inside, then the propellant is pumped in (Fig. 3c). This latter method requires the bladder to go through a cycle of collapse and extension which may be detrimental. Figure $3 \mathrm{~d}$ portrays a possible solution which avoids cycling. The vacuum is drawn on both sides of the bladder simultaneously to prevent collapse, then the propellant is loaded. Although these procedures as described are designed for bladders storing propellant inside, minor changes would make them applicable to ullage bladders.

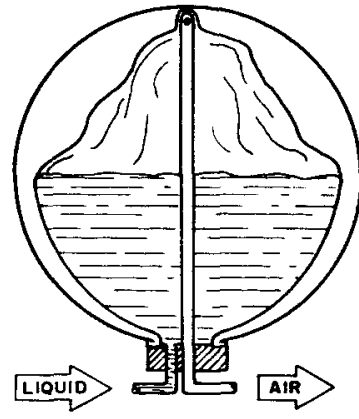

(a) BLEED AIR OFF THROUGH STANDPIPE

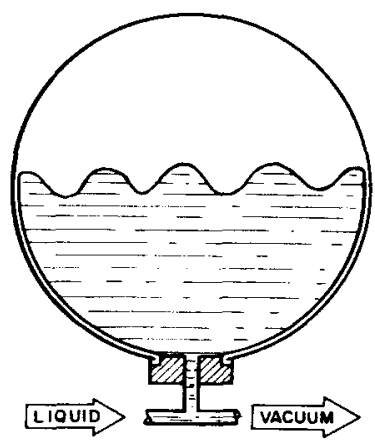

(c) eVACUATE TO COLLAPSE THEN FILL

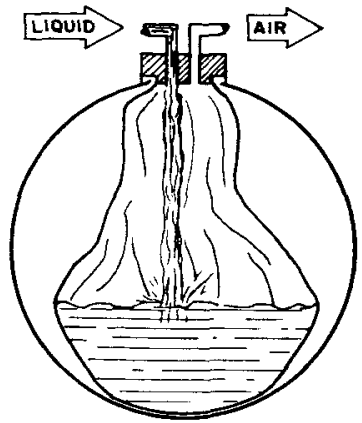

(b) GRAVITY FILL WITH AIR BLEED

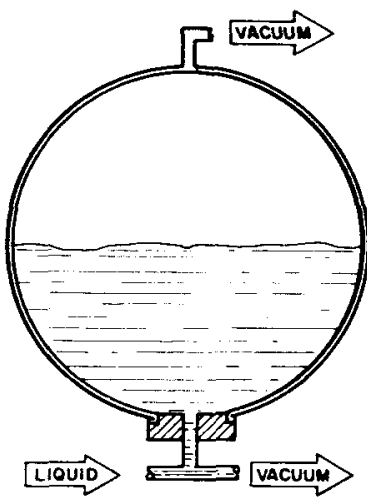

(d) EVACUATE BLADDER AND TANK, THEN FILL
Fig. 3. Possible methods of filling bladders

The foregoing possibly makes the filling operation sound considerabiy easier than it really is in some instances. One problem that may arise is damage to the bladder caused by forces generated on the bladder by the pressure of the incoming liquid; damage is possible if the filling process requires a relatively inelastic bladder to be either distended (unfolded) or collapsed (folded) (e.g., as required for the method shown in Fig. 3c). Visual observations made during tests of Teflon bladders at JPL verified that the filling operation was very close to being a reversal of the same kinds of folding actions that take place during expulsion; therefore, it can be assumed that substantial local stresses and strains occur. Precise metering of the total volume of propellants forced into a bladdered tank is necessary to avoid damage from excessive stretching or tight folding. Finally, removing all of the gas so that only liquid is contained in the bladder may prove to be difficult.

\section{G. Bladder Folding}

Most bladders are made in shapes which cannot be completely collapsed to near-zero internal volume without shrinking, stretching, or creasing at some stage in 
the process. ${ }^{3}$ A problem area begins to appear when it is realized that none of the materials that are adequately compatible with ordinary propellants is elastic enough to permit full expulsion without some folding. The amount of elongation available in the most elastic materials is sufficient only to prevent the folds from causing permanent creases. The selection of materials for some applications is limited (by the reactivity with or permeability to the propellants) to the more inert materials which, unfortunately, happen to be relatively inelastic. These inelastic materials are often creased by the fold pattern. Since this "cause and effect" relationship between folding patterns and damaging strains is so important, many bladder development programs initiate bladder folding studies with the prime objective of achieving high expulsion efficiency while minimizing damage.

Astro Research Corporation, of Santa Barbara, California, studied bladder folding under contract to JPL. This investigation was specifically directed towards describing the physical characteristics of an ideal material for a hemispherical bladder (see Ref. 5).

Two types of materials deformation which occur during the folding of a hemispherical bladder were analyzed:

1. The general tangential membrane strains that occur in an ideal infinitely thin membrane of originally hemispherical shape.

2. The localized bending and transverse shearing strains resulting from the creasing of the bladder material of finite thickness during the folding process.

A set of equations was developed describing the membrane strain distribution in a hemispherical shell subject to large deformations. Examinations of possible solutions for these equations revealed the existence of folded configurations of vanishing enclosed volume and zero membrane strain. These solutions require the material to be folded or creased along single, nonintersecting fold lines.

Local strain that results from creasing a sheet of finite thickness was shown to require an allowable, fully elastic and recoverable material strain of approximately $50 \%$ for a solid sheet. For a composite laminated sheet made

${ }^{3}$ This is one reason why it may be more desirable to use an expanding bladder with propellant on the outside. It is true that such an expanding bladder must be collapsed to fill propellant but usually some ullage is left inside the bladder to allow for thermal expansion of the propellant and thus the bladder never needs to be collapsed completely. from inextensible laminations, a transverse interlaminar shearing angle of approximately $57 \mathrm{deg}$ is required. Examination of the sharp double fold for the ideal bladder material for solid wall construction indicated the necessity for the following mechanical properties:

1. A sheet of the material in representative thickness should be capable of bidirectional stretching ( $100 \%$ axially and $10 \%$ transversely) without incurring disabling damage.

2. The material should fully recover from this biaxial strain, where bladders will be subjected to repeated test.

3. The area over which the material is to be stretched is confined to a square of side length approximately equal to the thickness of the sheet.

Astro Research concluded that membrane strain-free folding patterns of hemispherical surfaces allowing complete expulsion of contained liquid are theoretically possible. They require however, in the ideal case, folds of zero inside radius of curvature in the bladder material.

In addition, deviations from ideal folding due to the requirement to absorb sloshing motions during the expulsion process will aggravate the requirements for materials compliance (materials ability to undergo strain without disabling damage). As a result, choice of eligible materials for bladders of solid-wall construction is generally restricted to rubber-like elastomers capable of absorbing the large local strains required by single-fold or double-fold deformation. An alternate solution involving a composite multilaminar wall construction was suggested; details of a material embodying this approach are given in Section VIII.

Another way of characterizing the nature of bladder folding problems is to describe how real (non-ideal) bladders are expected to fold. Several common characteristics of bladder folding usually become apparent in these studies. Starting with simple geometrical shapes, homogeneous material, and uniform wall thickness, a generalized description of several steps in the collapse of a bladder can be given. It is assumed that gas pressure is applied to the exterior and that no hydrostatic pressure forces exist inside (i.e., the same differential pressure is applied to the entire surface). These steps are as follows:

1. The larger, least curved surfaces dish inward. Naturally, the weaker areas move first. The instantaneous rate of movement of each area is controlled by the changing restraints of edge support, shape, and 
material stress. The actual case is so complex for most bladder shapes that it is uneconomical to attempt mathematical analysis.

2. As these larger surfaces continue to move inward they become more and more restrained by shape stiffening. The shape of the locally stiffened sections usually takes the form of "channels" where the surface is doubled upon itself. There may be several of these channel sections in parallel, like corrugations, or a complex pattern of nearly intersecting channels. ${ }^{4}$ The loads upon these stiffened sections become greater and greater as the surfaces stretched from channel to channel are pushed further inward. Sometimes, particularly during sloshing, side forces cause a channel to move across the surface like a wave; the surface "flows" up one side, "rolls" over the top, and "flows" down the other side of the channel. More often, however, the moments or compression loads on the channels increase until they buckle. The buckling causes a "double" fold. In effect, the original channel is divided lengthwise into two intersecting channels. Unless the material is very elastic, the inside radius at the point of intersection becomes essentially zero, which causes a highly stressed point on the outside surface. Sometimes the wave action mentioned above happens where two channels intersect; the rolling action of the material causes a "traveling" or "rolling" crease which is formed along the line traced by the point of intersection. Three-corner folds are also found; these folds may be incomplete double folds or the result of bladder contours which favor the formation of three-corner folds rather than double folds. Figure 4 shows a close-up of several folds in a bladder.

3. The final stage of collapse causes the channels to be flattened, and the bladder wraps up or twists around itself.

This grossly simplified picture is modified in practice by a number of factors. First of all, real bladders are seldom made in simple geometrical shapes because outlet necks, bleed ports, or standpipe sockets are needed. And, although nearly uniform, homogeneous materials can be used, a composite structure of varying thickness is often chosen. The wall may be laminated of several different materials to reduce permeation or to give "shear

${ }^{4}$ When elastic materials are used to make cylindrical bladders, the familiar three- to five-lobed pattern of parallel channels is obtained; this is probably the simplest pattern normally obtained.

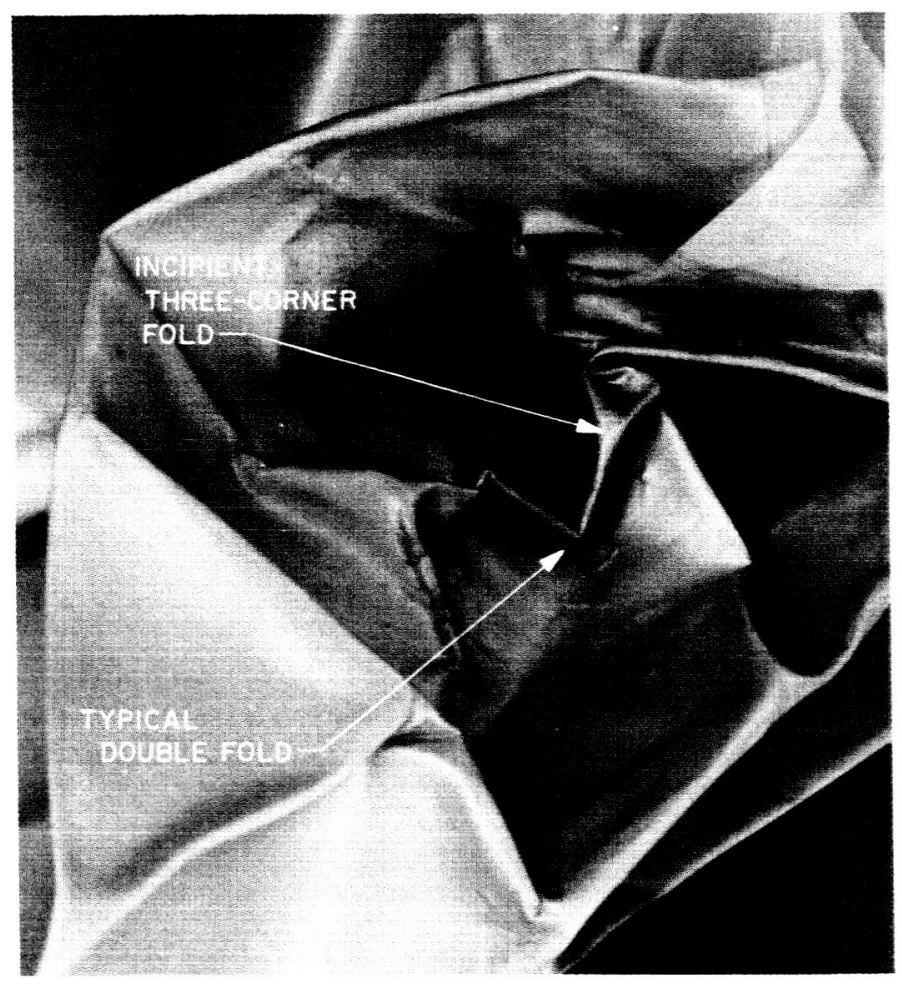

Fig. 4. Double and three-corner folds in a bladder

compliance" which minimizes creasing. Different areas may be made of materials varying in stiffness to induce controlled folding. For the same reason, bladder walls may be reinforced with splines or springs. Ribs or channels may be molded or glued onto the surface to prevent sealing propellant off from the outlet port. These and other deviations from the simplified model cause the bladder to be a complex structure.

The real forces acting on this complex structure also must be considered. Under acceleration, the hydrostatic pressure of the fluid to be expelled exercises a strong influence on the shape of the bladder and on how it folds. Bladders which are very flexible will almost always collapse from the "top" downward. Some designs may try to exploit the distribution of the hydrostatic pressure by using the resultant forces as part of a scheme for controlled folding. Judgment must be exercised because bladders which are easily flexed by such low pressures may also be affected by the motion of the fluid inside the bladder; these fluid motions may be induced by vehicle attitude maneuvers, decelerations, and tank "breathing." Unless the pressurizing gas is admitted at low velocity, the jet may exert a force on the bladder wall. Normally, the other forces, such as the weight of the bladder and the hydrostatic pressure of the pressurant, can be ignored. 
Mechanical folding control devices are often tried. One type used by JPL is a mast about which the (elastomeric) bladder collapses. Usually the mast is a rod just long enough to reach the center of the bladder; an enlargement at the end of the rod prevents excessive local stresses in the bladder where it folds over the end. The bladder folds up around the mast in a reasonably reproducible manner.

Another mechanical aid to folding is a spring which pushes or pulls on part of the bladder. For example, for a spherical bladder which is considerably smaller than the tank, a coil spring might be attached to the bladder at the pole opposite the outlet. As the contents are squeezed out, the spring pulls the bladder into an elongated shape so that it becomes longitudinally lobed (similar to Fig. 1c).

Adhesives or bands can be used to retain parts of the bladder against the tank wall while other parts collapse. The commonest usage of this aid is to restrain the lower half of a sphere so that the top half reverses itself into a mirror image down inside the bottom. This particular folding scheme may allow some random folding as the top half reverses itself but as expulsion is completed there are few, if any, creases.

No matter how it is approached, bladder folding is a serious problem. Damage from creases is probable with any but the elastomeric materials. At this stage, nonelastic materials can be expected to reliably perform repeated expulsions only if folding is controlled to avoid the random folds which cause the creases.

\section{H. Properties of Bladder Materials}

The ideal bladder materials would be chemically inert and impervious to the propellants and the pressurant, sufficiently strong and resistant to damage by repeated sharp creasing, and capable of fabrication into the shapes and stiffnesses needed to control folding. No such materials are available for most common propellants.

Chemical inertness is a relative matter and cannot be discussed well without reference to specific materials and propellants. Several publications attempt to describe the "compatibility" of materials with propellants. The bladder designer is cautioned to take these data with a grain of salt. Often the test conditions are not clear. In others, the test conditions are not too meaningful for bladders. Almost none of the data is from long-term tests (one year or longer).
The compatibility of metals is usually expressed as the rate of metal removal (e.g., mils per year). Unfortunately, this kind of data is insufficient for the selection of bladder materials. Many alloys are greatly weakened far beyond the degree indicated by such data because of selective corrosion which leaches out the alloying ingredients. The rate of corrosion may be accelerated by stress. Also, metal couples may allow galvanic corrosion to occur in real structures.

Some data are available on the compatibility of polymers. Most of the test methods used are valid only for indicating the general suitability of the compound for static O-rings seals. The swell, propellant absorption, and tensile strength may or may not be measured. These data are significant only if measured before the propellant gasses off-a point often left in doubt by the reports.

For both metals and polymers, a significant bit of information is the rate at which they cause propellant to decompose. This is a very difficult thing to tie down because of variations in composition, curing, surface finish, and cleaning.

JPL has not developed any all-inclusive compatibility tests $^{5}$. For metals, we are limited at present to simple corrosion tests of unstressed slugs. These samples are $1 / 4$ in. in diameter and $3 \mathrm{in}$. in length. Enough propellant (fuel or oxidizer) to cover one half of the sample is sealed into glass capsules with the slugs. Corrosion rate is deduced from weight difference before and after the test. Polymer samples are 1/2 in. wide and $4^{3 / 4}$ in. long. Some of these polymers are bonded to metal plates to get data on the combination of materials. The samples are submerged in $40 \mathrm{cc}$ of propellant inside glass capsules. Because some capsules containing polymers exploded early in the program, all such capsules are now fitted with pressure gauges; testing is terminated when 40 psia pressure is reached. The rate of pressure rise is recorded. Propellant composition is determined before and after the test. Table 1 gives some compatibility data obtained using these methods.

An unusual type of compatibility testing which has been performed at JPL involves simultaneous exposure

\footnotetext{
${ }^{5}$ It is anticipated that by 1966 the Laboratory will have a comprehensive compatibility program underway. Plans and equipment for testing approximately 2000 samples are being made; this will include plain, stressed, bi-metal and coated samples. Only glass will be in contact with the propellant and sample since a newly developed external strain gauge will be used to measure the pressure rise inside the capsules. This work will be reported in JPL Technical Reports.
} 
Table 1. Results of permeability and compatibility tests of polymeric materials and hydrazine

\begin{tabular}{|c|c|c|c|c|c|c|c|c|}
\hline \multirow{3}{*}{ Source } & \multirow{3}{*}{$\begin{array}{l}\text { Compound } \\
\text { number }\end{array}$} & \multirow{3}{*}{ Polymer } & \multicolumn{2}{|c|}{$\begin{array}{l}\text { Permeobility } \\
\text { of } 72^{\circ} \mathrm{F}\end{array}$} & \multicolumn{4}{|c|}{$\begin{array}{l}\text { Effect on hydrazine } \\
\text { of } 110^{\circ} \mathrm{F}\end{array}$} \\
\hline & & & \multirow{2}{*}{$\begin{array}{l}\text { Average rate, } \\
\mathrm{mg} / \mathrm{in.}{ }^{2} / \mathrm{hr}\end{array}$} & \multirow{2}{*}{$\begin{array}{c}\text { Test duration, } \\
\text { hr }\end{array}$} & \multicolumn{2}{|c|}{$\begin{array}{l}\text { Chonge in } \\
\text { composition }\end{array}$} & \multirow{2}{*}{$\begin{array}{c}\text { Pressure rise } \\
\text { in } 10 \text { days, } \\
\text { psi }\end{array}$} & \multirow{2}{*}{$\begin{array}{l}\text { Number of } \\
\text { days to reach } \\
30 \text { psia }\end{array}$} \\
\hline & & & & & $\%$ & $\begin{array}{l}\text { Number } \\
\text { of days }\end{array}$ & & \\
\hline The Connecticut Hard Rubber Company. & 3609 & BUTYL & 0.001 & 95.7 & 0.72 & 71 & 5 & 55 \\
\hline \multirow[t]{7}{*}{ New Hoven, Connecticut } & 3818 & SBR & 0.15 & 95.7 & 1.0 & 309 & 3 & 153 \\
\hline & 3906 & SBR & 0.13 & 95.6 & $\longrightarrow$ & 一 & 3 & 148 \\
\hline & 3954 & SBR & 0.21 & 116.75 & 0.72 & 124 & 4 & 97 \\
\hline & 4131 & BUTYL & 0.0004 & 116.75 & 0.92 & 77 & 5 & 58 \\
\hline & 4610 & SBR & 0.131 & 96.5 & 3.02 & 239 & 5 & 121 \\
\hline & 4706 & PBR & 0.204 & 116.75 & 1.38 & 71 & 9 & 34 \\
\hline & 4762 & SBR & 0.229 & 100.5 & 1.42 & 98 & 6 & 55 \\
\hline $\begin{array}{l}\text { E. I. duPont de Nemours, Inc., } \\
\text { Wilmington, Deloware }\end{array}$ & $51090-590$ & EPR & - & - & 2.4 & 10 & 42.5 & 9 \\
\hline Fargo Rubber Corporation, & FR 6-50-3 & BUTYL & 0.0 & 76.0 & - & - & - & - \\
\hline \multirow[t]{8}{*}{ Los Angeles, California } & FR 6-50-3 & BUTYL & $0.0^{*}$ & 51.0 & 1.0 & 61 & 8 & 30 \\
\hline & FR 6-60-2I & BUTYL & 0.58 & 97.0 & - & 一 & 一 & 一 \\
\hline & FR 6-60-21 & BUTYL & 0.22 & 97.0 & 一 & 一 & 一 & - \\
\hline & FR 6-60-25 & BUTYL & 0.0 & 76.0 & - & $\longrightarrow$ & - & 一 \\
\hline & FR 6-60-26 & BUTYL & $0.0^{2}$ & 98.0 & 0.72 & 105 & 1 & 87 \\
\hline & FR 6-60-26 & BUTYL & - & 一 & - & 26 & 37 & 1 \\
\hline & $F R 6-60-26$ & BUTYL & - & - & 0.4 & 73 & $\mathbf{5}$ & 48 \\
\hline & FR 6-60-27 & EPR & 0.013 & 95.7 & 0.59 & 71 & 10 & 34 \\
\hline Hadbar, Inc., & XB-800-71 & BUTYL & 0.0004 & 96.5 & 1.12 & 98 & 2 & 65 \\
\hline Alhambra, California & G.E.RTV-60 & SILICON & - & 一 & 0.5 & 459 & 2 & 262 \\
\hline Parker Seal Company, & B496-7 & BUTYL & - & 一 & 1.5 & 129 & 5 & 106 \\
\hline \multirow[t]{12}{*}{ Culver City, California } & B496-7 & BUTYL & - & 一 & 1.6 & 129 & 7 & 108 \\
\hline & B496-7 & BUTYL & - & - & 1.7 & 129 & 5 & 103 \\
\hline & B480-7 & BUTYL & - & - & 1.7 & 100 & 5 & 69 \\
\hline & B480-7 & BUTYL & - & 一 & 1.7 & 112 & 5 & 72 \\
\hline & B480-7 & BUTYL & - & $\longrightarrow$ & 1.6 & 100 & 5 & 66 \\
\hline & E529-6 & EPR & - & 一 & - & - & 2 & 400 \\
\hline & E529-6 & EPR & - & - & - & - & 2 & (b) \\
\hline & E529-6 & EPR & - & 一 & - & - & 3 & (c) \\
\hline & E $515-8$ & EPR & 0.029 & 99.0 & - & 一 & - & - \\
\hline & E 515.8 & EPR & $0.018^{\mathrm{n}}$ & 96.2 & - & - & 0 & (d) \\
\hline & E 515-8 & EPR & 0.036 & 168.8 & - & - & - & - \\
\hline & E-515-8 & EPR & 0.033 & 168.8 & - & $\longrightarrow$ & - & - \\
\hline Stillman Rubber Div., & SR 613-75 & BUTYL & $0.0^{\circ}$ & 97.0 & 1.0 & 35 & 14 & 20 \\
\hline Electrada Corporation, & SR 634-70 & BUTYL & 0.0005 & 95.7 & 0.71 & 78 & 2 & 64 \\
\hline \multirow[t]{15}{*}{ Culver City, California } & SR 634-70 & BUTYL & - & - & - & 16 & 40 & 5 \\
\hline & SR $634-70$ & BUTYL & - & - & 0.4 & 69 & 8 & 39 \\
\hline & SR 722-70 & EPR & $0.0^{2}$ & 97.0 & 1.9 & 175 & 0 & 152 \\
\hline & SR 722-70 & EPR & $0.001^{*}$ & 97.0 & 1.9 & 175 & 0 & 148 \\
\hline & SR 722-70 & EPR & 0.001 & 97.0 & - & 71 & 6 & 43 \\
\hline & SR 722-70 & EPR & 0.045 & 70.0 & - & - & - & - \\
\hline & EX 1004B & EPR & 0.445 & 94.0 & - & - & - & - \\
\hline & EX 1004B & EPR & 0.320 & 94.0 & - & - & - & $\rightarrow$ \\
\hline & EX 1004E & EPR & 0.124 & 94.0 & - & 一 & - & - \\
\hline & EX 1004E & EPR & 0.079 & 94.0 & 一 & - & - & - \\
\hline & EX 1004-70 & EPR & 0.164 & 94.0 & 一 & - & 一 & 一 \\
\hline & EX 1004-70 & EPR & 0.276 & 94.0 & - & $\longrightarrow$ & - & - \\
\hline & EX 1004-70 & EPR & 0.03 & 116.7 & 0.97 & 35 & 10 & 24 \\
\hline & EX-9835-75 & EPR & $0.002^{2}$ & 96.0 & - & 517 & 6 & 250 \\
\hline & EX-983S-75 & EPR & $0.001^{*}$ & 96.0 & 1.8 & 477 & 2 & 311 \\
\hline \multirow{2}{*}{\multicolumn{3}{|c|}{$\begin{array}{l}\text { SBR-Styrena-Butadieno Rubber PBR-Polybutadieno Rubber } \\
\text { "The somple was not from the same batch as that used for the compatibility test. } \\
\text { b22 pai of } 458 \text { days. }\end{array}$}} & EPR-E & thylene Propylene & Uubber & & & \\
\hline & & & $\begin{array}{l}\text { C2d psi } \\
\text { d10 psi }\end{array}$ & $\begin{array}{l}\text { of } 458 \text { days. } \\
\text { of } 865 \text { days. }\end{array}$ & & & & \\
\hline
\end{tabular}


to both fuel and oxidizer; these tests are designed to duplicate the conditions which would exist if propellant leaked from one bladder in a bipropellant system and came into contact with the outside of the bladder containing the other propellant. Severe internal damage can be caused by the reaction between permeating fuel and oxidizer within the bladder wall. Figure 5 shows a patch sample of Teflon after such a test. Details of the test are given in Section VIII.

The permeability of bladder materials is of great concern even if chemical reactions are not possible. Propellant permeating into the ullage is not available for burning in the engine, the partial pressure of the vapor in the ullage will raise the total pressure in the tank, and the vapor could be condensed and frozen solid to form plugs if cold enough temperatures should occur in the pressurization lines. Permeation of the pressurant, conversely, can cause partial loss of tank pressurization during storage periods and dilute the propellant. The

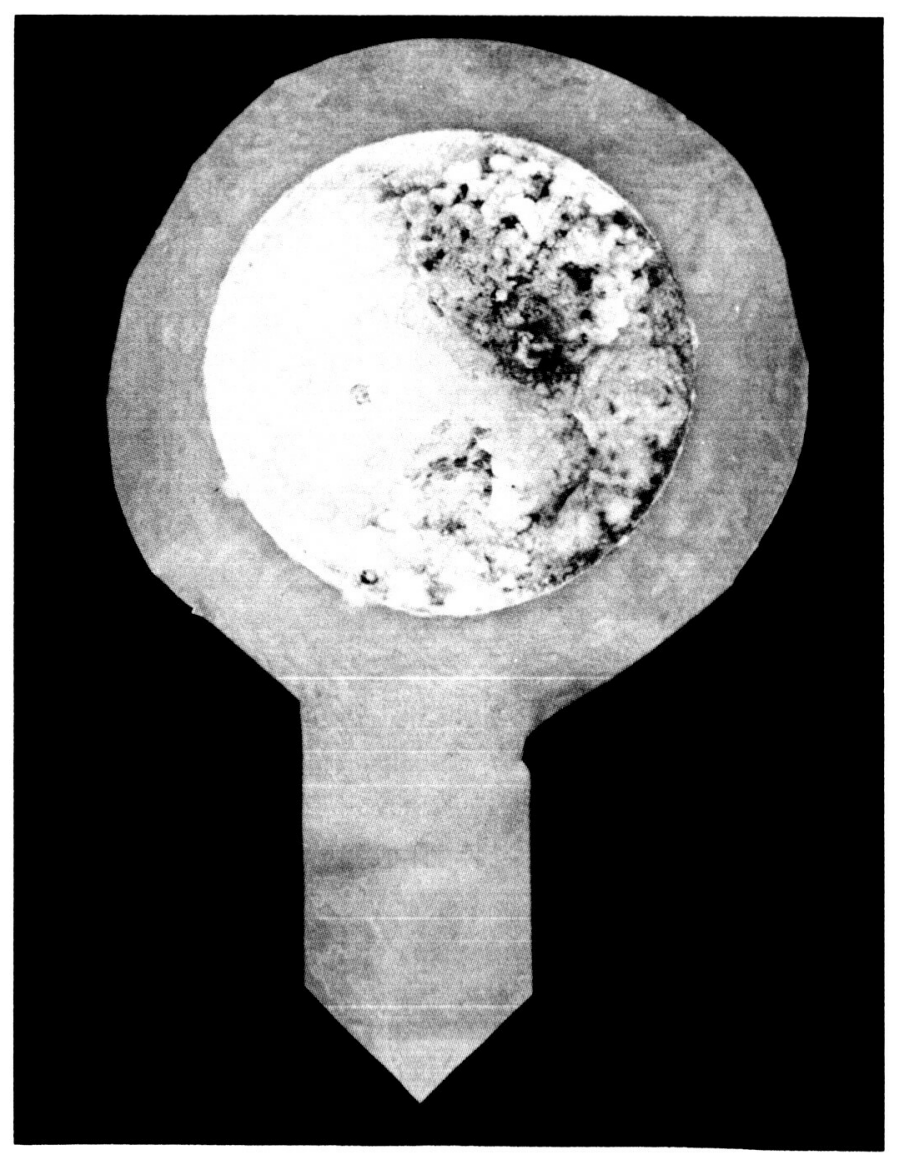

Fig. 5. Damage to Teflon caused by simultaneous contact with fuel and oxidizer diluted propellant may be compressible (and therefore affect the system response) and susceptible to the formation of bubbles of gas (particularly during propellant flow when reduced pressures in downstream plumbing may cause foaming as the gas desorbs).

Most of the propellant permeation tests performed on patch samples at JPL have been made according to the procedure outlined in Ref. 6. This method uses an apparatus that puts a small quantity of liquid propellant on one side of the sample and sweeps away the permeant from the reverse side with a gentle flow of nitrogen gas. The vapor in the gas is frozen out in a cold trap consisting of a section of glass tubing cooled with liquid nitrogen. Periodically the accumulated amount of propellant is measured by melting it and titrating. Figure 6 shows several of the permeation test apparatuses in use.

The results of permeation tests of over 100 samples of potential bladder materials with nitrogen tetroxide are reported in Ref. 7 and summarized in Table 2. Section VIII discusses some of the findings of this survey.

In practically all instances, the permeability of undamaged material is measured. An actual bladder, however, is usually somewhat damaged (even if only by collapsing it for installation in the tank) before the propellant storage period begins. Therefore it may be important to measure the increase in permeability with increased degree of damage. Simply folding materials with reasonable physical properties, such as Teflon, does not seem to radically change the permeability of large pieces unless the folding is repeated many times; this may be partially due to the fact that the percentage of the total area which is damaged is quite small. If, on the other hand, the damage is severe enough, the permeation rate may markedly increase. Measured rates may become large enough to signify that leakage, not permeation, is the mechanism. (Leakage, which occurs through fractures or passages, is a fundamentally different phenomenon than permeation; leakage denotes the passage of a stream of molecules through a physical opening in the material while permeation is characterized by the mechanisms of adsorption onto the inner surface, diffusion through the intermolecular structure of the bladder, and desorption from the outer surface.) The majority of the holes through which the propellants leak are either flaws in the raw material or fractures caused by creasing. These fractures may occur when the material is forced into three-cornered or double folds but are most likely to happen when traveling creases are induced by the collapse or extension of the bladder. 


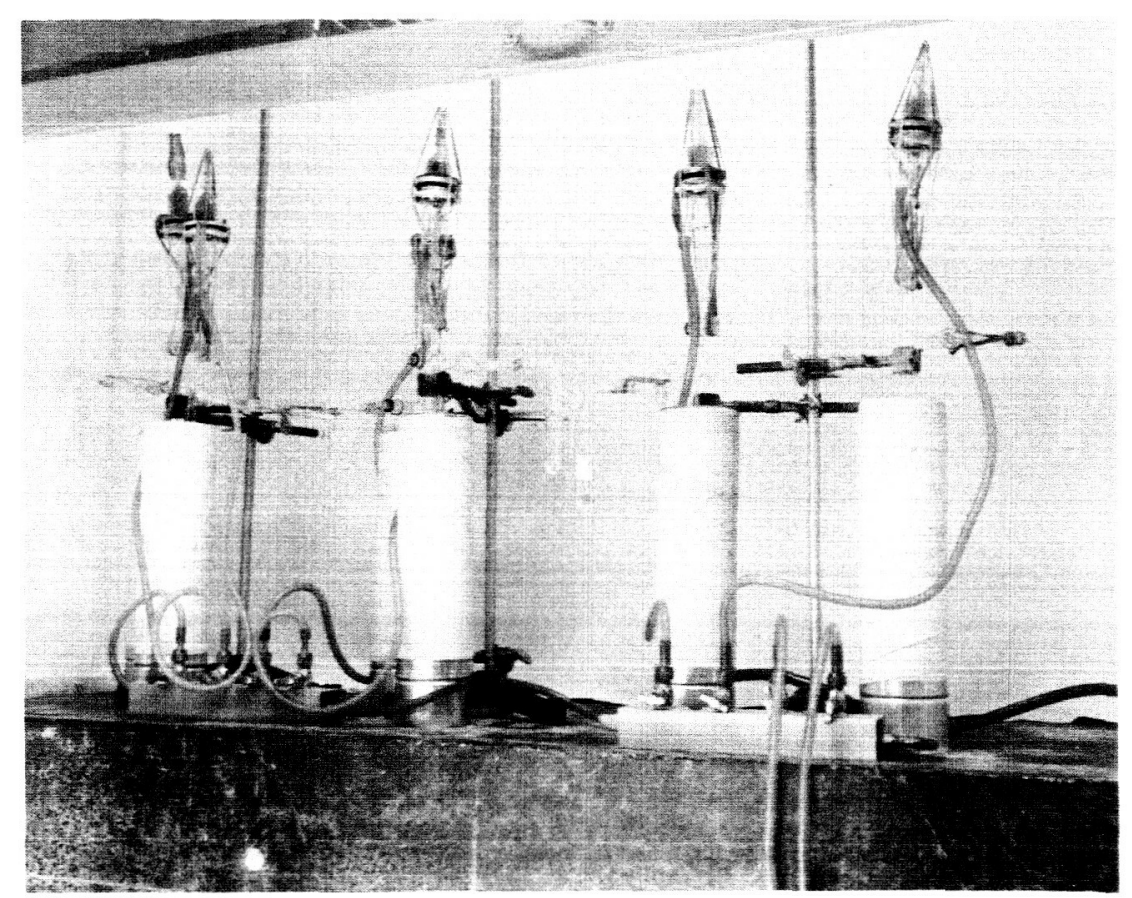

Fig. 6. A battery of permeation testers measuring the permeation of $\mathrm{N}_{2} \mathrm{O}_{4}$ through potential bladder materials

Table 2. Average permeability to nitrogen tetroxide of potential bladder materials

\begin{tabular}{|c|c|c|}
\hline Material & Average thickness, in. & $\begin{array}{l}\text { Average permeability rate, } \\
\qquad \mathrm{mg} / \mathrm{in}^{2} / \mathrm{hr}\end{array}$ \\
\hline 1. Teflon (TFE) sprayed dispersion & 0.014 & 2.400 \\
\hline 2. Teflon (TFE and FEP) sprayed dispersion & 0.008 to 0.015 & 1.030 \\
\hline 3. Teflon (FEP) extruded film & 0.010 & 0.660 \\
\hline 4. Multiple laminate of Teflon (TFE and FEP) sprayed dispersion and chemically plated gold & 0.014 & 0.260 \\
\hline 5. Aluminum flake in Teflon (FEP) sprayed dispersion & 0.011 & 0.290 \\
\hline 6. Laminate of Teflon (FEP) heat bonded to 0.001 -in. aluminum foil & 0.0065 & $\begin{array}{l}0.086 \\
(3 \text { samples showed } 0.000)\end{array}$ \\
\hline 7. Ultrasonic weld in 0.001 -in. aluminum foil & - & $\begin{array}{l}0.044 \\
(4 \text { samples showed } 0.000)\end{array}$ \\
\hline 8. Heat bonded overlap seam in laminate of Teflon (FEP) and aluminum foil & - & 0.002 \\
\hline 9. Laminate of Teflon (FEP) and 0.003 -in. tantalum foil & 0.005 & 0.000 \\
\hline $\begin{array}{l}\text { 10. Composite material of armalon (TFE cloth bonded to FEP film) coated with } \\
\text { vacuum-deposited aluminum }\end{array}$ & 0.011 & 0.73 \\
\hline
\end{tabular}

As has been repeatedly mentioned above, it appears that resistance to damage from creasing is an important property of bladder materials. Therefore, a test program was initiated at JPL to evaluate the relative crease durability of the most promising bladder materials. Since no suitable commercial tester was found, a machine was devised to repeatedly induce a traveling crease in small material samples; the crease approximates the type of crease which occurs during bladder collapse. The crease tester (shown in Fig. 7) consists of two inclined blades over which the material sample is folded to form two rolling surfaces which intersect at an angle. A gap between the blades allows the radius of the inside surface of the material to become essentially zero and form a crease. The angle and gap position settings of the blades can be determined and/or preset by means of calibrated 


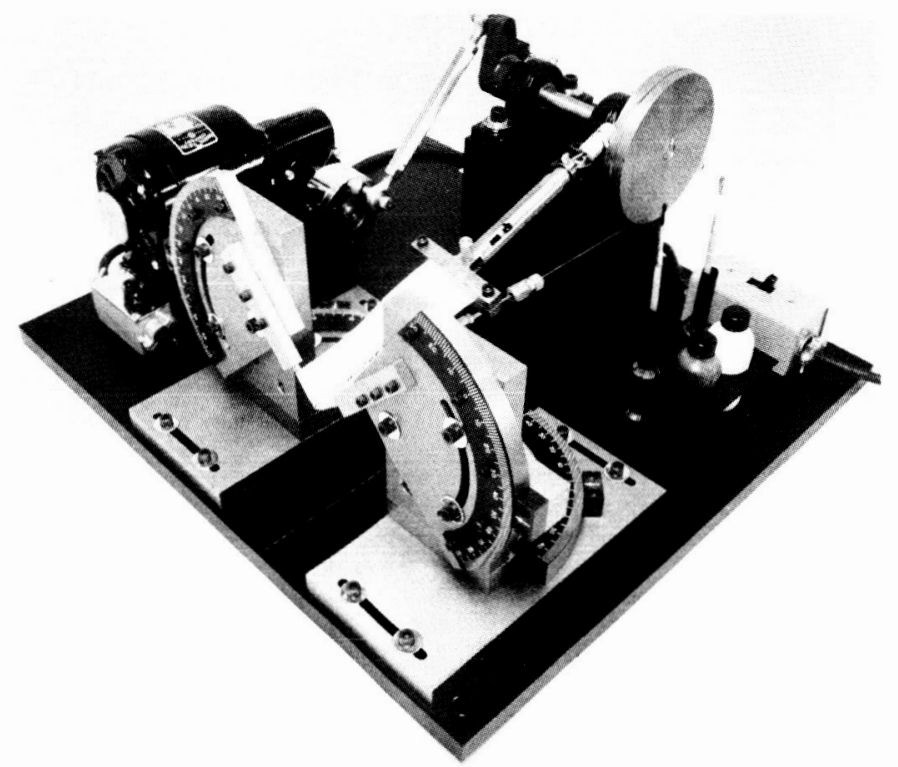

Fig. 7. JPL crease tester for evaluating bladder materials quadrants attached to the machine frame. Clamps secure the ends of the sample and connect them by a cable and a precalibrated spring tensioning device to a motordriven crank which pulls the material back and forth in a reciprocating motion over the blades, repeating the crease along the same line. Failure is defined as the formation of a pinhole. Pinholes are detected by a dye penetrant of the type normally used to locate cracks in welds. The red dye penetrant (applied to the outside surface of the fold) is readily seen in the white indicator (applied to the inside surface of the fold) when a pinhole occurs. Typical test data obtained from the crease tester are shown in Fig. 8 and Table 3; these results are discussed in Section VIII.

\section{Fabrication}

Much of the delay in developing new bladder concepts is caused by difficulties encountered in fabricating some

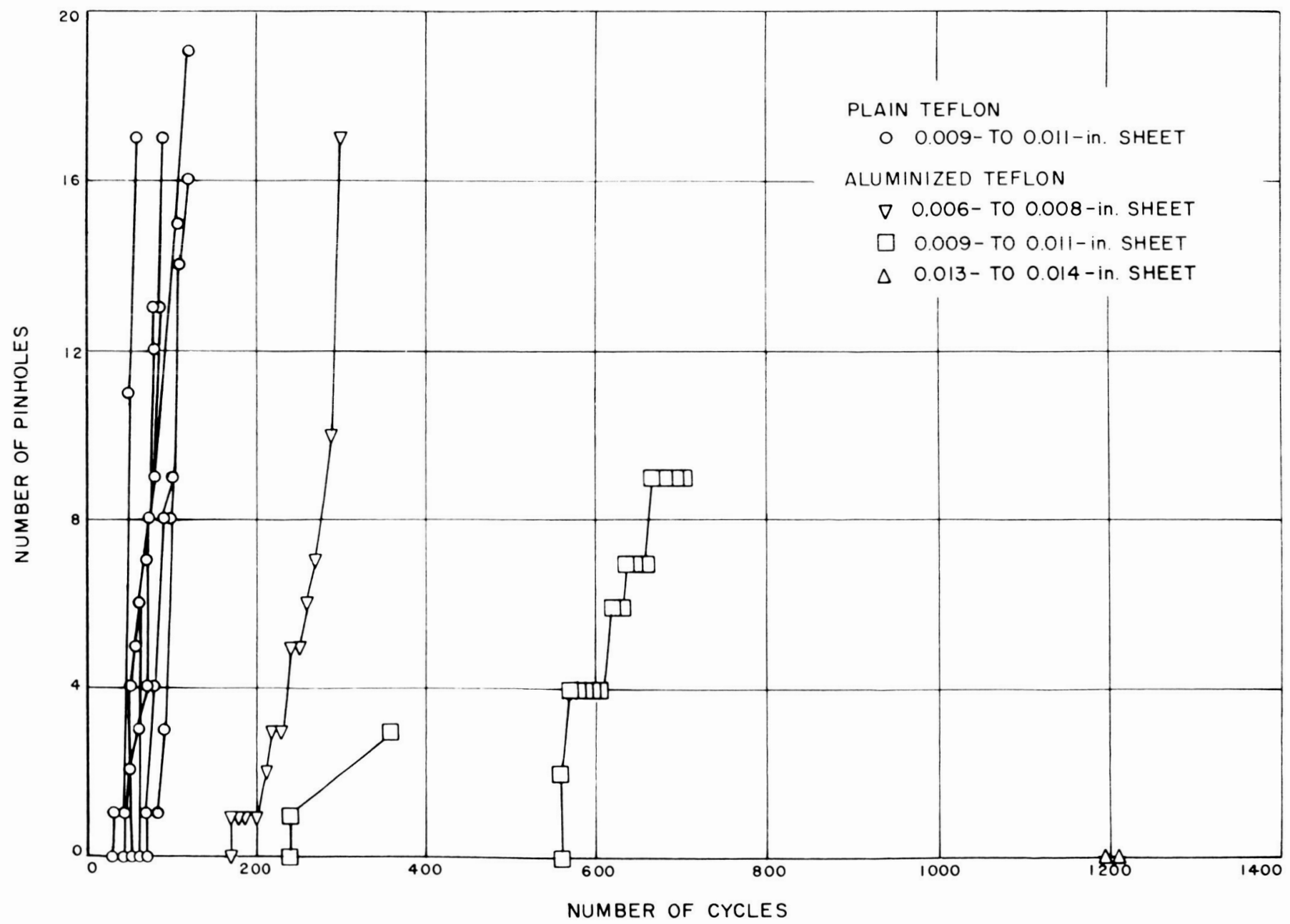

Fig. 8. Some results obtained on the JPL crease test machine 
Table 3. Results of crease resistance testing

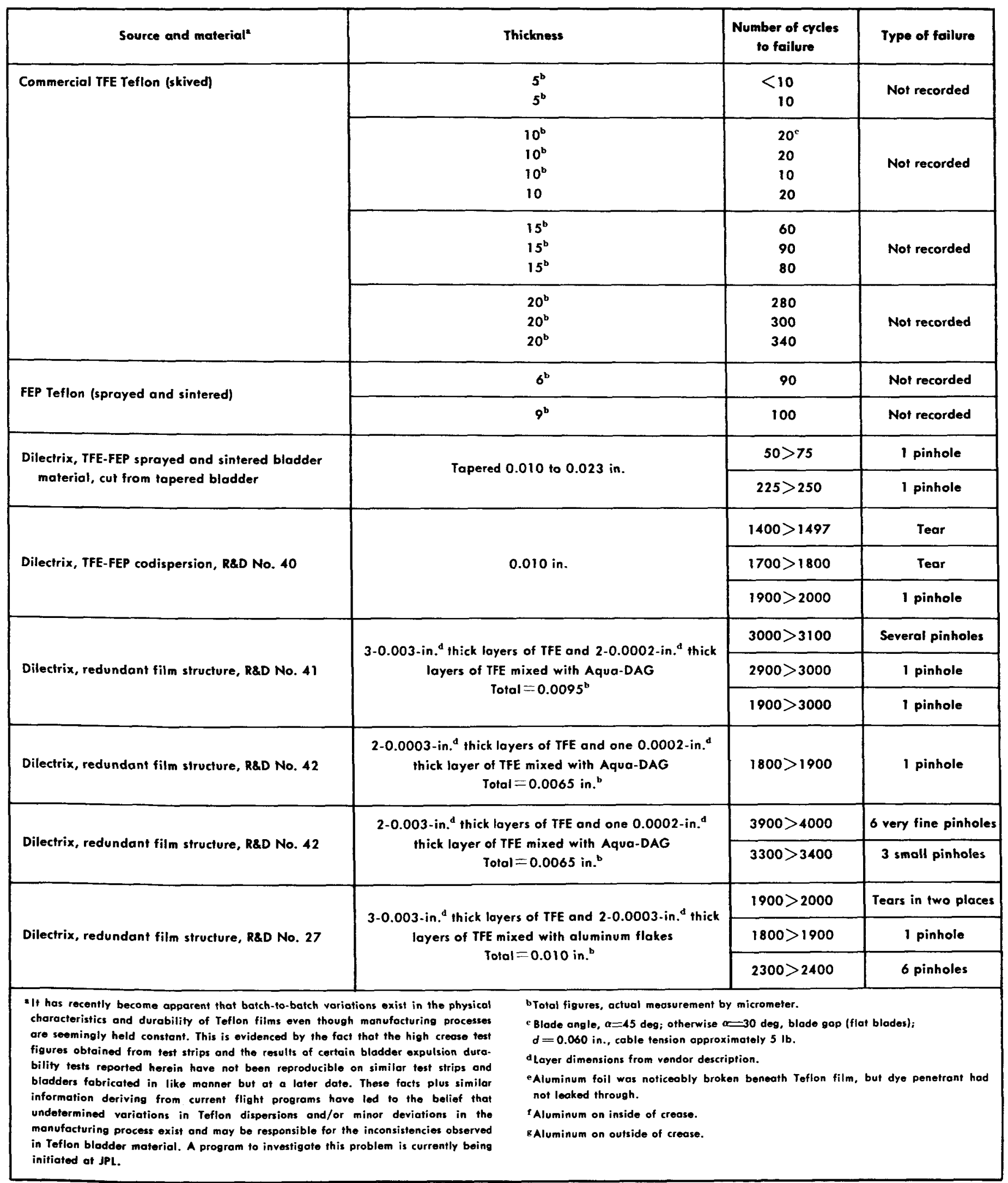


Table 3 (Cont'd)

\begin{tabular}{|c|c|c|c|}
\hline Source and material ${ }^{\mathrm{n}}$ & Thickness & $\begin{array}{l}\text { Number of cycles } \\
\text { to failure }\end{array}$ & Type of failure \\
\hline Dilectrix, Tefion and aluminum foil laminate & $\begin{array}{c}\text { Al } 0.0005 \text { in. }^{d}, \text { FEP } 0.003 \text { in. }^{d}, \text { TFE } 0.012 \text { in. }^{d} \\
\text { Total }=0.0155 \text { in. }^{b}\end{array}$ & $25>50$ & $\begin{array}{l}\text { Fine line crack } \\
\text { in aluminum }\end{array}$ \\
\hline $\begin{array}{l}\text { Raybestos Manhatian, No. L.S. } 12.018 \\
\text { Teflon-Teflon cloth-aluminum laminate }\end{array}$ & $\begin{array}{l}6.2^{\mathrm{b}} \\
6.2^{\mathrm{b}} \\
6.2^{\mathrm{b}} \\
6.2^{\mathrm{b}} \\
6.2^{\mathrm{b}} \\
6.2^{\mathrm{b}} \\
6.2^{\mathrm{b}} \\
6.2^{\mathrm{b}} \\
6.2^{\mathrm{b}} \\
6.2^{\mathrm{b}} \\
6.2^{\mathrm{b}} \\
6.2^{2}\end{array}$ & $\begin{array}{c}10^{e, r} \\
5^{e, k} \\
5^{n, r} \\
10^{k} \\
10^{e, r} \\
25^{g} \\
15^{k} \\
10^{k} \\
<5^{p, r} \\
<5^{g} \\
<5^{g} \\
5^{r}\end{array}$ & Not recorded \\
\hline $\begin{array}{l}\text { Raybestos Manhattan, No. L.S. } 12.026 \\
\text { Tefion-Teflon cloth-aluminum laminate }\end{array}$ & $\begin{array}{l}9^{\mathrm{b}} \\
9^{\mathrm{b}} \\
9^{\mathrm{b}} \\
9^{\mathrm{b}} \\
9^{\mathrm{b}} \\
9^{\mathrm{b}} \\
9^{\mathrm{b}} \\
9^{\mathrm{b}}\end{array}$ & $\begin{array}{l}<5 \\
<5 \\
<5 \\
<5 \\
<5 \\
<5 \\
<5 \\
<5\end{array}$ & Not recorded \\
\hline $\begin{array}{l}\text { Raybestos Manhattan, No. L.S. } 12.030 \\
\text { Teflon-Teflon cloth-aluminum laminate }\end{array}$ & $\begin{array}{l}9^{b} \\
9^{b} \\
9^{b} \\
9^{b} \\
9^{b} \\
9^{b} \\
9^{b} \\
9^{b}\end{array}$ & $\begin{array}{r}<5 \\
<5 \\
<5 \\
5 \\
<5 \\
<5 \\
<5 \\
<5\end{array}$ & Not recorded \\
\hline Commercial Mylar & $\begin{array}{l}2^{\mathrm{b}} \\
2^{\mathrm{b}} \\
2^{\mathrm{b}} \\
2^{\mathrm{b}}\end{array}$ & $\begin{array}{l}290^{\circ} \\
200 \\
400 \\
200\end{array}$ & Not recorded \\
\hline & $\begin{array}{l}3^{b} \\
3^{b}\end{array}$ & $\begin{array}{l}140^{\circ} \\
100\end{array}$ & Not recorded \\
\hline & $\begin{array}{l}10^{b} \\
10^{b} \\
10^{b}\end{array}$ & $\begin{array}{l}110^{\circ} \\
120 \\
120\end{array}$ & Not recorded \\
\hline \multicolumn{4}{|c|}{$\begin{array}{l}\text { bTotal figures, actual measurement by micrometer. } \\
\text { "Blade angle, } \alpha=45 \text { deg; otherwise } \alpha=30 \text { deg, blade gop (flot blades); } \\
\alpha=0.060 \text { in., cable tension approximately } 5 \mathrm{lb} \text {. } \\
\text { a Layer dimensions from vendor description. } \\
\text { eAluminum foil was noticeobly broken beneath Teflon film, but dye penetrant had } \\
\text { not leaked through. } \\
\text { 'Aluminum on inside of crease. } \\
\text { BAluminum on outside of crease. }\end{array}$} \\
\hline
\end{tabular}


of the inert and impermeable materials into the desired shapes. Practically every material requires slightly different handling, tooling, and techniques. Only the elastomers seem to be susceptible to standard procedures, although even these must be modified somewhat to insure quality control.

Butyl rubber bladders are made in metal molds with soluble cores. The sheet stock is cut into gores and laid up over the core. Pressure and heat are applied by the female mold. After the curing operation is completed, the core is dissolved. Later the bladder surface is inspected and ground smooth. This produces a good quality, seamless rubber bladder.

FEP Teflon sheet stock has been successfully formed into quarter spheres for JPL by Astro Research. Complete bladders could be made from these quarters by heat sealing several together.

About 1957, commercial firms developed a method for fabricating seamless TFE Teflon bladders. The bladders are made by spraying a Teflon dispersion onto an aluminum mandrel to a thickness of about $0.0003 \mathrm{in}$. and then sintering the coating in an oven. Many such layers are applied until the desired thickness, usually 0.005 to 0.020 in., is reached and then the mandrel is chemically dissolved. In 1961, the dispersion of FEP Teflon became available. This material sinters at a lower temperature $\left(550^{\circ} \mathrm{F}\right.$ compared with $650-700^{\circ} \mathrm{F}$ for $\left.\mathrm{TFE}\right)$ and into a more cohesive film than TFE Teflon. A multilayer laminate of TFE and FEP dispersions also can be made by spraying and sintering. Still later, a "codispersion" of TFE and FEP was developed that produces a material in which both of these Teflon products are evenly intermingled on a microscopic scale. Reference 8 discusses these Teflon materials and describes the fabrication of seamless Teflon bladders in considerable detail.

The heat-sealed laminates of Teflon and aluminum, found to be impermeable as mentioned below, might be considered for bladder construction provided that the following problems of fabrication can be solved.

1. Inspection of the aluminum foil for pinholes and other defects prior to lamination and after forming.

2. Formation of the laminate into cylindrical and spherical shapes.

3. Joining the formed segments with a gas-tight metalto-metal seam of adequate flexibility.
The first problem has not been completely solved but a method using photographic printing paper was tried at JPL (see Ref. 9). Strong light was directed toward a sheet of aluminum foil so that light passing through pinholes would strike the paper behind the aluminum sheet. When developed, the location of pinholes was indicated by black spots on the paper. More work is being done on this problem.

The second problem was studied by Swedlow, Inc., of Los Angeles, as part of the task of fabricating bladders for JPL. By a process involving sandwiching the thin laminate with heavier sheet aluminum they were able to have 18-in.-diameter hemispheres spun from a single piece of laminate. Later, they were able to successfully form hemispheres by hydroforming. The flat side (necessary for completion of the hemispherical bladder) and the outlet neck were initially joined to the formed hemispheres by heat bonds between the Teflon and aluminum parts. Later this joining was accomplished by a very small-bead fusion weld, and eventually, it is understood, the seams were made by electron beam welding, although none made by this process was ever delivered to JPL. All units received had excessively heavy and stiff seams.

The ultrasonic welding technique is being investigated at JPL as a means of fabricating the seams where the segments of a Teflon-aluminum foil laminate bladder are joined. The welder is shown in Fig. 9. Tests with pieces of 0.001-in.-thick aluminum foil have proven that continuous metal-to-metal weld seams can be made that are impervious to $\mathrm{N}_{2} \mathrm{O}_{4}$ within the resolution limits of the permeation detection method used. The problems inherent with this fabrication process will become more apparent when it is applied to the construction of bladders.

The lead-plated Teflon described in Section VIII is also interesting because not only does the lead plate provide an impervious barrier to permeation but it can greatly facilitate fabrication. Lead plate apparently can be applied to bladders of any shape, including the seamless Teflon variety. In case seams should be necessary, however, it was shown that lap and butt joints were easily made using a soldering iron and 60-40 solder.

\section{J. Inspection}

Bladders as received from the fabricator or newly repaired bladders should be inspected before being used. Confirmation of the material composition and hardness is often desirable at this stage. Dimensional checks are 
standard practice. An inch-by-inch search for imperfections may require considerable time, particularly if pinholes are of special concern.

\section{K. Cleaning}

Cleaning procedures should be selected which accomplish two main objectives: the removal of particulate matter which may clog, jam, or damage other parts of the system and the elimination of reactive substances which may be incompatible with the bladder, the pressurant, or the propellants. With some propellants, such as hydrazine, there is a very important connection between the cleaning procedure and material compatibility. The very same material may exhibit marked changes in apparent compatibility, as evidenced by propellant decomposition and corrosion rate, with variations in the cleaning techniques used. These changes are probably due to differences in surface oxidation, surface roughness (area), and
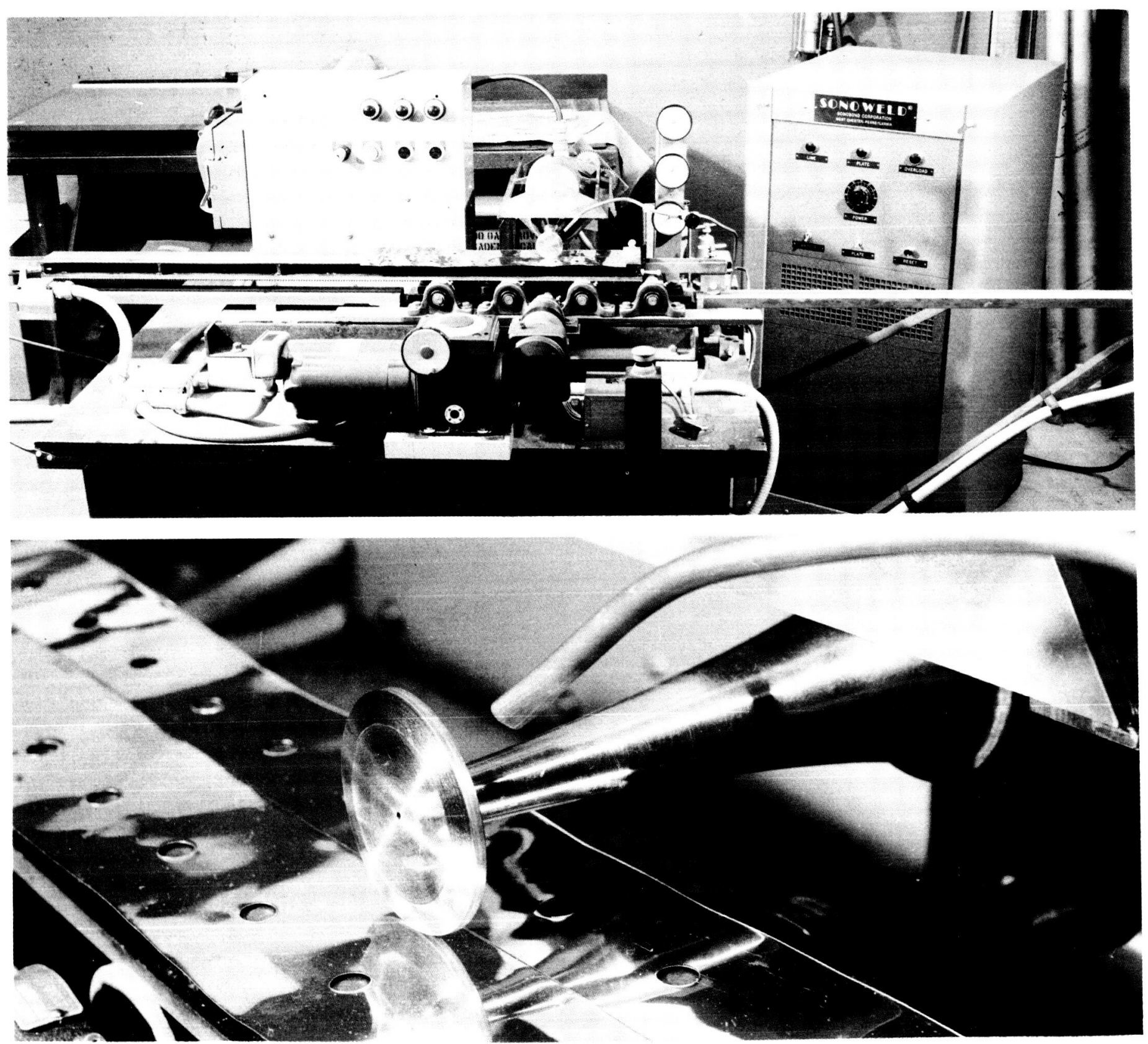

Fig. 9. Sonic welder used at JPL to make seams in thin aluminum foil 
absorption of solvents. Therefore, the cleaning procedure should be tested along with the bladder material whenever compatibility is being determined. It may even be necessary to follow the cleaning procedure with chemical passivation if extremely reactive propellants (such as hydrogen peroxide) are to be stored in the bladder. Normally, the last step in the cleaning procedure is to dry the bladder thoroughly.

\section{Testing}

At JPL, tests falling into four distinct categories are performed: feasibility, development, "type-approval," and "flight-acceptance." Feasibility test procedures are custom designed by the cognizant engineer; there are no standards or set patterns. Usually feasibility tests are limited to leak and water expulsion tests (presuming earth-storable propellants are to be used, not cryogenics). The sole purpose of these tests is to determine whether or not the particular concept or design has sufficient probability of usefulness to warrant development.

Development tests are also devised by the cognizant engineer. In the beginning, considerable test flexibility is evident as data are gathered merely to guide the design evolution. Eventually, however, the tests must investigate a wide range of functional and environmental parameters until there is assurance that the design can pass the typeapproval tests.

Type-approval tests are made to demonstrate that a fully flight-worthy design has been developed. First, very explicit test procedures are written. These establish test conditions and functional requirements which are somewhat more severe than will be encountered during preparation, launch, and flight. Upon approval of the procedures, items conforming exactly to the "frozen" design are subjected to the tests under stringent control. Successful completion of these tests qualifies the design for flight.

Flight bladders are subjected to flight-acceptance tests to give assurance that they are truly the same as the samples which passed the type-approval test and are free of hidden flaws. In most cases, the flight-acceptance tests are as limited as possible to avoid wear or damage.

Within the general categories discussed above are many specific tests. Most bladders are subjected first to a leak check; this may be repeated several times between other tests and after installation in the tank. The simplest method of finding leaks is to immerse the inflated bladder in water or alcohol and look for bubbling. A much more sensitive (and expensive) technique is to inflate the bladder with a suitable gas (helium, Freon, etc.) and locate the leaks with a "sniffer" (mass spectrometer).

Measuring the expulsion characteristic of a bladder is fairly simple. Figure 10 shows a setup used at JPL for this purpose. The volume of liquid forced into the bladder is carefully measured, then the differential pressure across the bladder and the volumetric flow rate is continuously recorded as the liquid is expelled. Plotting the percentage of liquid expelled as a function of the differential pressure results in a curve similar to Fig. 11. For a given differential pressure, the expulsion efficiency is the percentage of the loaded volume expelled. If very accurate data are desired the measurements must be corrected for thermal expansion and contraction. Also, the liquid volumes measured must be those going into and out of the bladder; liquid trapped in the standpipe, outlet strainer, plumbing, etc., must be accounted for by the

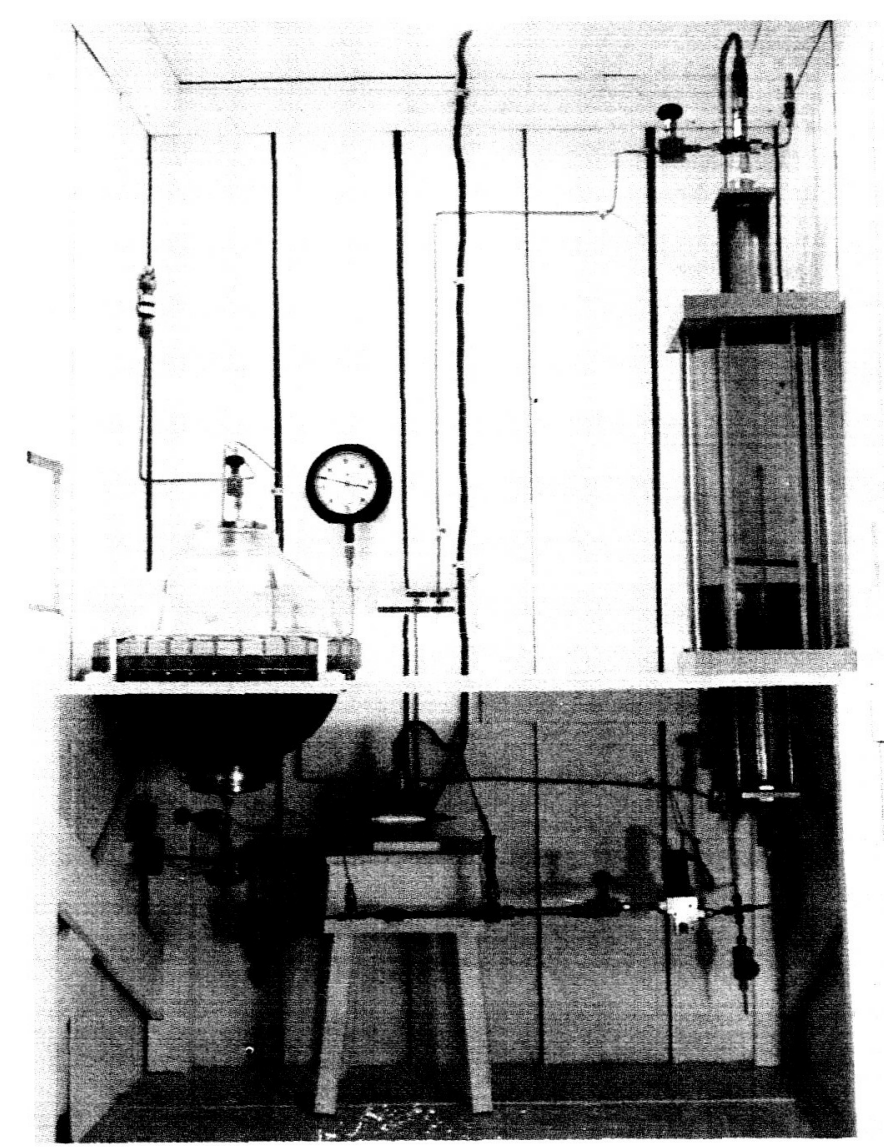

Fig. 10. Test setup used to measure expulsion efficiency of small bladders and diaphragms 


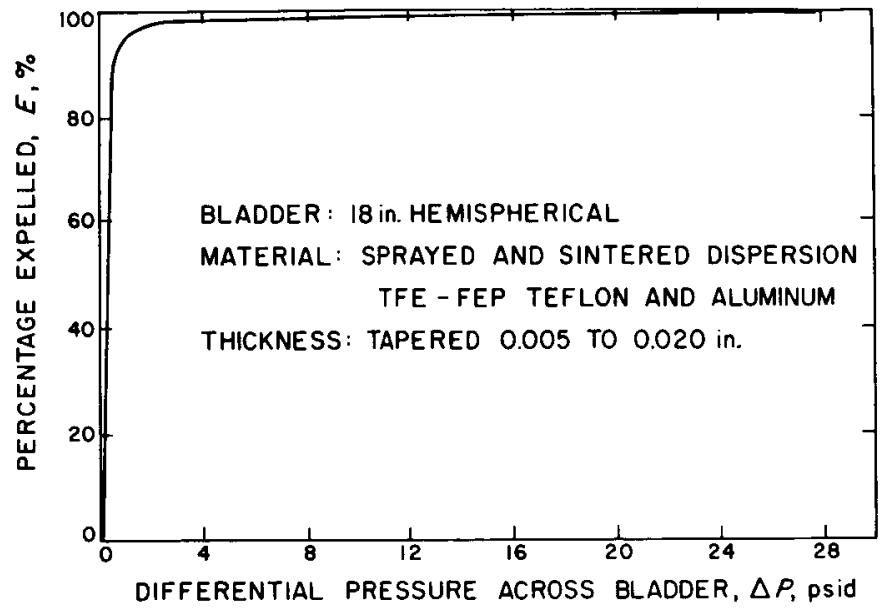

Fig. 11. Expulsion characteristic of a hemispherical Teflon bladder

propulsion system designer but it must not be erroneously deducted from the expulsion efficiency of the bladder. Errors in measuring the volume of liquid put into the bladder can arise from bubbles in the liquid and drops clinging to the walls of the volumetric tank after filling. At JPL, distilled water in clean systems and bladders is used to avoid these two problems; attempts to use wetting agents were not successful. Another source of error in measuring expulsion efficiency is drainage out of the bladder at the end of expulsion due to gravity rather than bladder expulsion forces. This extra volume of propellant would not be available to the engine because propellant must be forced into the engine under pressure; the hydrostatic and vapor pressures which cause residual drainage are insufficient to pump the propellant at any reasonable flow rate.

Cycle durability of a bladder can be assessed by repeated expulsions using the same apparatus used for measuring expulsion efficiency. A truer indication of the bladder's life expectancy may be obtained by a somewhat more involved test which includes periods of sloshing, temperature cycling, and storage between repeated expulsion cycling. A critical test parameter to be chosen whenever cycle durability tests are contemplated is the maximum pressure differential across the bladder which will be permitted at the end of expulsion. For example, in a propulsion system operating with 200 -psia tank pressure, this pressure becomes the final differential pressure if the system is fired to propellant exhaustion. Repeatedly applying this differential to the bladder may be a far more severe test than necessary since in actual usage it may occur only once. Recycling capability is important in a bladder because it permits checkout cycles and possible draining and refilling in case a flight is postponed. These cycles should not be accomplished with full tank pressure but rather at the minimum necessary to expel the contents. A realistic durability test might call for several low pressure expulsions for each high pressure cycle.

Figure 12 shows the equipment used at JPL to apply sloshing loads to bladders (and diaphragms). It is capable of accelerating an 18-in.-ID spherical Plexiglas tank containing water and bladder to $1.5 \mathrm{~g}$ in either linear or rotational motion, singly or simultaneously. The limits of amplitude are $\pm 1^{7 / 16}$ in. linear motion and $\pm 4^{1 / 4} \mathrm{deg}$ angular motion with oscillation frequencies up to $3 \mathrm{cps}$. Volumetric tanks are provided at this facility to measure expulsion efficiency.

Vibration and shock tests are usually made with the bladder and tank assembly or the complete propulsion system. Frequently these tests are made in expensive environmental facilities so water (or another "referee" fluid) is substituted for the propellant to avoid subjecting the facility to extra hazard. Water matches the properties of hydrazine very well but it does not closely simulate other propellants.

Temperature cycling may be done in a special environmental facility or by storing the unit where ambient temperatures vary over the desired range. The former method is required to reach extreme temperatures, but it subjects the facility to considerable hazard because these tests mean little unless the bladder is filled with propellant. Current JPL flight systems must be stored and fired at bulk temperatures up to $+167^{\circ} \mathrm{F}$. Future systems may be heat sterilized in the fully loaded and pressurized condition by maintaining them at $+275^{\circ} \mathrm{F}$ for $24 \mathrm{hr}$. The bladder for this service may have to pass typeapproval tests including three cycles of $36 \mathrm{hr}$ each at $+293^{\circ} \mathrm{F}$.

The second method mentioned above is actually a combined temperature cycling and storage test. At JPL's Edwards Test Station the ambient temperature ranges from approximately +15 to $+115^{\circ} \mathrm{F}$; midcourse propulsion systems containing bladders have been stored there for periods up to ten months in length prior to firing tests.

In order to complete all of the above tests it is necessary to handle, fill, and drain the bladders a number of times. This frequent repetition offers ample opportunity 


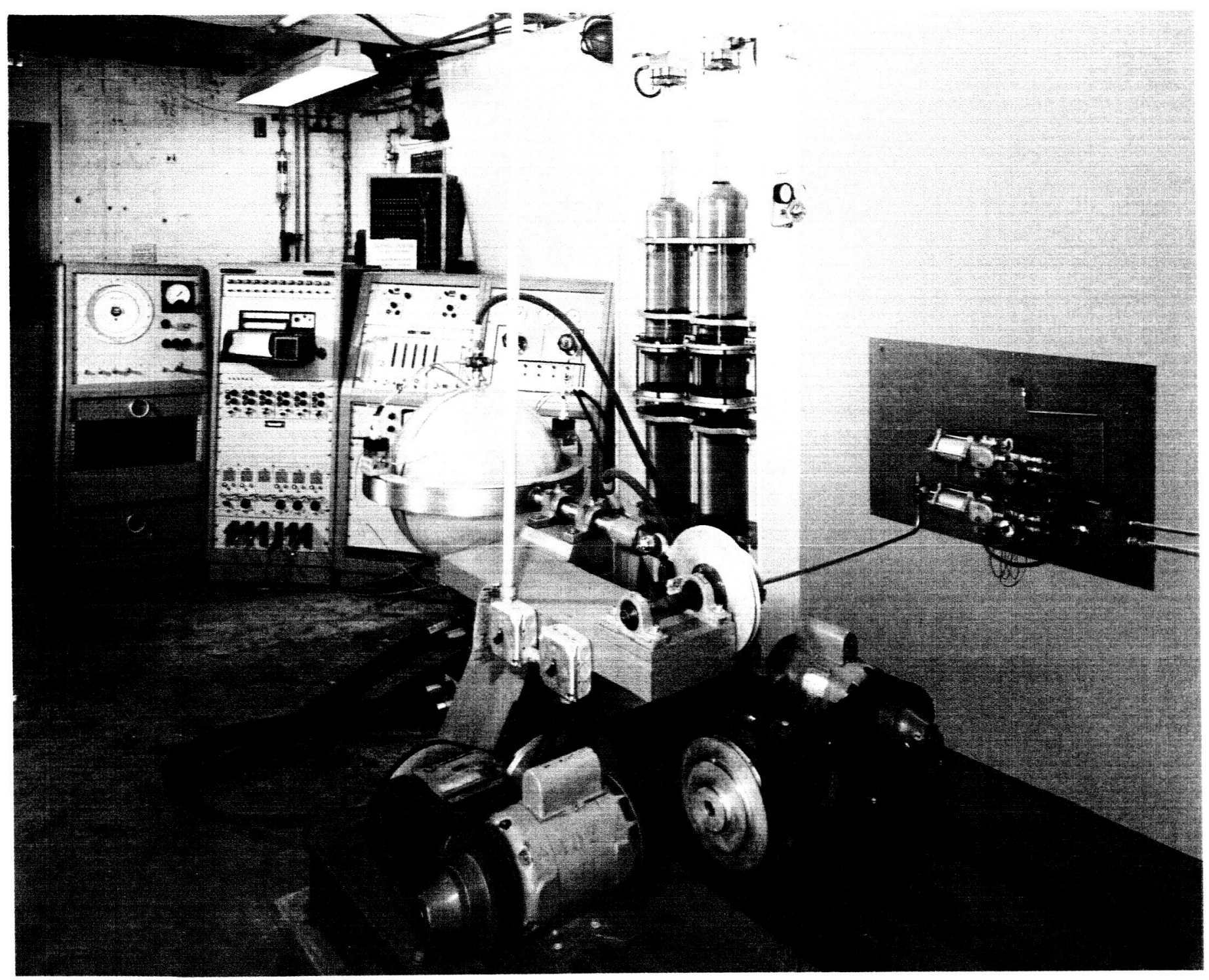

Fig. 12. Facility used to slosh test and measure expulsion afficiency of bladders and diaphragms

to develop the handling, filling, and draining techniques to a high level. Sometimes, however, procedures which may not be useful in the field are adopted during testing for the sake of expediency. If this happens, it may be necessary to do additional testing of the procedures specifically designed for flight operations. 


\section{DIAPHRAGMS}

\section{A. Definition}

The devices which fall into this category are thin, extensible or collapsible membranes, which divide the tank into two compartments. Diaphragms are usually a surface of revolution. The outermost edge or periphery is almost always fastened to the tank. Unlike bladders, diaphragms allow the tank to be exposed to both the propellant and the pressurant. Some diaphragms may be completely reversed upon themselves; that is, they may end up in a configuration which is a mirror image of the original shape. Others may start from some intermediate shape and be formed by pressure to a completely different final shape.

\section{B. Shape}

The original and final shapes of diaphragms are dependent upon the tank shape and the shape of the volume to be expelled. Often, a longitudinally symmetrical volume (usually a sphere) is to be swept by the diaphragm(s). One or two diaphragms may be used. With one, a reversing diaphragm is required. A dual diaphragm installation involves membranes which either collapse to the midplane or expand from the midplane. For the latter case, the diaphragms may be preformed into convolutions.

The fundamental concept in convoluting diaphragms is to so fold them that upon extension no stretching or shrinking of the material is necessary. To achieve this goal, the convolution shape must be designed with great care to make sure that the total surface area is exactly the same as the total surface area of the shape to which it will be extended (this is usually the shape of the inside surface of the tank). Several basic convolution designs for sweeping a hemisphere are illustrated in cross-section in Fig. 13 (see also Ref. 1). It can be seen that the surface area of the hemisphere is divided up into zones by planes which are parallel to the plane of the periphery. The planes may be located so as to produce convolutions of equal height, equal pitch, etc. Alternate or odd-numbered zones, starting with the third zone from the peripheral plane of the diaphragm, are transposed back to where the major diameter of each zone lies on the peripheral plane. For the sake of convenience, these odd-numbered zones (or bands) are called the "forward" surfaces in this report inasmuch as they project forward from the peripheral plane. Mirror images of the even-numbered zones (or bands) are transposed back so that they connect the minor diameter of each forward surface with the major diameter of the next smaller forward surface. These connecting surfaces, which are mirror images, are called "reflected" surfaces. By means of this kind of geometrical manipulation, the folded or convoluted shape has the same surface area as the hemisphere into which it will be extended. It seems apparent that other shapes could also be convoluted in this manner; for example, Honeywell has built cylindrical tank and diaphragm assemblies.

As with bladders, the shape of the diaphragm exerts a strong influence on the folding process and the same concern for the factors that cause creasing in bladders should be shown for creasing in diaphragms. The shape is also affected by the need to fasten the diaphragm's periphery to the tank.

\section{Installation and Removal}

Normally, the peripheral anchoring of a diaphragm means that the widest part of the swept volume is chosen for the attachment plane. This, in turn, makes the closure flange or clamp relatively heavy. The heaviest designs feature midplane tank flanges for opening the tank, insertion of the diaphragm, clamping and sealing the edges upon tank closure, and opening the tank again for removal. Some reduction in weight might be achieved if the diaphragm could be folded up and passed through a smaller port and then clamped in place inside the tank with a sectioned ring. The lightest tankage and diaphragm assemblies are made by permanently welding or brazing all of the parts together. This latter scheme obviously lacks the convenience of easily opened tanks, but the penalty may be small if the diaphragm can be recycled many times.

\section{Anchor and Seal Design}

A number of designs for anchoring and sealing diaphragms have been proposed and some have been tried successfully (see Fig. 14). The problem of clamping an elastomer or even the edges of a metal diaphragm (Fig. $14 \mathrm{a}$ and $14 \mathrm{~b}$ ) between the halves of a tank are not very difficult, and the welding of the closure seam between a tank half and a ring at the edge of an all-metal diaphragm (Fig. 14c) is almost equally straightforward. In both cases, the section rigidity and the diaphragm loads will 


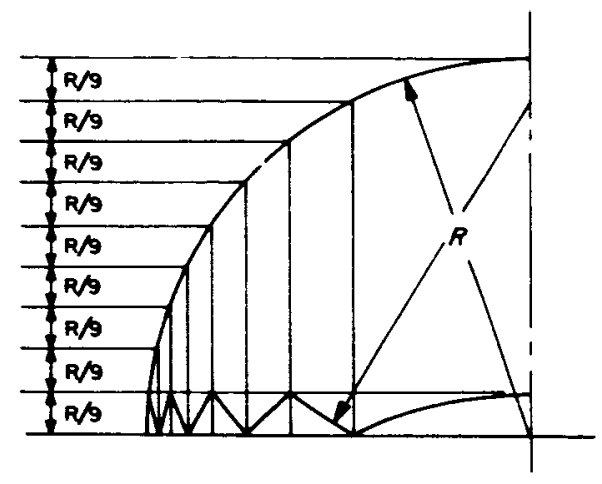

(a) CONSTANT DEPTH CONVOLUTIONS

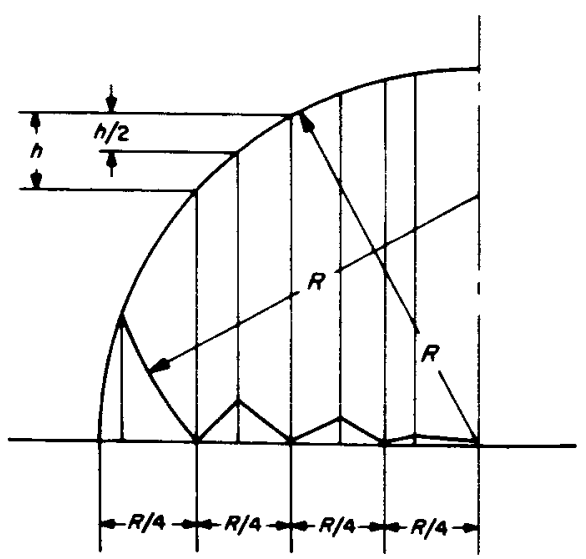

(b) CONSTANT PITCH CONVOLUTIONS

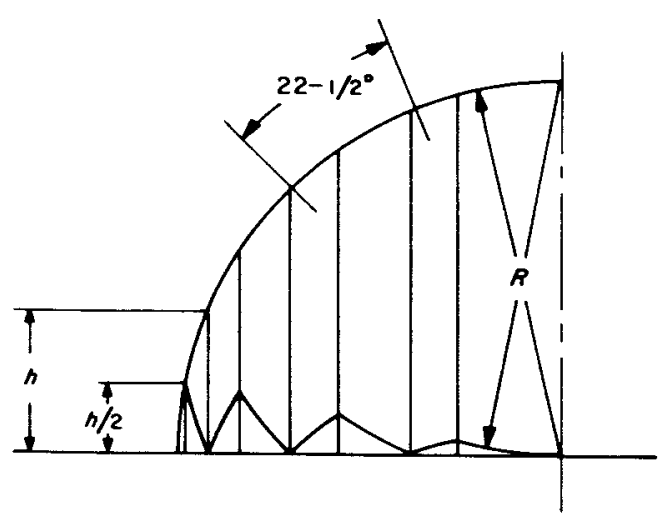

(c) CONSTANT DEVELOPED-LENGTH CONVOLUTIONS

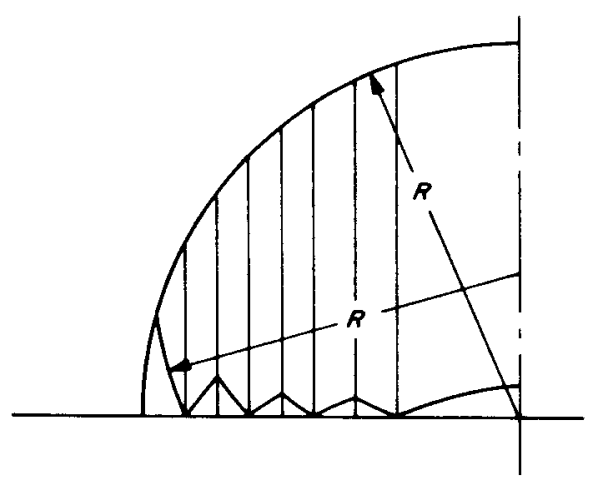

(d) COMBINATION CONVOLUTIONS

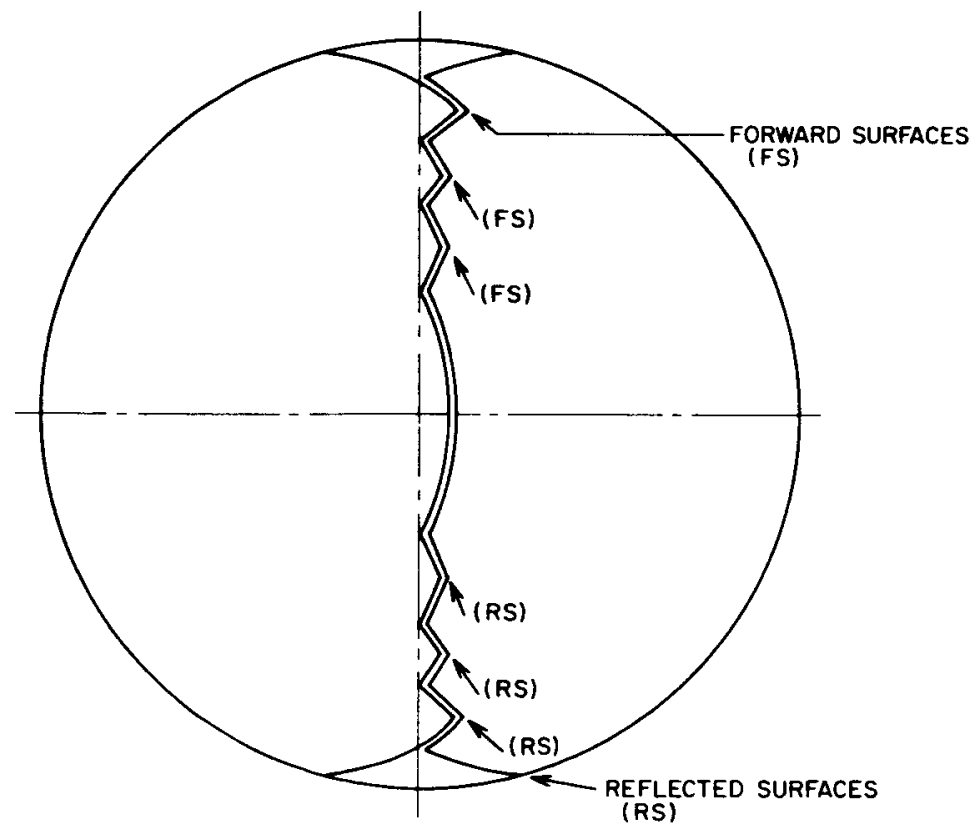

(e) NESTED CONVOLUTIONS FOR DUAL DIAPHRAGM INSTALLATION

Fig. 13. Some convolution geometries suitable for hemispherical expulsion diaphragms 


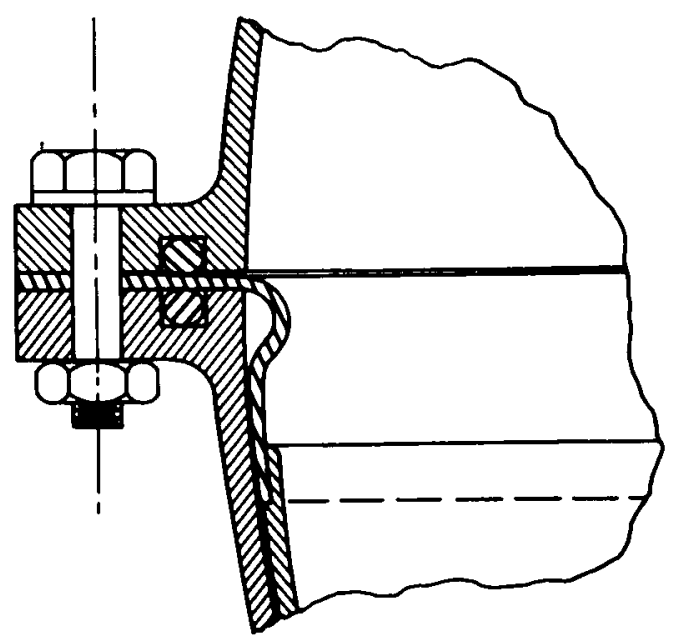

(a) METAL DIAPHRAGM OR RUBBER DIAPHRAGM BONDED TO METAL RING (ALPS TEST DIAPHRAGMS-1961)

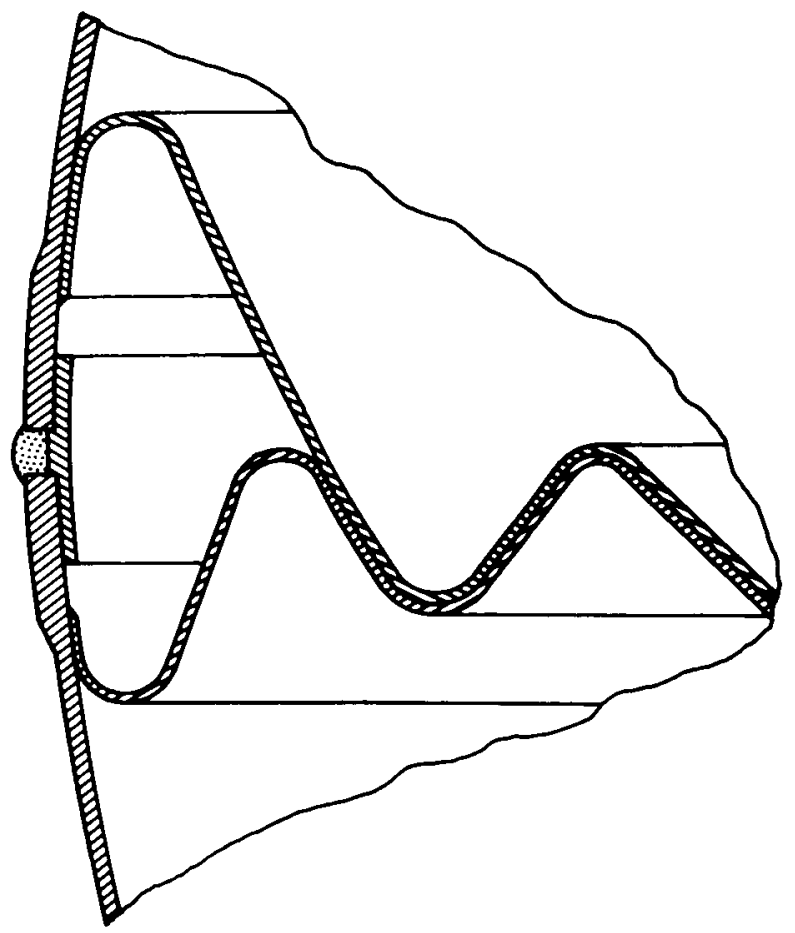

(c) NESTED METAL CONVOLUTED DIAPHRAGMS WELDED INTO TANK (PROPOSED, ALPS - 1963)

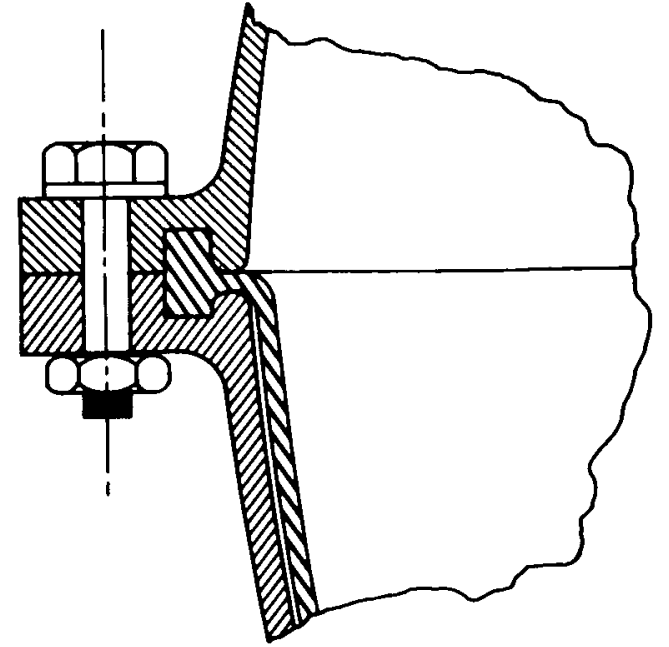

(b) RUBBER DIAPHRAGM WITH BEAD CLAMPED BETWEEN TANK HALVES (PROPOSED - 1962)

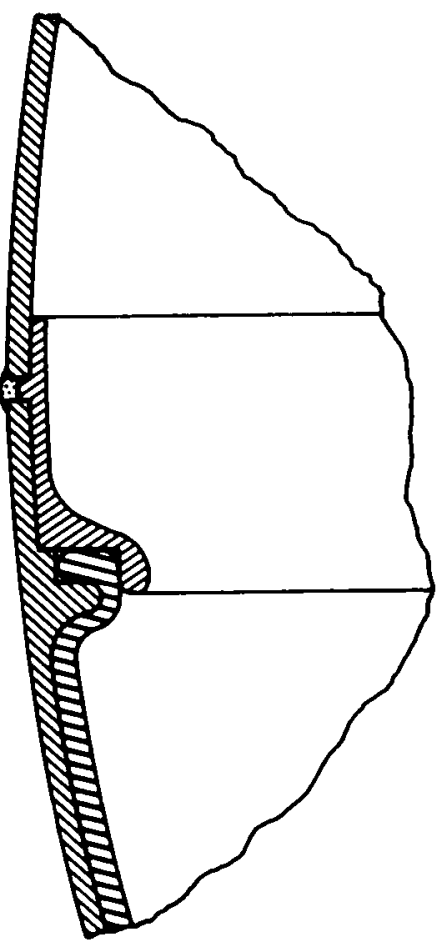

(d) RUBBER DIAPHRAGM WITH BEAD BONDED TO BACKUP RING AND CLAMPED BETWEEN WELDED TANK HALVES (ALPS - 1961 )

Fig. 14. Methods of fastening and sealing diaphragms 
apply bending loads to the tank shell for which the designer must allow adequate margins. Special fabrication problems arise when an elastomeric diaphragm is to be welded into a tank. A design for accomplishing this is shown in Fig. 14d. The concept involves bonding the edge of the diaphragm to a metal ring. This ring serves as the back-up ring for the closure weld. The major problem is that the welding process heats the ring to temperatures which may be detrimental to the elastomer. A tank fabricator (Airite) under contract to JPL performed some welding tests, which showed that sufficient local cooling could be achieved with water-cooled chill rings to avoid damage to the diaphragm (see Ref. 10). Later, another fabricator (Pressure Systems, Inc.) successfully manufactured several complete tank assemblies using this procedure (see Ref. 11).

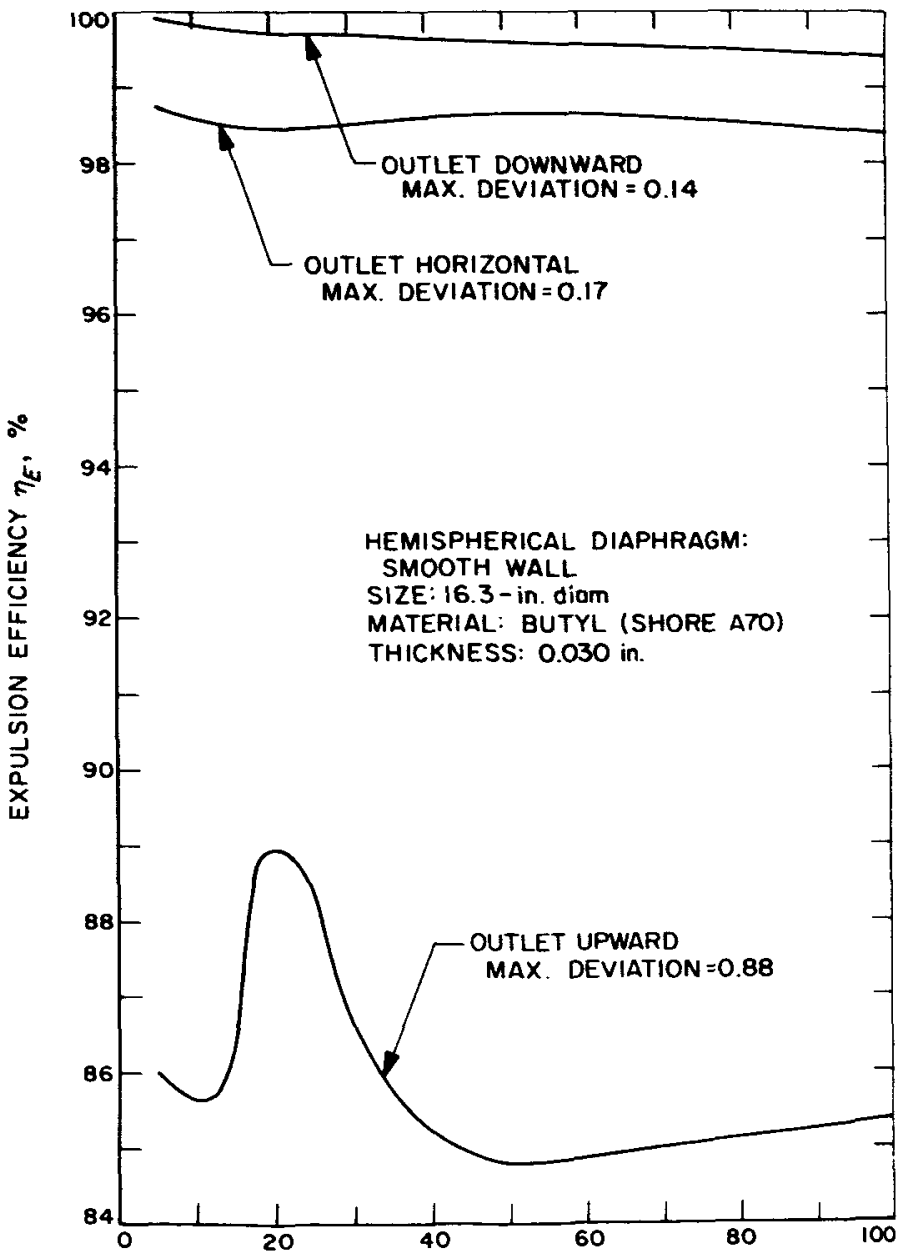

MAXIMUM PRESSURE DIFFERENTIAL ACROSS DIAPHRAGM, $\triangle P$ psId

\section{E. Ports}

The pressurization and outlet ports of a tank fitted with diaphragms must be protected against extrusion of the diaphragm. Usually a strainer matching the inner contour of the tank is adequate. As with bladders, many devices have been tried to prevent blocking off the ports.

The particular shape, folding pattern, and material of the diaphragm must be considered in choosing the optimum design. For thin, flexible diaphragms molded of rubber, small ribs located to hold the diaphragm away from the tank wall have proven very effective. Expulsion efficiency exceeded $99.7 \%$ in all tests of the ribbed diaphragm compared to a minimum efficiency of $84.4 \%$ for the smooth diaphragm. In Fig. 15, smoothed curves are drawn through averaged data, which demonstate how

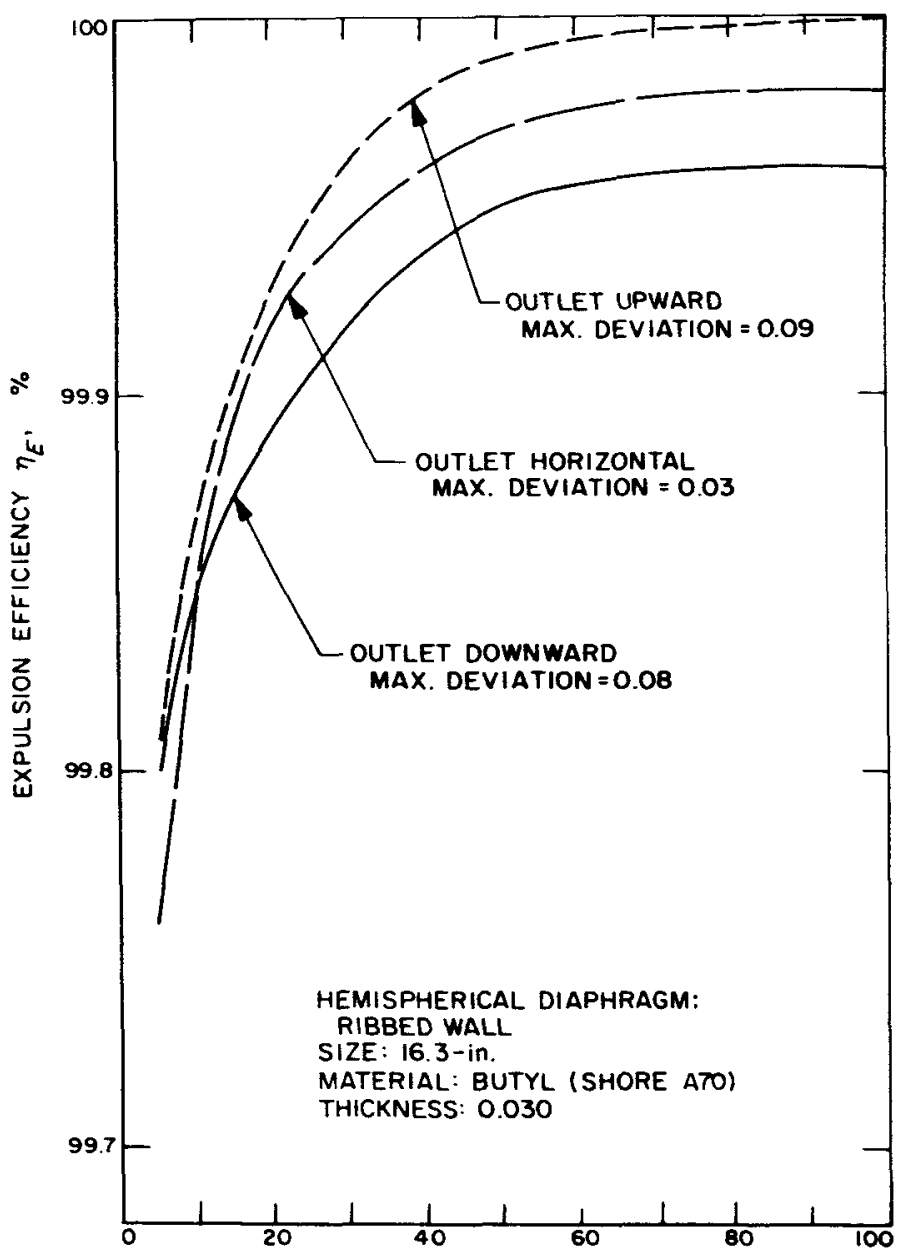

MAXIMUM PRESSURE DIFFERENTIAL ACROSS DIAPRAGM, $\triangle P$, DSId

Fig. 15. Effect of ribs on the expulsion efficiency of a rubber diaphragm 
well small ribs provided repeatable expulsion efficiency with the tank in three different orientations. These data were collected at ambient temperature using inert gas to expel water under static conditions (no sloshing). Three to fourteen measurements were made at each of five pressures $(5,10,20,50$, and $100 \mathrm{psig})$ for three positions of the diaphragms. A considerable improvement in the repeatability was achieved with the ribs; maximum deviation from nominal value was tenfold less for the ribbed diaphragm than for the smooth diaphragm. The maximum deviations in some instances include tests on two different diaphragms under the same conditions.

\section{F. Filling}

Figure 16 schematically describes six possible ways of filling a tank and diaphragm assembly with bubblefree liquid. Convoluted diaphragms are shown; but suitable procedures would allow most of these methods to be used with other types of diaphragms. The first (Fig. 16a) is to provide a vent at the top of the tank through which the gas or air is allowed to escape. An alternate means of accomplishing the same thing is to run a vent tube from the top (Fig. 16b); this avoids the necessity of putting a port in the tank wall. Two paths for the vent tube are shown, but routing the vent tube through the liquid would be less desirable since the tube would have to be collapsible. Figure 16c shows the entire tank inverted so that liquid can be poured in and the gas or air can escape through the same port. Diaphragms capable of recycling can be subjected to a vacuum that would collapse the diaphragm as if fully expelled, then the liquid is pumped in (Fig. 16d). Because metal diaphragms seldom allow cycling, it has been proposed that balloons be installed and pressurized on both sides of the diaphragm to support it, then the space outside the balloon on the liquid side be pumped down to a vacuum. The liquid as it enters displaces one balloon, and finally both balloons are removed (Fig. 16e). The last method (Fig. 16f) is to carefully keep both sides at the same pressure while pumping both sides of the diaphragm down to a vacuum and then fill the liquid. As with bladders, precise metering of the volume of propellant loaded is necessary to avoid undue stretching or deformation.

\section{G. Folding}

Reversing diaphragms, such as hemispheres, fold in much the same manner as bladders. Ideally they should circumferentially roll, starting from top center, so as to gradually invert the entire diaphragm into a mirror image of the original shape. This sequence seldom is followed because the hydrostatic pressure, tending to establish a planar liquid level, causes the diaphragm to fold in a random pattern of many small wrinkles approximating the liquid level. The most severe working occurs when the liquid level has passed center and the fixed periphery of the diaphragm is, in effect, an anchor against which the folded center is straining as it is pushed downward. The folds and wrinkles in the center are forcefully pulled out. Where double folds exist, traveling creases are frequently generated. Finally, as the diaphragm is pulled taut against the lower tank surface, all folds and wrinkles should disappear.

Overall, the folding problems associated with the reversing diaphragm are less severe than with bladders. (At least two industrial rocket firms have taken advantage of this fact by installing metal rings at the equator of spherical bladders so that the upper half behaves like a reversing hemispherical diaphragm while the bottom half remains against the tank wall.)

Reversing diaphragms apparently are more suitable for recycling and long storage periods than conventional, random folding bladders. They have the advantage of being nearly free of folds or creases when full or empty and thus avoid prolonged storage in the strained condition.

Convoluted diaphragms are fabricated in the "folded" position. The convolutions are shaped to have a surface area equal to the fully expelled form (see Fig. 13). Ideally, expulsion causes the entire surface, except for the outermost forward band, to move perpendicular to the nominal tank center plane as the reflected surfaces circumferentially roll. In theory this provides a means of extending the diaphragm with no metal stretching or shrinking. The first deviation from this ideal is the stretching of the radius joining the forward and the reflected bands. Secondly, the reflected surfaces do not roll perfectly but buckle at several places. The buckling allows the reflected bands to tilt; this gives the surface the appearance of forming corners (see Fig. 17a) hence the term "cornering." When the diaphragm surface is extended, the local areas where buckling occurred show signs of considerable metal working (see Fig. 17b). A third factor contributing to nonideal unfolding of the convoluted diaphragm is the hydrostatic pressure. With fairly flexible diaphragms which can be extended most of the way with 2- or 3-psi pressure, the entire diaphragm is tilted or grossly misshaped during the expulsion process by the distribution 

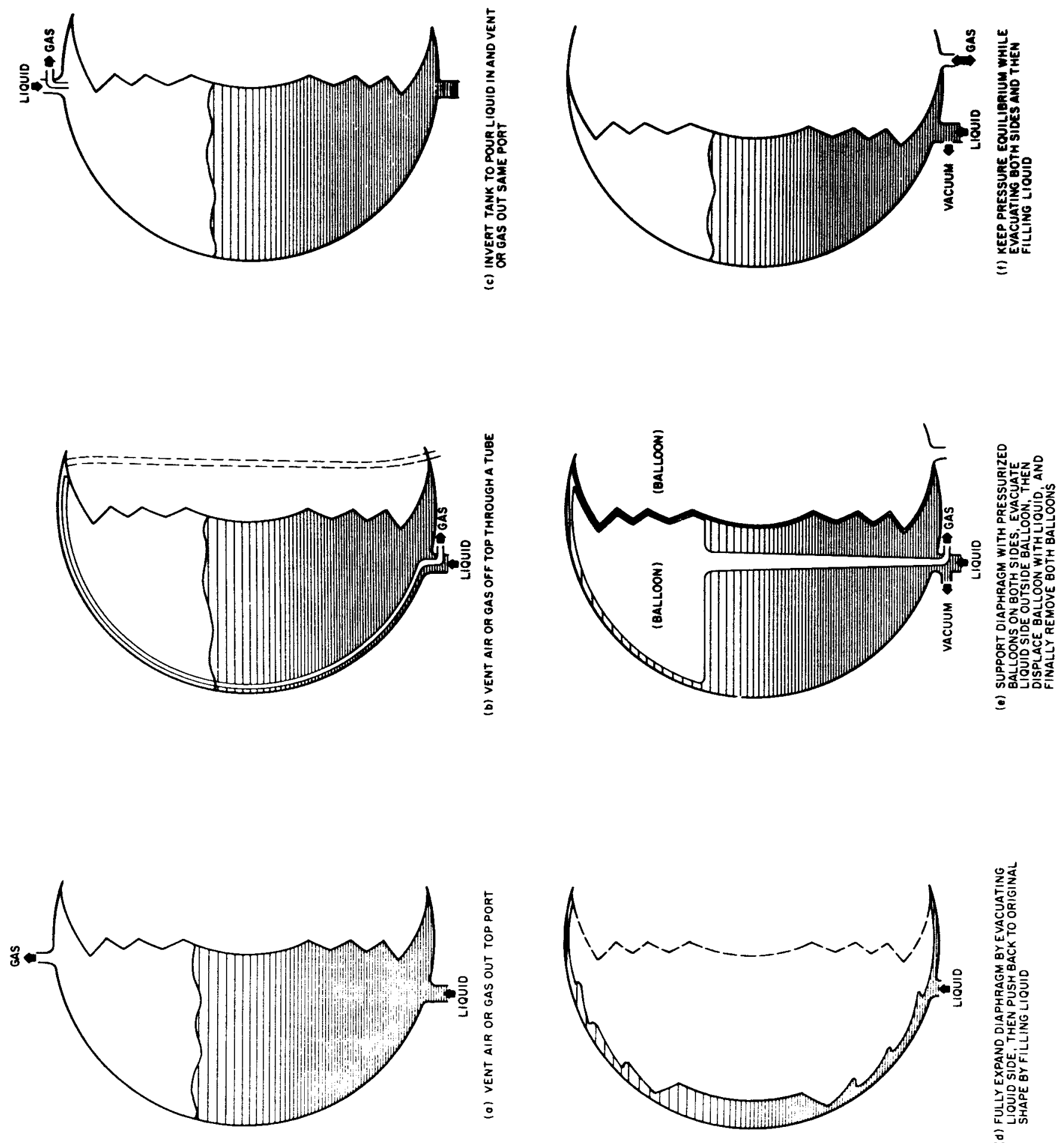

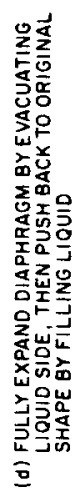

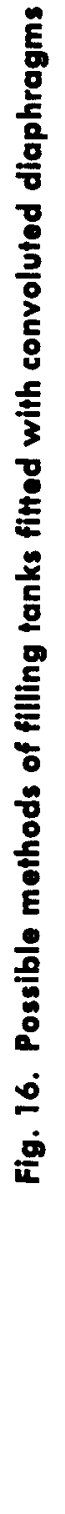



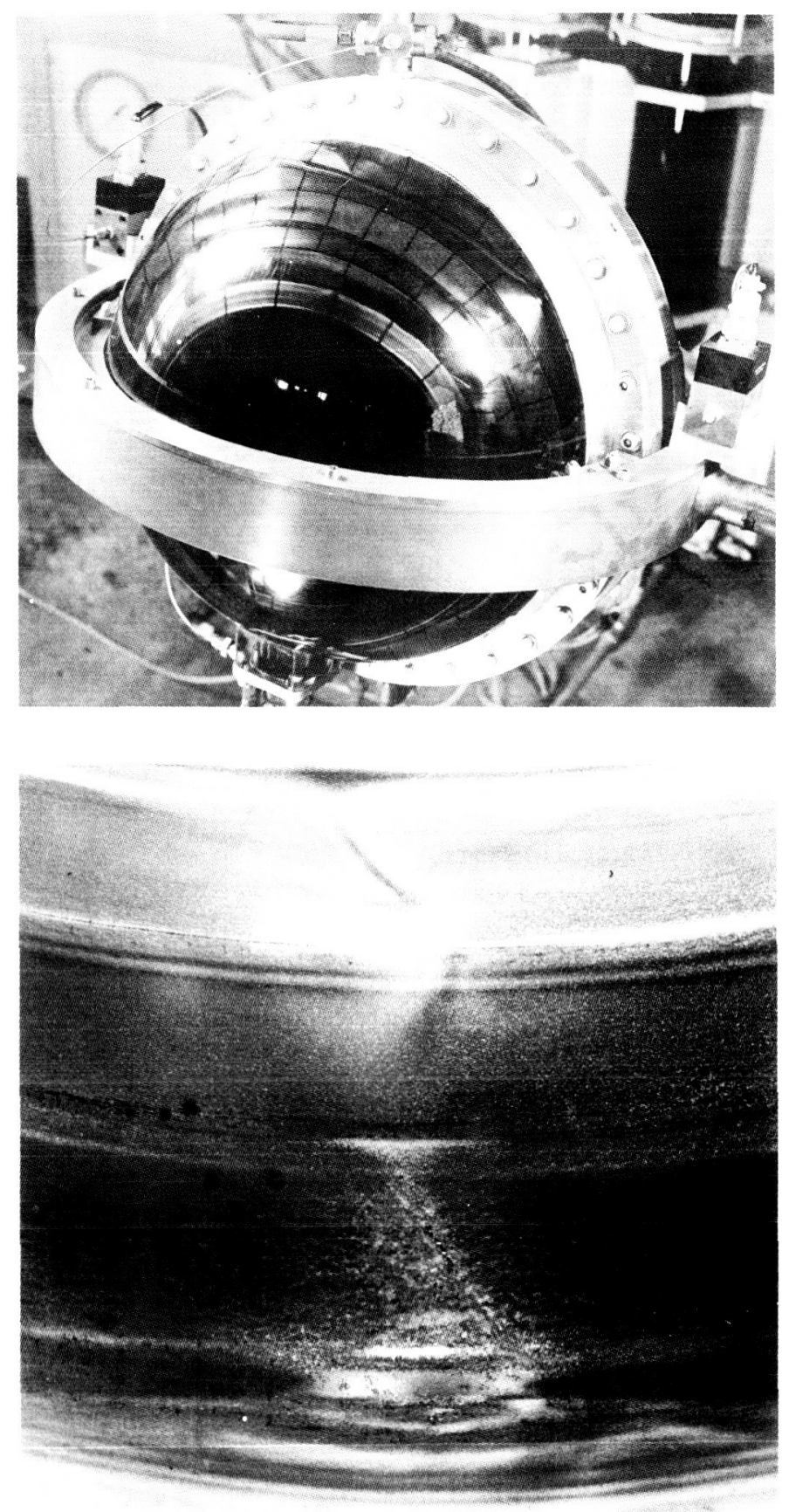

Fig. 17. Typical buckling (cornering) pattern occurring in convoluted diaphragms during expulsion, and the resulting creases

of hydrostatic pressure. This nonsymmetry may be only temporary, however, since the diaphragm can be forced to conform to the tank at the end of expulsion if sufficient pressure differential is allowed to develop.

Ordinary convoluted diaphragms cannot be recycled. When the liquid is pumped back into the tank, the dia- phragm, which has been extended into a hemispherical shape, simply buckles inward at the bottom. If the wrinkling caused by collapse does not cause leaks, then the next expulsion usually does. Figure 18 illustrates three stages in the life of an ordinary convoluted diaphragm. On the left is a diaphragm ready for installation. In the middle is a diaphragm after expulsion. On the right is a diaphragm after an attempt was made to refill it.

\section{H. Materials}

The same materials are used for diaphragms as for bladders since the requirements are essentially the same. An exception is the relatively thick metal sheet from which convoluted diaphragms are made. Usually, a soft aluminum is chosen for this application to minimize fabrication problems and expulsion pressure.

\section{Fabrication}

The fabrication of nonmetallic reversing diaphragms is very similar to the fabrication of bladders except that it is easier. With elastomeric diaphragms there is no need to have a soluble core. Diaphragms of Teflon or Teflonmetal laminate are much easier to make because there is no closure seam or neck.

Convoluted metal diaphragms are made by at least three different processes at this time. A fabrication method, developed by the Aeronautical Division of Honeywell for JPL, utilized air pressure drawing, annealing, explosive forming, and chemical milling to form hemispheres of uniform thickness from flat sheets of type 1100 aluminum. Hemispheres having thicknesses ranging from 0.010 to $0.040 \mathrm{in}$. can be made by this process. Convoluted diaphragms are then formed from these hemispheres by a punch and progressive die process. Each convolute surface, forward or reflected, is formed in consecutive order starting from the outside. In this process, the material inboard of any surface already formed is reversed by a hemispherical punch until it conforms to the proper die. Seven complete reversals of the innermost metal are required to form the 18-in. diaphragms. This severe working of the metal makes at least three annealing treatments necessary. Although this method was successful so far as forming was concerned, it was not altogether satisfactory since it severely worked the metal, causing it to be stretched and wrinkled.

Effort was later applied to the development of an improved method of fabrication. Success was achieved and 


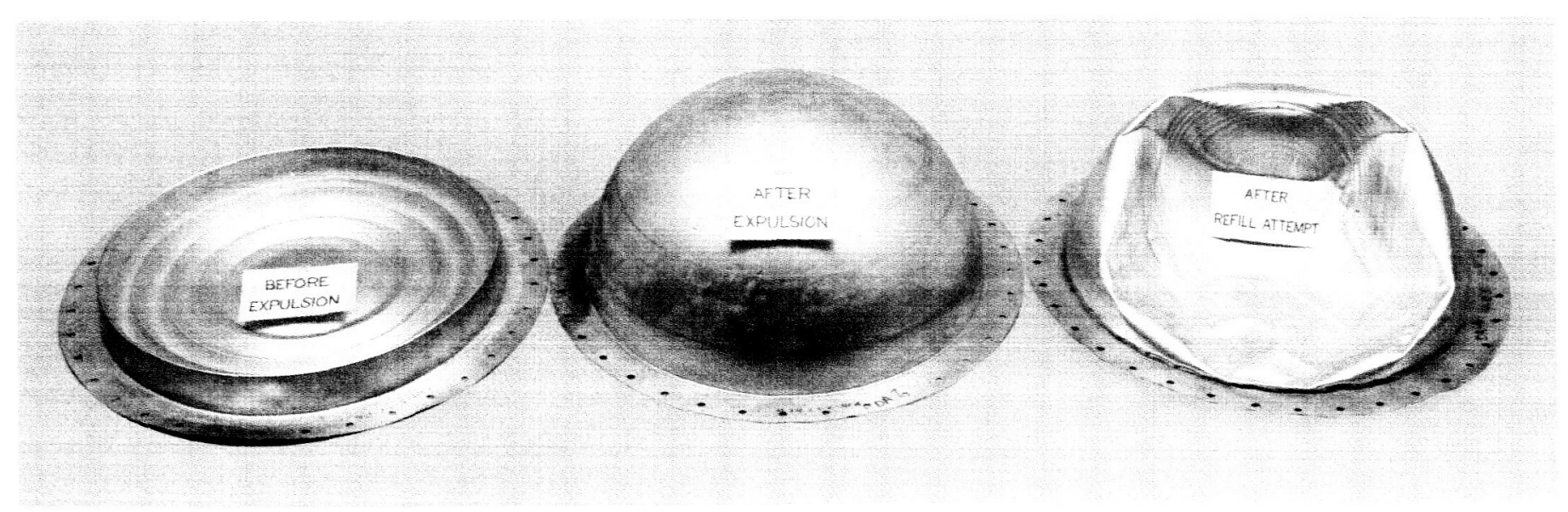

Fig. 18. Metal convoluted diaphragms showing appearance before expulsion, after expulsion, and after attempt to refill

it is now possible to form the 18-in.-diameter hemispheres without explosive forming and to develop the completed convolutions from the hemispherical shape in one step by means of a single punch and telescoping die. Only one annealing treatment is given to the diaphragm. The resulting diaphragms are wrinklefree and have very sharp radii where the forward and reflected surfaces intersect (0.020 to $0.030 \mathrm{in}$. compared to 0.060 to $0.080 \mathrm{in}$. for the original diaphragms).

A third method involves spinning the diaphragms from flat sheet stock. This is an established and proven method, and diaphragms with very deep convolutions can be fabricated in this manner, although certain problems are inherent due to the process. One is the fact that spinning is a metal stretching procedure which causes thinning in the stretched areas. Therefore, spun diaphragms tend to be thick in the center, becoming progressively thinner toward the outer edge or in the area of deep convolutions. Holding close tolerances while evening out this thickness variation by sanding or chemical milling has proven difficult. The other drawback to diaphragms made by the spinning process is the fact that, in order to prevent tearing the material and to conserve tooling, it has been necesary to leave relatively large radii ( $1 / 8 \mathrm{in}$. for 18 -in.-diameter diaphragms) at the intersections of the forward and reflected surfaces. This condition is theoretically undesirable since it violates the principle of keeping these radii as small as possible to promote expulsion efficiency. Neither of these problems is insurmountable and for large diaphragms, particularly, spinning may well prove to be the most economical and satisfactory method of fabrication.

\section{J. Inspection}

Diaphragms are inspected in much the same way as bladders.

\section{K. Cleaning}

The same comments apply for cleaning diaphragms as for bladders.

\section{Testing}

Diaphragms are tested using the same procedures as for bladders. Leak checking diaphragms is slightly more complicated since the diaphragms cannot be inflated like a balloon but instead must be installed in a tank or fitted with a closure plate.

Because ordinary convoluted metal diaphragms are not recyclable, special tests may be necessary to determine how well a particular convolution design will accommodate repeated partial cycling caused by propellant bulk density changes with temperature. 


\section{PISTONS}

\section{A. Definition}

Pistons used for positive expulsion are rigid bodies, sealed at the periphery to the tank, that are forced to travel the length of the tank. Sealing may be accomplished by rings on the piston which are in sliding contact with the tank wall or by bellows which are either collapsed or extended as the piston moves down the tank. Many pistons are free-floating but held against the liquid by gas pressure. Other pistons are held in position by mechanical actuation devices. Pistons are inherently recyclable unless special seals (such as hermetically sealed metal diaphragms that tear upon movement of the piston) are used.

\section{B. Shape}

In the cross section perpendicular to the path of travel, pistons are usually round so as to fit easily within and seal against the walls of round tanks. Lengthwise, their shape may be flat, cylindrical, concave, or convex. Flat pistons are prone to cocking, so their use is limited to applications where suitable center guides are provided (see below). Cylindrical pistons are usually made at least $\%$ of a diameter in length so that the tank walls serve as the guide. Concave or convex pistons are made to take advantage of shape stiffening (for reducing weight) and to fit tightly against domed tank ends (for maximizing volumetric efficiency).

\section{Seals}

The major problems with piston expulsion are maintaining a good seal between the piston and the tank and obtaining low, reproducible friction. Two distinct functions must be performed by the seal. First, it must prevent leakage past the piston. Secondly, it must wipe the tank wall free of propellant as the piston moves down the tank.

Sliding seals, such as conventional piston rings, O-rings, and pressurized, flexible walls have been tried. These devices have several drawbacks. During static (storage) conditions, the seal must constantly bear upon the piston and tank surfaces with sufficient pressure to prevent leaks. Cold flow, permanent set, and propellent absorption are likely to result. Certain materials, particularly Teflon, seem to flow into the pores of the tank wall during ex-

'Exceptions to this statement are the elastomeric pistons used in toroidal or spiral tanks. tended periods so that static friction increases. Some materials, in the presence of propellant or moisture, cause corrosion so that a band of corroded and roughened tank surface is created under the seal. Any of these factors can substantially increase the breakaway force needed to start piston movement. The excess pressure required to initiate pumping then causes a pressure surge in the propellant feed pressure. Once breakaway has been achieved and the piston moves down the tank, these seals usually fail to wipe the tank walls dry of propellant. If an inert pressurant is used, this latter problem may not be serious. In many systems, however, no propellant or propellant vapor can be allowed upstream of the pistons so sliding seals cannot be considered.

In the early 1950's, a technique of welding very thin sections of metal together was advanced to the stage where bellows could be fabricated from washers. These welded bellows have spring constants and nesting capabilities which make them suitable for piston seals. A hermetic seal is provided by a good bellows. The disadvantages of a bellows are weight, cost, and development time. Bell Aerosystems Company, under a NASA contract, is currently working on the problems of designing, fabricating, and testing bellows (Ref. 2).

\section{Guide}

Pistons must be guided to avoid cocking which would jam the piston in the tank. Two basic approaches are used: center guides and peripheral guides. The center guide usually consists of a rod located along the centerline of the tank. This rod passes through the center of the piston. Several disadvantages of this type of installation are the need for seals in the piston around the rod, and the stringent requirements for exact alignment and straightness of the rod.

Pistons with adequate length can be guided by the tank wall. The seals around the piston double as resilient spacers to accommodate slight variations from the true straightness or roundness in the wall.

When sealed by a bellows, the piston and the bellows must be guided to prevent cocking of the piston and "squirming" of the bellows. Fortunately, bellows are fairly stable when the external pressure is greater than the internal. The exact degree of guidance required is a 
function of the length; a very short bellows needs no guide.

\section{E. Insfallation and Removal}

Pistons, since they are rigid bodies, must be installed through tank openings as large as the tank diameter. As the piston is installed, the assembly should be checked for fit, leakage, and smooth travel. Tank closure is accomplished by a screwed cap, bolted flange, or weld-on end. The closure design should prevent distortion of the tank (and piston guide).

\section{F. Filling}

Usually, piston tank assemblies are filled by a vacuum technique. This method is almost mandatory to get a bubblefree load of propellant into a bellows-sealed unit. Slide seals have fewer crevices so gravity filling may be successful with assemblies using these seals. The center guide rod could conceivably be used as a standpipe if the piston were held at the top with the rod seals above the ports in the standpipe. These less sure means of filling do not appear attractive since the piston is a recyclable device and thus overcomes one of the serious objections to using a vacuum-fill technique for bladders or diaphragms.

\section{G. Expulsion}

Unlike the bladders and diaphragms, there is essentially no deformation of the piston as it expels the liquid. The piston simply is translated from one end of the tank to the other. Wear and flexure are limited to the surfaces which rub against each other. The tank (and guide rod) flexes very little if made stiff enough to be an effective guide. When soft seals are used, the wear is confined to the seals. Bellows are flexed sufficiently to cause failure after a number of cycles. Actually, the externally generated loads due to shock and vibration may be the sever- est operational hazards; these can cause chattering or cavitation.

\section{H. Materials}

Many metallic materials are suitable for making pistons. For each propellant there is at least one compatible metal that can be readily machined into the desired configuration. The difficulty lies in providing seals. As mentioned above, the seals must be resilient in order to obtain adequate bearing pressure. Polymers which are compatible with the more reactive propellants are inelastic and absorb propellant. The only universal seal at this writing is a metal bellows.

\section{Fabrication}

Standard fabrication procedures are used throughout in making pistons and their seals. The sole exception is the art of constructing bellows. At this stage, the main problem seems to be quality control.

\section{J. Inspection}

Standard inspection procedures are used on pistons. Bellows must be given extra attention to assure that the critical weld beads are properly made and flawless.

\section{K. Cleaning}

The same comments apply as for bladders. Bellows, which have many crevices, cannot be adequately cleaned without brushing and ultrasonic treatments.

\section{Testing}

Piston tank assemblies are subjected to essentially the same tests as bladders. 


\section{HISTORICAL BACKGROUND}

The work at JPL on bladders, diaphragms, and pistons has been prompted just as much by a desire to isolate the pressurizing gases from the propellants as by the need to expel the propellants under adverse gravity conditions. The first interest in these devices developed during the middle 1940's. The idea of replacing relatively heavy, stored inert gas pressurization systems with lighter generated-gas systems sounded fine. But an examination of available theoretical and test data resulted in the judgment that no single gas generator was suitable for direct pressurization of both fuel and oxidizer because of the properties of the gases. Dual gas generators could have been used with each gas generator producing gases compatible with the propellant it was pressurizing; however, this would have increased the complexity of the system. It was proposed that flexible barriers be placed between the hot, chemically reactive gases and the propellants.

The development of America's first sounding rocket, the WAC-Corporal, provided sufficient justification to push the idea of barriers into the hardware stage. Two advantages of barriers were cited: The WAC's dry weight could be reduced by using a gas generator rather than stored gas for pressurization and positive propellant expulsion could be assured. The latter reason was valid even though the sounding rocket's trajectory was nearly straight up. As it ascended, the WAC was spun about its longitudinal axis for stabilization. This spinning motion generated a vortex in the propellant which could allow gas to be ingested before the end of the firing. Also, if completely stable flight were not maintained, a momentary deviation toward horizontal flight could unport the propellants and cause the engine to explode. Spurred by these considerations, both bladders and pistons were tested during 1945 and 1946.

The bladder concept was investigated using a cylinder of Lucite fitted with flat end plates and a standpipe down the center. A sleeve of neoprene rubber was fastened into the assembly to simulate a bladder. Nitrogen gas pressure collapsed the sleeve about the standpipe in a four-lobed pattern. Water was used instead of propellants in the early tests. Although only one major problem was apparent, the development of a bladder for the WAC was never completed. This problem was the lack of a suitable material for the oxidizer (red fuming nitric acid) bladder. A vinyl plastic reinforced with glass fibers was tried without success. Shortly before the effort was stopped, a new, highly inert plastic called "Teflon" was mentioned as a possibility.

The WAC-Corporal piston design (see Fig. 19) featured a neoprene rubber seal ring which was inflated with liquid to a pressure approximately $10 \mathrm{psi}$ above the tank pressure. A rod down the center of the tank served as a guide for the piston. Variable friction, leakage and lack of compatible seal materials for the oxidizer caused this approach to be abandoned also.

All of the WAC's were flown with an inert-gas pressurization system and without any positive expulsion devices. This settlement upon the conventional approach did not signify discouragement but rather an acknowledgement of the limited scope of the WAC-Corporal program and the increasing importance of the Corporal.

Interest in the concept of reducing weight by substituting a gas generator for stored gas carried over from the WAC-Corporal to the Corporal program. This was natural since the Corporal sounding rocket was to some degree an outgrowth of the "model-size" WAC-Corporal. A conservative design approach was taken in the early stages by essentially scaling-up the WAC-Corporal's stored gas pressurization system. The majority of the developmental rounds and all of the operational missiles were flown with compressed air pressurization and no barriers.

The development of a gas generation system for the Corporal was accomplished in steps starting about 1950 . Initially tests were made by firing a 1500 -lb-thrust acidaniline rocket engine which was fed propellants from tanks pressurized by means of a monopropellant hydrazine gas generator. Cylindrical propellant tanks with traveling pistons (see Fig. 20a) to separate the propellant from the pressurizing gas were used. It was found that by anodizing the inside of the cylinder and using Fluorolube as a piston seal lubricant, four or five tests could be made before reconditioning of the cells was required. Twelve successful firings were made with this system as a forerunner to the full-scale Corporal conversion.

The first attempt to convert the Corporal missile to gas generator pressurization was one which substituted a bundle of 14ST-6 aluminum tubes $(6 \%$ in. OD $\times 0.070 \mathrm{in}$. wall thickness $\times 25 \mathrm{ft}$ long) for the original fuel and oxidizer tanks. There were 19 tubes in the bundle. Eight 


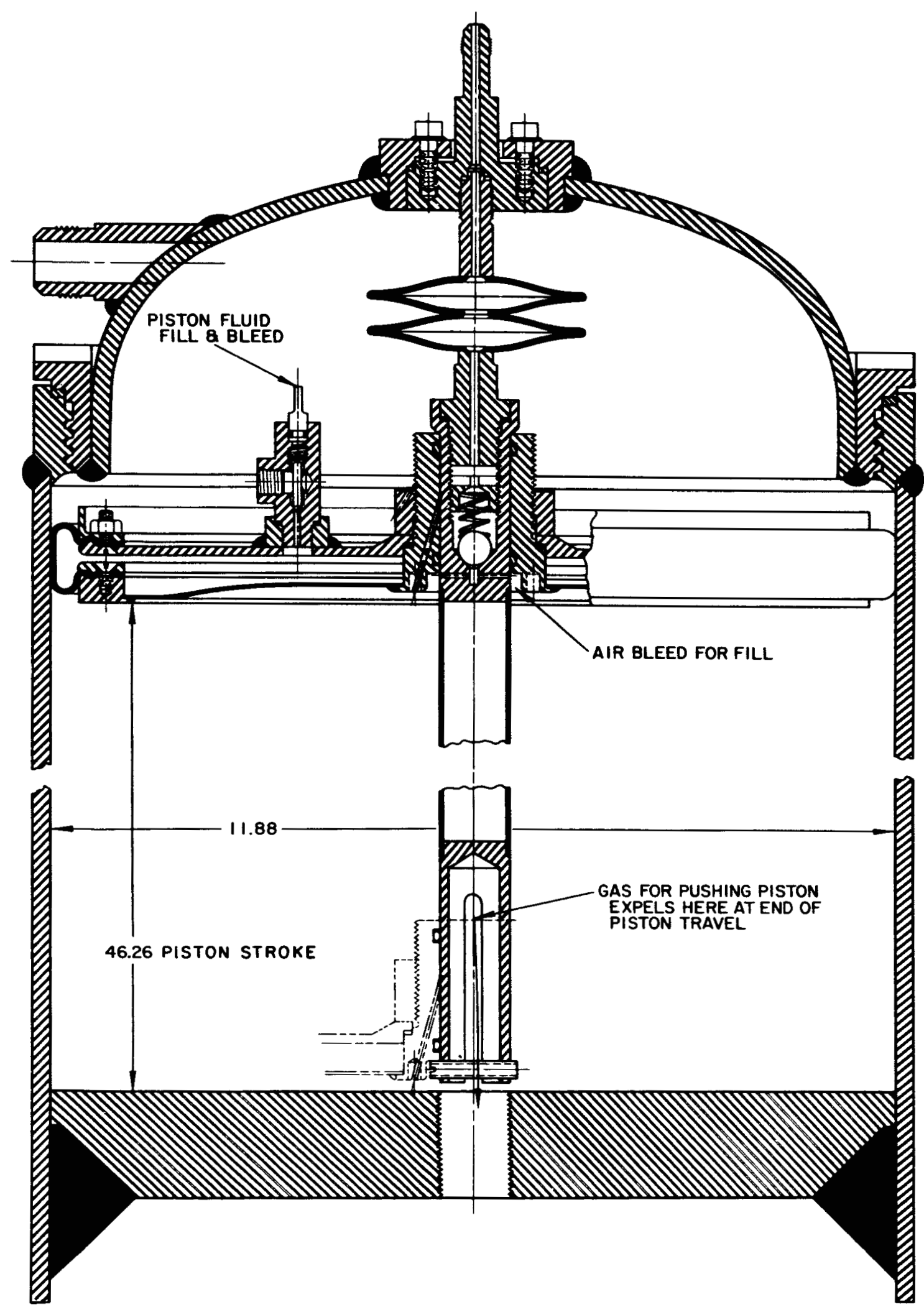

Fig. 19. Experimental WAC Corporal piston tank 

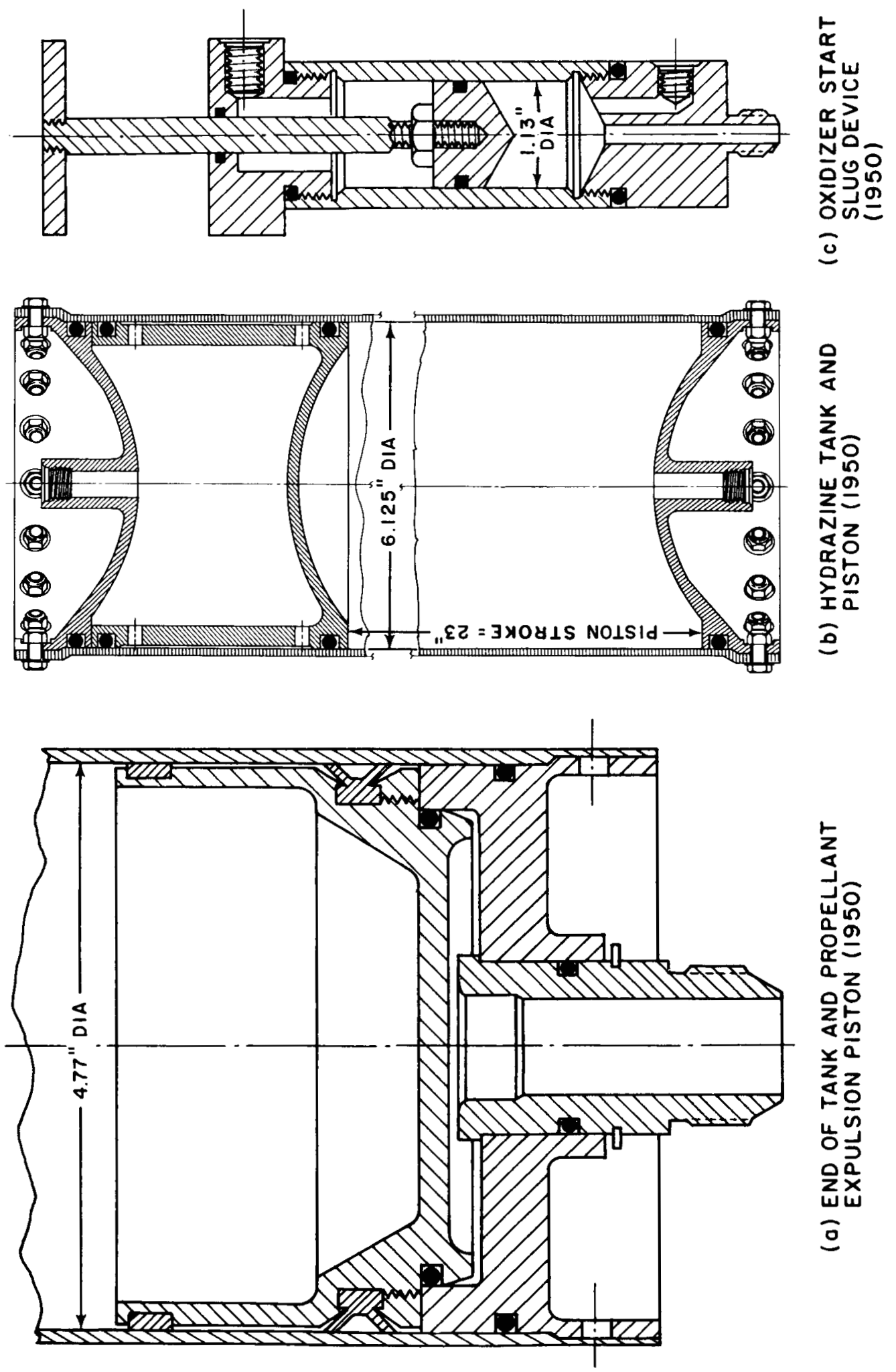

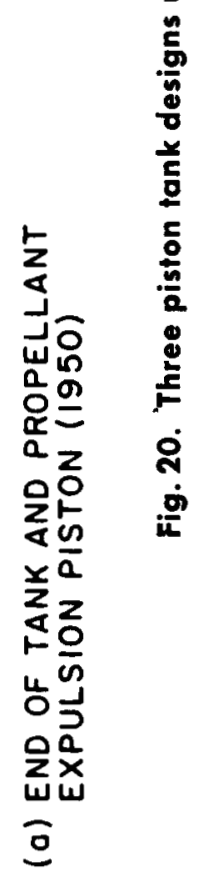


of the tubes manifolded together at the outlet end were for fuel (a mixture of aniline and furfurlyl alcohol) and eleven were for oxidizer (red fuming nitric acid, RFNA). All of the tubes were manifolded at the upper end and connected to the output of a monopropellant hydrazine gas generator. Each tube had a floating piston which served to separate the pressurizing gas from the propellants. In operation the oxidizer leaked past the piston and reacted with fuel-rich gas from the gas generator resulting in a catastrophic explosion and fire. This failure adequately demonstrated the inherent weaknesses of pistontype expulsion, namely those of leakage past the piston and inability to wipe the cylinder walls clean of propellant.

The difficulties encountered in attempting to use a single $\mathrm{N}_{2} \mathrm{H}_{4}$ gas generator system to pressurize both fuel and oxidizer caused the investigation to be redirected toward the development of the dual gas generator system. It had already been proven that the output of a monopropellant $\mathrm{N}_{2} \mathrm{H}_{1}$ generator could be used to directly pressurize the fuel side of a missile system without a separation between the gas and the propellant, provided the gas was adequately cooled. It remained then to develop a generator whose output gas could be made oxidizer-rich so that the oxidizer (RFNA) could be pressurized safely. This was accomplished by quenching the output gas of a bipropellant generator (burning $\mathrm{N}_{2} \mathrm{H}_{4}$ and RFNA) with additional acid. The resulting mixture was not only cooled by this additional acid but was suffciently oxidizer-rich to be safely injected into the oxidizer tank without a separating device. The addition of an extra gas generator to the system increased the weight compared to the original single generator concept, but it removed the necessity for separating the pressurizing gas from the propellants and allowed a return to the original Corporal propellant tank configuration.

The dual gas generator system required a small supply of pressurizing gas for the gas generator propellant. Military requirements specified that this be air. Due to the explosion hazards inherent with the combination of $\mathrm{N}_{2} \mathrm{H}_{4}$ and high-pressure air, it was decided that these fluids would be isolated from each other by a piston similar to that described above for the original Corporal conversion. A cylindrical tank approximately $30 \mathrm{in}$. in length was designed and fabricated of 24 ST aluminum and fitted with a floating piston-type separator using a butyl rubber $O$-ring seal (see Fig. 20b). This tank was subjected to 14 air-pressure expulsion tests which were made without incident. A series of six water pumping tests was made with the dual generated-gas system in which this generant tank was pressurized with air. Some leakage of hydrazine past the piston seal was detected in the latter tests. Consequently, the six subsequent firings were made with the generant tanks pressurized with nitrogen. Since this method of expulsion was already suspect, effort was directed toward the development of a more reliable device for separating hydrazine and the pressurizing gas. Butyl rubber was considered compatible with hydrazine, so the obvious solution was to fabricate an expulsion bladder of butyl rubber. Voit Rubber Corporation used a beach ball mold to make a 13.5-in.-ID spherical bladder with a 0.037 -in.-thick wall of Voit 1840 Butyl. It was attached inside a stainless steel sphere by means of a device similar in design to a Schrader automotive inner tube stem fitting (Fig. 2A). Compatibility and expulsion tests were successfully conducted at Edwards Test Station and this expulsion device was incorporated into the dual gas generator conversion of the Corporal missile.

An additional propellant expulsion component used in the dual gas generation system was the RFNA start slug piston shown in Fig. 20c. It was used to inject a small amount of acid into the monopropellent hydrazine gas generator to secure bipropellant combustion for a sufficient time to raise the catalyst bed temperature to the point where spontaneous decomposition of the hydrazine would take place. The design of the start slug device was similar to that of an oversized hypodermic syringe with the extended handle being used as a fill indicator and for manual filling. Type 302 stainless steel was used for the body. The 24 ST aluminum piston was sealed with polyethylene $\mathrm{O}$-rings. This device was used many times and was considered to be an entirely successful component.

In late 1955 and early 1956, two Corporal missiles converted to gas generation were successfully flown at White Sands Proving Ground. In both missiles, the positive expulsion devices proved to be entirely satisfactory as far as could be determined by the limited data. References 12 and 13 describe this part of the Corporal program. Further work on the Corporal was not attempted because its successor, the Sergeant, was nearing the end of development at JPL.

As a part of the Sergeant missile development program, a pump-fed monopropellant-hydrazine auxiliary-power unit (APU) was designed and built in 1956. Initially the design involved a piston-type hydrazine tank (see Fig. 21) that was pressurized by means of bypass gas flow 


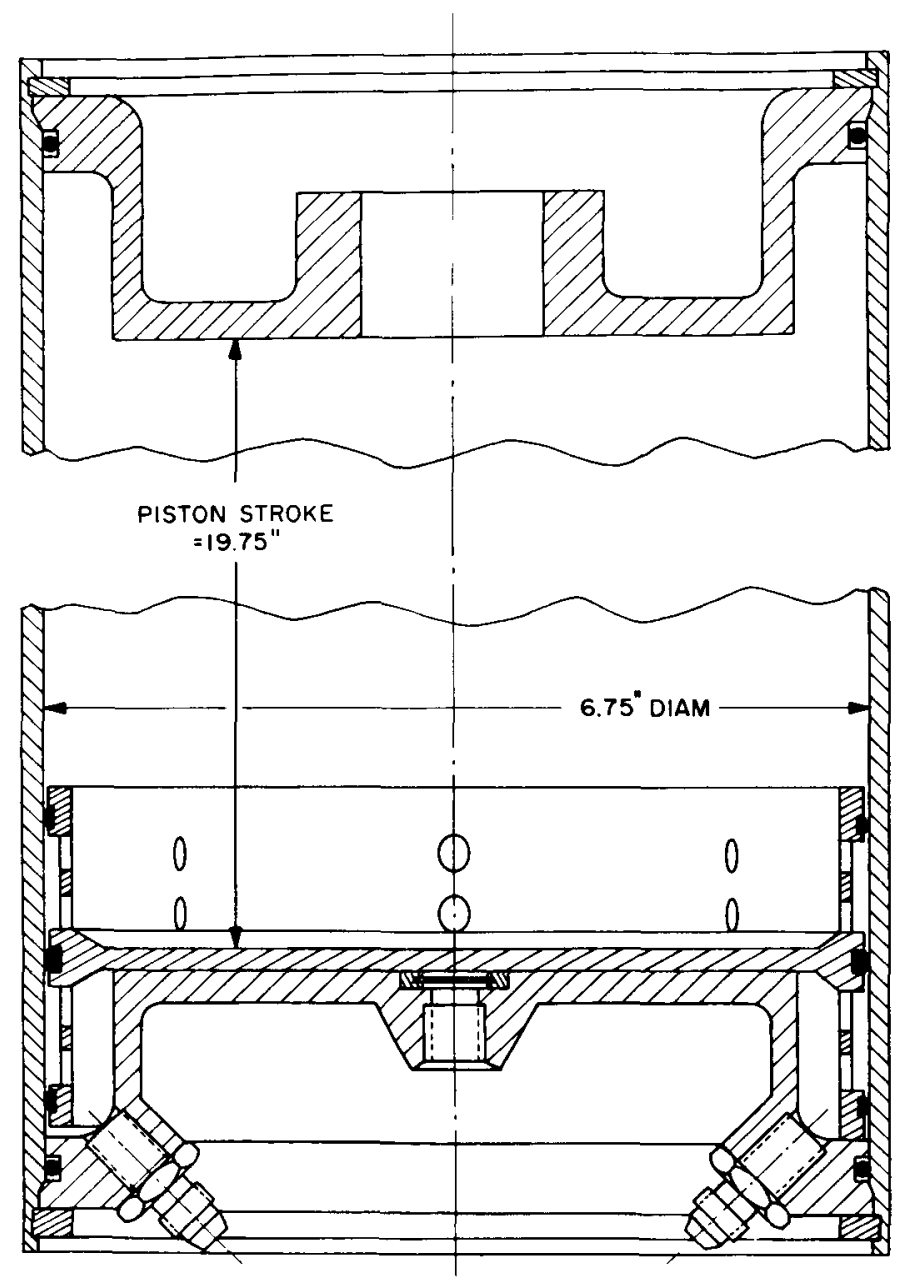

Fig. 21. Sergeant APU hydrazine tank with piston expulsion

from the gas generator. The gas flow was cooled by passage through a heat exchanger to a maximum temperature of $250^{\circ} \mathrm{F}$ and admitted to the top of the hydrazine tank at 20 to 30 psig pressure. Several tests indicated this configuration worked properly. However, the piston and tank, though built of 6061-T6 Aluminum, weighed $14 \mathrm{lb}$ and weight was ultimately important. Consequently a spherical tank of spun aluminum containing a butylrubber bladder, to separate the gas and liquid, was designed and fabricated. This tank and bladder proved successful in 15 tests of the prototype system. Improvements in the Sergeant battery-type APU obviated the necessity for further effort on the hydrazine-powered APU. The Sergeant was the last missile developed by
JPL. The space age dawned in 1957, and the laboratory thereafter became involved in space work.

The greater energies required for space missions invested new urgency in the efforts to use more powerful propellants. Among these propellants was nitrogen tetroxide $\left(\mathrm{N}_{2} \mathrm{O}_{4}\right)$. The increasing interest in $\mathrm{N}_{2} \mathrm{O}_{4}$ as an oxidizer during the late 1950's was somewhat tempered by the lack of a suitable elastomeric material for seals. Bladder development was also delayed for the same reason. In the absence of a true elastomer, the most flexible of the compatible polymers (Teflon) seemed to be the next best choice for bladder construction. Late in 1959, JPL ordered several 41-in.-diameter spherical bladders and hemispherical diaphragms from Chemgineers, Inc., of Los Angeles, California, for the specific purpose of evaluating the state of the art of Teflon bladders. Fabricated by a process of alternately spraying TFE Teflon dispersion onto a mandrel and sintering the coating in an oven, several layers were built up until a total thickness of 0.012 to $0.018 \mathrm{in}$. was reached. These were the first seamless Teflon expulsion devices tested by the Laboratory.

Static expulsion and slosh tests were made using a Plexiglas tank, water as test fluid, and nitrogen gas as the pressurant. A total of 12 expulsion cycles were completed on a bladder and 14 on a diaphragm without apparent leakage. Two tank orientations were investigated: outlet downward and outlet upward. Expulsion efficiency was above $99 \%$ at 7 to 8 psig pressure for all tests with the outlet downward. Erratic results were obtained with the outlet upward. Sometimes the pressurization port was blocked during filling and/or the outlet was blocked off during expulsion; strainers, screens, and standpipes were tried in an effort to eleminate these difficulties.

Every bladder and diaphragm developed leaks when the tank, containing either a partially-filled bladder or diaphragm, was moved back and forth to induce sloshing.

The method for measuring the permeability of bladder material outlined in Ref. 6 was used during this program to check several types of Teflon and related materials. No material was found to be impermeable to $\mathrm{N}_{2} \mathrm{O}_{4}$. By the time this work was underway, JPL was already building spacecraft, but fortunately none of these required bladders to hold $\mathrm{N}_{2} \mathrm{O}_{4}$. 


\section{CURRENT APPLICATIONS IN UNMANNED SPACECRAFT}

JPL's job of conducting unmanned explorations of the Moon and the planets for NASA is being accomplished with three series of spacecraft: Rangers, Mariners, and Surveyors. The Surveyor work has been subcontracted to industry and so will not be discussed here.

Spacecraft in the Ranger series were designed to impact on the Moon. The first two Rangers were test vehicles containing no propulsion equipment. The next three (designated RA-3, RA-4, and RA-5) were supposed to place an instrumented capsule on the lunar surface. The following four Rangers were designated to carry television equipment to relay pictures of the Moon's terrain during the last several minutes before impact. A means of identifying the subseries of spacecraft was necessary so RA-3, RA-4, and RA-5 were identified as Block II, and the later versions were called Block III.

The Mariner series was used to explore the closer planets. Mariner A was cancelled after considerable development because of delays in the Centaur booster vehicle program. Mariner $\mathrm{R}$ was a conversion of the Ranger basic "bus" to a lightweight spacecraft which could be boosted by the Atlas-Agena. The first Mariner flown was MR-1 which was unsuccessful due to a booster programming error. MR-2 was the first spacecraft to successfully transmit information back from the vicinity of Venus. These two vehicles were essentially identical. Since MR-2 was successful, later Mariner $\mathrm{R}$ flights were cancelled. The Mariner Mars project also consisted of two spacecraft. As before, the first launch attempt failed, in this instance due to a structural failure of the launch vehicle's aerodynamic fairing. The second spacecraft was successfully launched, and it transmitted back the first closeup pictures of Mars.

The available booster vehicles do not launch these spacecraft with sufficient precision to achieve the desired trajectories, so it is usually necessary to correct the flight path after injection. Data obtained by tracking the radio beacon signal from the spacecraft is used to determine exactly what changes in course are required, then a small rocket on board the spacecraft is fired to correct the trajectory. The type of rocket used for this purpose is called a midcourse propulsion system.

Since the beginning of the space program, a family of these small propulsion systems has been designed and developed at JPL. All are capable of being stored and fired in the spacecraft environment. Temperature limits of +40 to $+125^{\circ} \mathrm{F}$ are expected on board the spacecraft so most equipment, including the midcourse propulsion systems, is required to be able to survive higher test temperatures $\left(+167^{\circ} \mathrm{F}\right)$. Vibration and shock tests, devised to simulate the extremes of handling, transportation, and launch environments are also imposed on the systems. Overall, these are rugged units designed specifically for spacecraft application. The progenitor of this line was the system designed and developed for the original Ranger spacecraft (see Ref. 14). Similar systems were developed for the later Rangers (Ref. 15), the Mariner A (Ref. 16), and the later Mariners (Ref. 17).

At the start of the Ranger program, it was realized that reliability and precise control of the impulse delivered to the spacecraft were the prime requisites for the midcourse propulsion system, so a monopropellant liquid rocket was selected. Positive expulsion of the liquid propellant was considered to be necessary since the spacecraft would be in free-fall at the moment of ignition. It was decided that the hydrazine would be stored in a butyl rubber bladder. Spacecraft packaging limitations forced the designers to use a tank and bladder of oblate spheroid shape (see Fig. 22). To simplify plumbing, the gas inlet and liquid outlets were both located in the bottom closure flange. The exterior of the bladder was ribbed to prevent sealing off the gas; gas coming into the tank can easily push the bladder aside, but when

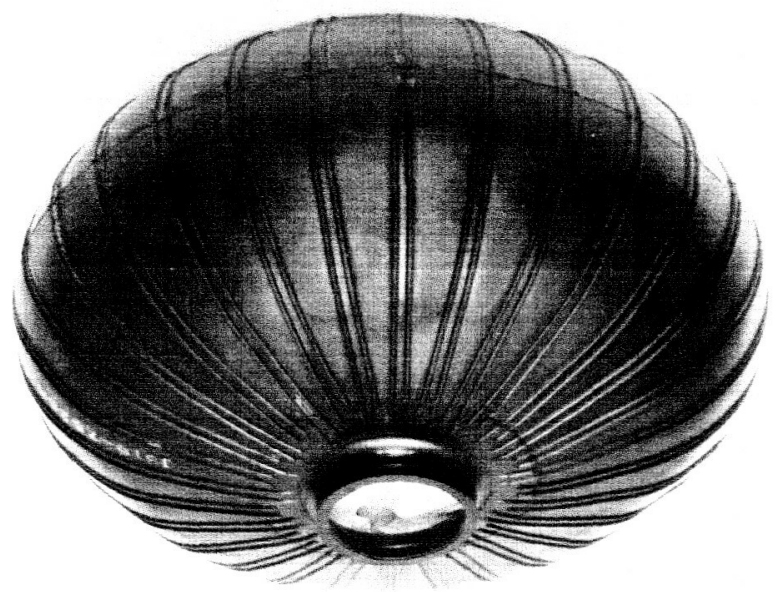

Fig. 22. Butyl bladder used in Ranger Block II spacecraft 
attempting to vent the gas from the tank with the bladder still full, the hydrostatic pressure of the liquid may press a smooth-wall bladder against the tank and seal off the gas port. The neck was designed to be sealed and anchored by a split collar wrapped with wire (see Fig. 2b).

After limited compatibility testing, a Fargo Rubber Co. butyl compound (Number FR-6-50-3) was selected. This contractor developed a method of fabricating onepiece bladders of this material using a soluble core and a metal female mold (see general description in Section III-H). An ordinary outlet was tried at first but expulsion proved to be erratic because of a tendency of the bladder to close off the port. By trial and error, the expulsion efficiency was increased and made repeatable by the evolution of a design with a central mast about which the bladder wrapped. When a suitable state of development was reached, the bladder was installed in a complete system which successfully passed the required vibration tests. During all of these tests, the bladders were filled by inverting them and pouring in the liquid.

The bladders were filled by a vacuum technique for all Ranger (and Mariner) flights. The only difficulty encountered in the flight operations was leakage at the neck caused by stretching the bladder during filling. This occurred during RA-3 launch preparations when a request was made to load an extra two pounds of propellant. Although earlier tests indicated sufficient margin existed to allow overfilling, the flight bladders apparently were thicker than the test bladders so the extra stress pulled the neck loose from the clamp. Otherwise, the limited data from these operations indicated the bladders were satisfactory.

It had been noticed, however, that smog seemed to cause deterioration during storage. When the bladders for RA-5 and MR-2 were ordered, the contractor supplied a different butyl compound (FR-6-60-21) with ingredients selected to minimize smog damage (unfortunately this fact was not made known to JPL at the time). These new bladders were subjected to fifty cycles of alternately pumping down to a vacuum (29 in. $\mathrm{Hg}$ ) and pressurizing to 2 psig with nitrogen gas; this cyclical repetition of the filling stresses had not been required in earlier typeapproval testing. When the MR-2 bladder was filled with hydrazine, some time prior to launch, a rise in tank pressure caused by decomposition of the fuel was detected. This and other problems required the spare midcourse propulsion system to be substituted. Fuel tank pressure began to rise in the spare system after it was filled with propellant. During the thirteen days between filling and launch, the pressure increased by fifty-seven psia (adjusted to constant temperature equivalent). By the time the engine was fired, on the 8th day after launch, tank pressure was 78 psi above the original prepressurization level. Even though the midcourse maneuver was successfully performed and the pressure rise did not constitute a serious hazard to the system, this degree of incompatibility between the bladder material and the hydrazine was considered to be very undesirable.

This same problem of hydrazine decomposition was encountered also during the earlier Mariner A program. Stillman Rubber Company fabricated a spherical bladder for this system of their compound SR 613-75. Unlike the Ranger bladders, this part was made up of two separately cured hemispheres which were joined at the equator. One of these bladders was installed in the test model of the Mariner A midcourse and approach correction propulsion system. The complete system was filled with hydrazine, pressurized, and put in storage at JPL's Edwards Test Station on the Mojave Desert. Some time later it was evident that the propellant tank pressure was increasing. The tank was partially vented and then the storage test continued until a total elapsed time of nine months had passed. Without further attention, the system was successfully fired twice. A postfiring inspection of the bladder revealed many blisters near the seam joining the two halves. These blisters contained gas, probably generated by hydrazine decomposition or reaction in contact with an ingredient used to make the joint. Further development of the Mariner A bladder was not attempted because of cancellation of the program.

Screening of potential bladder materials was started again soon after the MR-2 incident. Several different materials were subjected to both permeability and compatibility testing with hydrazine. The first material to show really significant improvement over the FR-6-60-21 compound was FR-6-60-26. This material was chosen for use in Ranger Block III and Mariner Mars spacecraft.

A long-term storage test, conducted with a complete Mariner Mars propulsion system, provided detailed information on the compatibility of these bladders with hydrazine under high temperature conditions. The system was loaded with propellant and pressurized and then stored in a container maintained at $+125^{\circ} \mathrm{F}$. During the first month the fuel tank pressure was found to be rising approximately $1 \frac{1 / 2}{2}$ psi per day which indicated that hydrazine was decomposing. At the end of the month, the system was removed from the storage area, test fired for $60 \mathrm{sec}$, then returned to storage at $+120^{\circ} \mathrm{F}$. It 
was observed that the pressure continued to climb at the same rate. Two and one-half months later the storage temperature was reduced to $+90^{\circ} \mathrm{F}$; no further pressure increase could be detected over a period of two weeks. This temperature dependency was expected since other tests had indicated that the reaction rate was changed by a factor of three for each ten degrees change in temperature.

The system was test fired a second time after a total storage of four months; as before, the performance closely matched the predicted value. When returned to storage at $+120^{\circ} \mathrm{F}$, the fuel tank pressure resumed the $1^{1} \%$ psi per day rate of increase. The storage temperature ranged between +80 and $+100^{\circ} \mathrm{F}$ during the final four months of the test; no additional increase in pressure was detected.

When the fuel tank was vented at the conclusion of the ten months of testing, no fuel or ammonia vapors were noticed. This fact was interpreted to mean that the bladder had not been permeated to a significant degree. Removal and dissection of the bladder, however, revealed a multiplicity of bubbles in the bladder wall (see Fig. 23). These bubbles were evidently filled with gas generated by the reaction between some ingredient in the rubber and the permeating propellant.

This test clearly demonstrated the crucial need for careful control of the compounding ingredients and thorough testing in order to assure predictable results when storing hydrazine in rubber bladders. The exact temperature dependence of the reactions must be known. In the case of the Mariner Mars, no special problem appeared to exist since the expected (and actual) temperatures during flight were about $40^{\circ} \mathrm{F}$ less than the level $\left(+90^{\circ} \mathrm{F}\right)$ at which essentially no decomposition occurred.

The later bladders (for Ranger Block III and Mariner Mars spacecraft) were subjected to more closely controlled inspection, testing, and handling procedures. Both

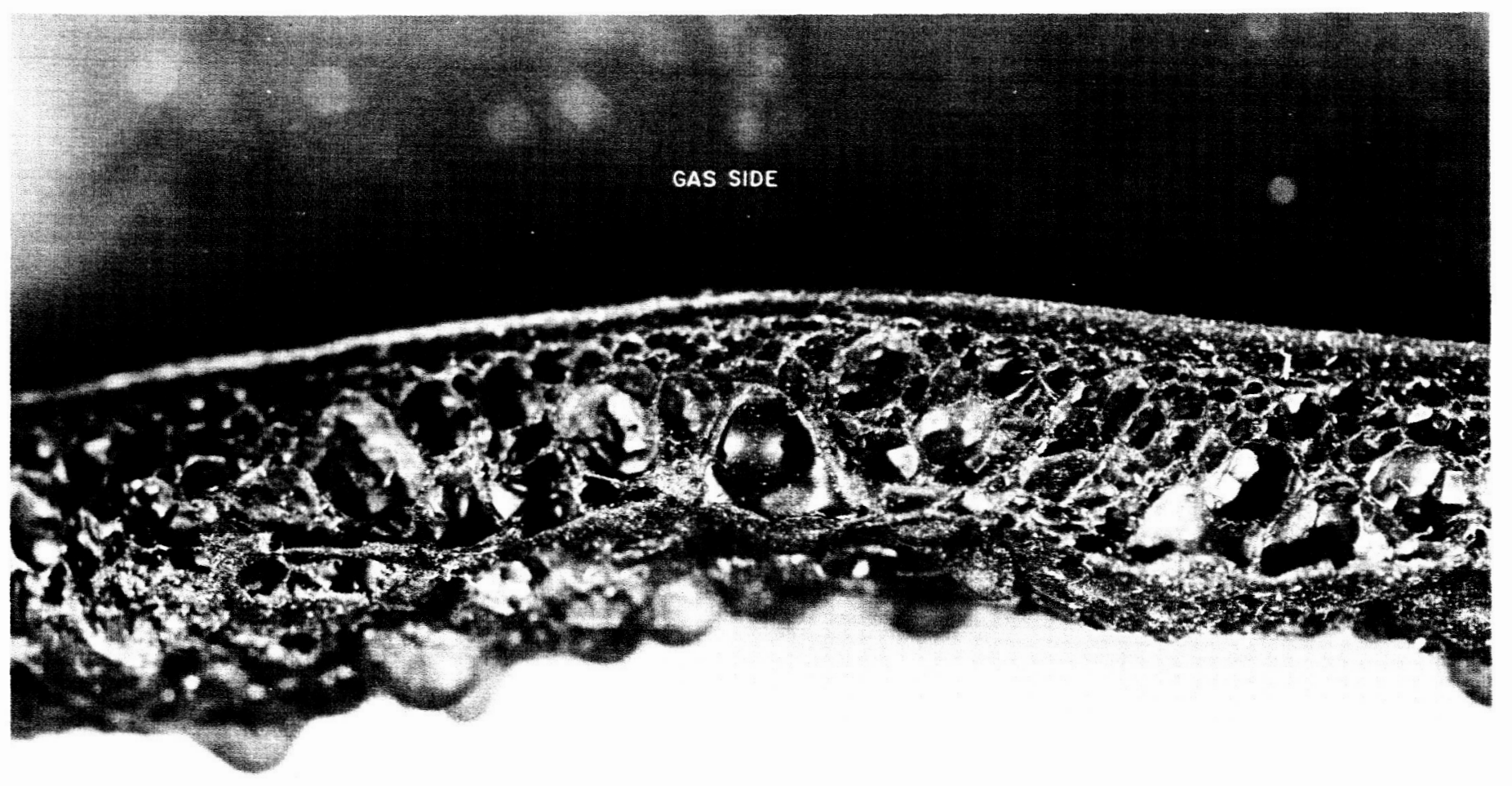

LIOUID SIDE

Fig. 23. Section through wall of Butyl bladder of the type used in Mariner Mars spacecraft showing blistering that occurred during a ten-month storage test 
varieties were treated the same; the only difference between them was that the Ranger bladder was an oblate spheroid and the one for the Mariner Mars was a sphere. These later Ranger bladders held 50\% more propellant than the previous model. To avoid stretching, the design volume was $105 \%$ of the volume occupied by the specified weight of hydrazine at $+125^{\circ} \mathrm{F}$. This was proven adequate by the bladders successfully passing a series of type-approval tests. Fifty cycles of evacuation to $29 \mathrm{in}$. of mercury and pressurization to 2 psig with nitrogen gas were accomplished without apparent damage. Then a bladder installed in a complete midcourse propulsion system was subjected to various vibration and shock tests. The system was fired at +40 and $+167^{\circ} \mathrm{F}$, stored for one month at ambient temperature and fired again. No pressure rise was noted during the storage period.

Experience obtained in preparations for the earlier flights was used to evolve the carefully prescribed manner for handling flight bladders used in the Ranger Block III and Mariner Mars. The incoming bladders were carefully inspected for defects. Next, each bladder was subjected to flight-acceptance tests. These tests consisted of a leak check (by immersion in water while pressurized to 2 psig), two cycles of vacuum and pressurization, a second leak check, a thorough cleaning, installation into the propellant tank, and a final leak check. This last check was made over a period of 5 to 10 min while the bladder was pressurized to $2 \mathrm{psig}$. Any gas leaking into the tank either through the bladder or past the neck seal was bled off through a small tube attached to the pressurization manifold. The other end of the tube was immersed in alcohol so that the gas could be detected by bubbling. A similar leak check was performed just prior to the propellant filling operation during launch preparations.

The cleaning procedure mentioned above involved a preliminary swabbing and rinsing with a detergent solution, then a 20 -min soak in detergent solution at $180^{\circ} \mathrm{F}$, a thorough rinsing with distilled water until a prescribed level of freedom from particulate matter was reached, and finally drying in a vacuum oven.

In addition to positive expulsion of propellant with bladders, JPL's midcourse propulsion systems have used various types of pistons to force start slugs of oxidizer into the thrust chambers at start in order to achieve hypergolic ignition. Each of these start slugs consists of approximately $15 \mathrm{cc}$ of $\mathrm{N}_{2} \mathrm{O}_{4}$. The original design for Ranger Block II and the Mariner $\mathbf{R}$ had no piston but relied instead upon storing the start slug as a long column of liquid which was expelled by direct gas pressure (see Fig. 24a). Theoretically, the long column of liquid served as its own expulsion piston when the gas was released by an explosive valve. Several problems arose in operational use of this device including trouble with the burst diaphragm which sealed off the outlet of the tube.

The Ranger RA-5 midcourse propulsion system was fitted with a small piston to expel the start slug (see Fig. 24b). A vacuum-fill technique was used to load the assembly with nitrogen tetroxide. The gas side of the piston was pressurized to approximately 390 psia. An explosive valve downstream of the start slug contained the liquid under pressure, until the firing signal. This device passed all required environmental tests and 100 cycles of expulsion with no trouble. Two of these units were used in one-month system storage tests followed by firings. The RA-5 flight system with one of these piston assemblies on board was prepared and launched. At no time was any difficulty experienced with these pistons. Nevertheless, the possibility of failure due to leakage past the Teflon O-rings, excessive friction, or a build-up of salts was adequate reason to seek an improvement.

For the Ranger Block III series, the piston design was changed to use a welded, nesting bellows for the seal (see Fig. 24c). Three bellows-sealed piston assemblies were subjected to one-hundred functional cycles, a series of acceleration, shock, and vibration tests, and then another sixty functional cycles. These assemblies were then installed in systems for firing tests at temperatures ranging from +40 to $+167^{\circ} \mathrm{F}$. Finally, all three assemblies were functionally cycled to failure. Leaks in the bellows outside diameter weld were detected after a total of 180 to 190 cycles had been performed by each unit. This level of cycle durability is felt to be more than adequate for a "one-shot" device.

A dual unit, comprised essentially of two parallel Ranger start slug assemblies, were used in the Mariner Mars midcourse propulsion system. One of these units was used in the 10-month Mariner Mars storage test described above. It successfully performed its function twice, once after being stored for one month at $125^{\circ} \mathrm{F}$ and then again after an additional three months at 90 to $120^{\circ} \mathrm{F}$. These temperature levels were considerably higher than actually observed during the flight to Mars.

Another interesting start slug expulsion system was built and tested for the Mariner A. The Mariner A midcourse and approach-correction propulsion system was designed for five starts, each of which required a start 

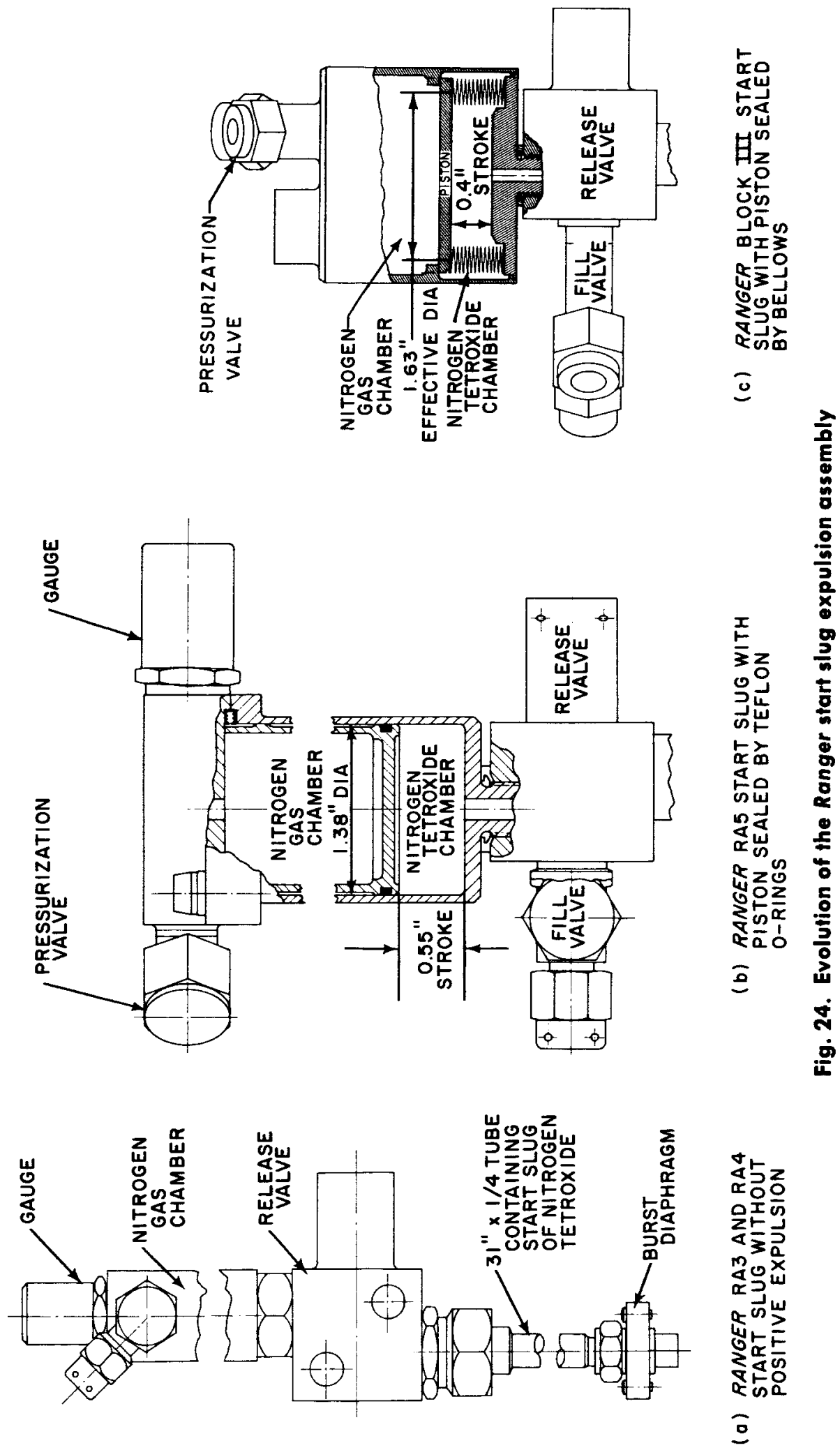


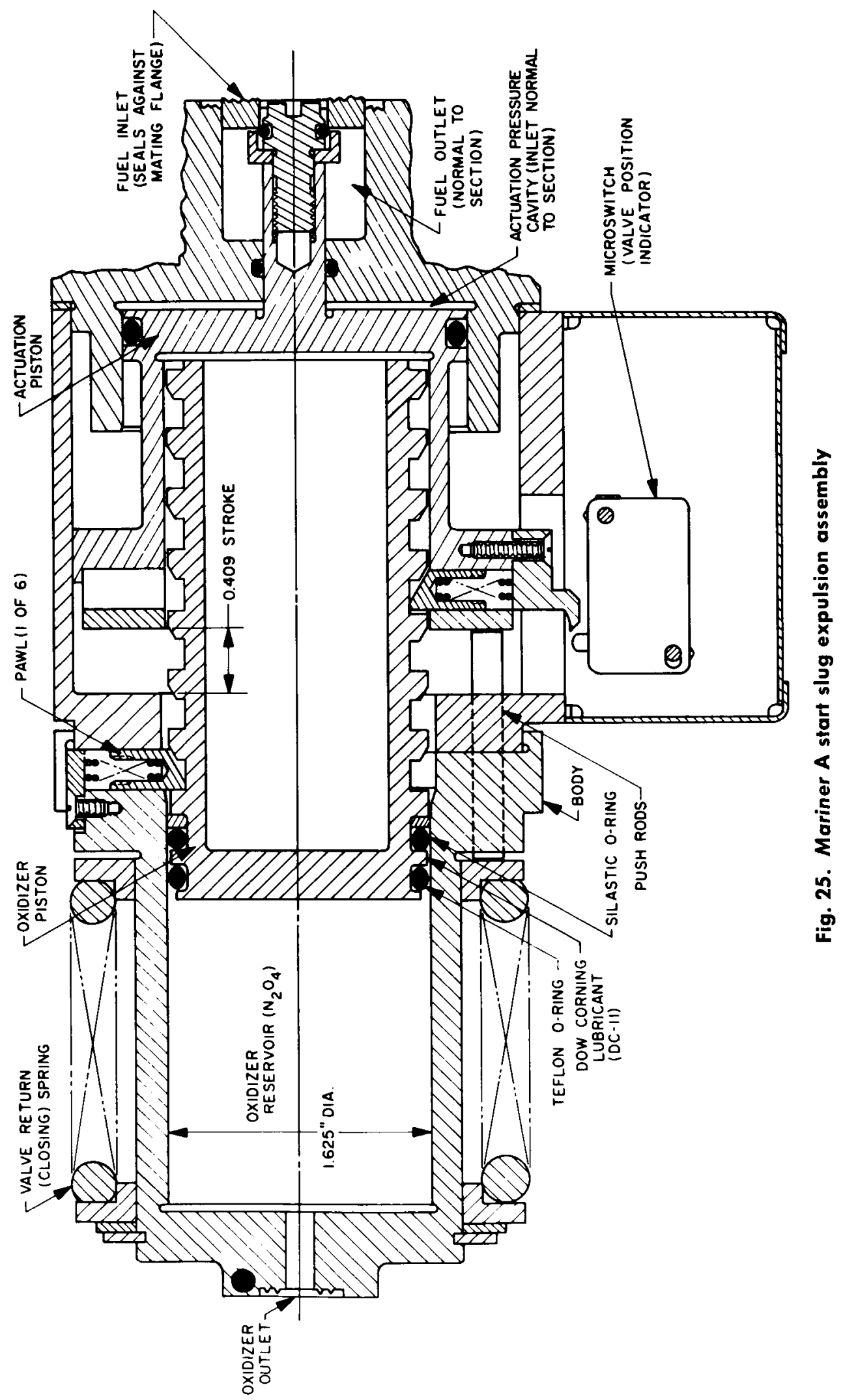


slug. The idea of using a battery of five parallel explosive valves was ruled out in favor of a new approach using a ratcheting piston. The device in its final form (see Fig. 25) performed both the fuel valving and oxidizer expulsion functions. A vacuum filling technique was used to completely fill the volume between the oxidizer piston and a relief valve (not shown) located downstream of the oxidizer reservoir outlet. A complex seal, consisting of a Teflon O-ring, a Silastic O-ring, and a Teflon backup ring, was packed with Dow Corning DC-11 to prevent leakage past the piston. When gas pressure from the system control circuit was applied, the actuation piston moved until it was stopped by the body; this action opened the fuel valve, stroked the oxidizer piston (the force being transmitted to the latter piston by three pawls), and partially compressed the return spring. Movement of the oxidizer piston increased the oxidizer pressure until it was sufficient to open the relief valve, then the volume of nitrogen tetroxide displaced by the piston was pumped into the thrust chamber. At the end of the stroke, the pressure decayed and the relief valve closed. The firing was terminated by venting the gas actuation pressure. The return spring then pushed the actuation piston back to its original position and closed the fuel valve. This movement of the actuation piston caused the three pawls to be ratcheted to engage a new position on the oxidizer piston while it was restrained from backward movement by three other pawls anchored to the body. At this stage the unit was ready for another cycle.

After individual component development tests had been successfully passed, the ratchet start slug device was used in system development tests. Later, the Mariner
A system, loaded with propellant and pressurized, was stored at ambient temperatures for nine months and then fired twice. The ratchet device worked properly, but when it was disassembled for inspection, salts were found above the piston seals. Apparently the formation of these salts was caused by a slight leak of $\mathrm{N}_{2} \mathrm{O}_{4}$ past the seals. A second 9-month storage test was performed on the ratchet start slug device alone. At the end of that period two engine starts were made using the device, which functioned normally. An inspection of the unit after disassembly revealed no salts or other signs of leakage. Despite the good results achieved with this design, no further work was done on it after the finish of the Mariner A program.

Overall, the experience to date with positive expulsion devices in spacecraft has been very good. The only serious difficulty was the obvious incompatibility of the butyl compounds used in bladders and this problem has been solved by newer formulations. The small size of the units may have been a factor in the ease with which the development and flight operations were accomplished. Even so, the first successful use of positive expulsion hardware in deep space is an important step toward assurance of spacecraft system reliability in the future.

On the ground, the reliability of future spacecraft systems is being enhanced by advanced development programs. Newer concepts, better materials, and more thorough testing procedures are being developed and evaluated so that spacecraft system designers will have a backlog of technology from which to draw.

\section{ADVANCED DEVELOPMENTS}

Advanced development of positive expulsion devices is one phase of the Laboratory's Advanced Liquid Propulsion Systems (ALPS) program. The general objective of the program is to investigate selected problems in spacecraft propulsion. These problems are generated by spacecraft operational requirements for high inherent reliability, long-term sturage in space, multiple start in free fall (zero-g), and engine throttling. An attempt has been made to study these problems in a coordinated manner so that the solutions are mutually compatible and suitable for practical application in a complete system. The solutions proposed to satisfy these requirements have been incorporated in the ALPS system.

The ALPS system is a bipropellant, pressure-fed rocket. Pressurizing gas is produced by a monopropellant (hydrazine) gas generator. The propellants are contained in two positive expulsion devices mounted side-by-side 
in a spherical pressure vessel (see Figure 26 and References 18 and 19).

Two basic approaches to developing positive expulsion are being persued. One is the fabrication of bags or bladders which would contain the propellant and separate it from the pressurizing gas and the tank walls. The other is the fabrication of metal diaphragms which would essentially do the same job so far as expulsion was concerned but would place the propellant in direct contact with the tank wall. While reliable bladders were considered to offer more advantages than equally reliable diaphragms, the development of diaphragms was thought to be an easier task than the development of bladders

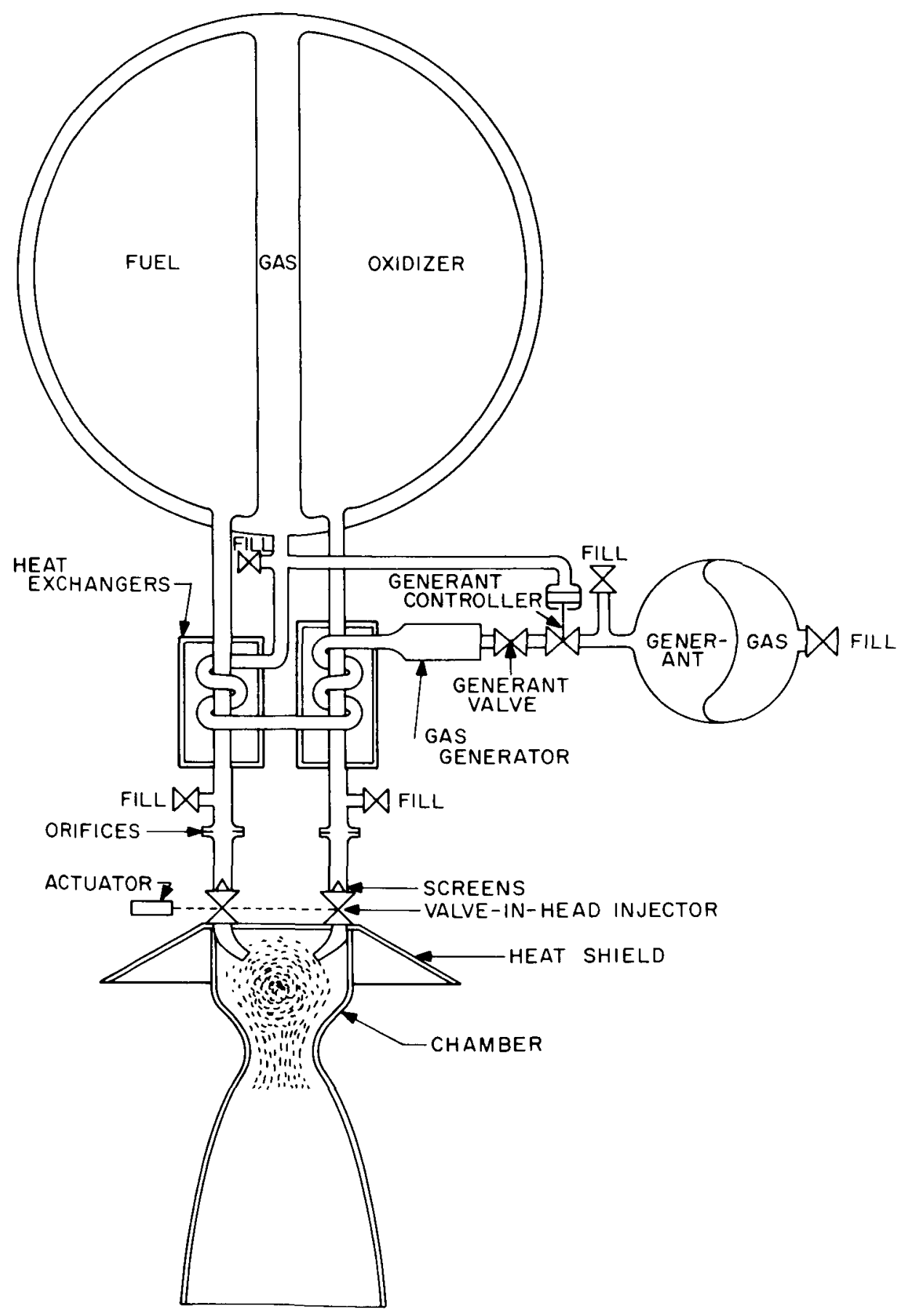

Fig. 26. Schematic diagram of the Advanced Liquid Propulsion System (ALPS) 
and therefore diaphragms could serve as a conservative choice for a "backup" expulsion device, which could be used if reliable bladders were not obtained; the major problem to be overcome before reliable bladders could be made was the lack of a suitable material.

\section{A. Bladder Maferials}

An extensive search was made for a satisfactory material from which to fabricate bladders for use with hydrazine $\left(\mathrm{N}_{2} \mathrm{H}_{4}\right)$ and nitrogen tetroxide $\left(\mathrm{N}_{2} \mathrm{O}_{4}\right)$ in the space environment. Since requirements of the ALPS system specified that both propellants be stored in the same tank, permeation of the propellants through the bladder wall was chosen as the critical parameter for the early screening. The rate of permeation of $\mathrm{N}_{2} \mathrm{O}_{4}$ (perhaps as $\left.\mathrm{NO}_{2}\right)^{z}$ through a given membrane is many times greater than that of $\mathrm{N}_{2} \mathrm{H}_{4}$. For this reason, tests that determine the rate of $\mathrm{N}_{2} \mathrm{O}_{4}$ permeation were used to select and/or eliminate candidate bladder materials.

Over 100 samples of various materials and combinations of materials have been tested. Included were: FEP Teflon, TFE Teflon, FEP-TFE laminates, metal-plated Teflon, FEP Teflon-aluminum foil laminates (both heat and adhesive bonded), TFE dispersion cast on aluminum foil, Mylar, Aclar, Kynar, impregnated Teflon, nitroso rubber, and laminates of FEP Teflon and butyl rubber. None of these materials has proven entirely satisfactory.

These potential bladder materials were screened for relative permeability using the equipment shown in Fig. 6 and the test procedure outlined in Ref. 7. Reference 8 gives detailed results of many of the tests. A short summary of the most significant data is found in Table 2 .

Teflon is a commonly used material which is compatible with both $\mathrm{N}_{2} \mathrm{O}_{4}$ and $\mathrm{N}_{2} \mathrm{H}_{4}$. However, Teflon is not impervious to these propellants. The permeability of Teflon is due not only to small holes (present in both cast and extruded Teflon) but is also due to the solubility of nitrogen dioxide in Teflon. This solubility is apparent from the fact that Teflon exposed to liquid nitrogen tetroxide turns yellow, swells, and loses tensile strength. On removal from the nitrogen tetroxide, Teflon loses the yellow color and recovers its dimensions and tensile strength as the propellant gasses off.

'Nitrogen tetroxide exists in equilibrium with nitrogen dioxide $\left(\mathrm{N}_{2} \mathrm{O}_{4} \rightleftarrows 2 \mathrm{NO}_{2}\right)$.
Permeability rates of $\mathrm{N}_{2} \mathrm{O}_{4}$ through TFE Teflon were found to average $3 \mathrm{mg} / \mathrm{in}^{2} / \mathrm{hr}$ (for sprayed dispersion material 0.010 in. thick) which is considered to be an intolerably high rate of permeation for many applications. By combining TFE and FEP dispersions into a multilayered laminate film ranging from 0.004 to 0.020 in. thick, a material was produced ${ }^{8}$ which incorporated the favorable strength characteristics of TFE Teflon and the lower permeability of FEP Teflon; the average permeability of this film was found to be in the order of $1 \mathrm{mg} / \mathrm{in}^{2} / \mathrm{hr}$ of $\mathrm{N}_{2} \mathrm{O}_{4}$ when tested for 24 -hr periods. Although this material was a significant improvement over TFE alone, it was considered to be far too permeable to serve as an adequate bladder material in the ALPS system.

The importance of bladder permeability depends upon the system design, the storage period, and the propellants to be stored. In the ALPS system, it is very important since both bladders (fuel and oxidizer) are to be stored in the same pressure vessel. To study the condition expected to arise if the liquid $\mathrm{N}_{2} \mathrm{O}_{4}$ had permeated the oxidizer bladder and had condensed on the outside of the fuel bladder, an apparatus was set up which permits the liquid propellants to be brought into simultaneous contact with a disc of bladder material (with one propellant on each side). A sample of duPont TFE Teflon skived to 0.010 -in. thickness was installed in the equipment and liquid $\mathrm{N}_{2} \mathrm{O}_{4}$ and $\mathrm{N}_{2} \mathrm{H}_{4}$ placed on opposite sides. After a few hours' exposure, bubbles were observed on the $\mathrm{N}_{2} \mathrm{H}_{4}$ side of the Teflon test sample indicating that the $\mathrm{N}_{2} \mathrm{O}_{4}$ was permeating the sample and reacting with the $\mathrm{N}_{2} \mathrm{H}_{4}$. After 4 days of exposure, all the $\mathrm{N}_{2} \mathrm{O}_{4}$ had dissipated from the fixture, thus terminating the test. When the Teflon sample was inspected, deterioration of the $\mathrm{N}_{2} \mathrm{H}_{4}$ side was obvious. Another sample was installed and exposure to both propellants continued for one week. Upon removal of the Teflon disc, severe structural damage was noted again on the $\mathrm{N}_{2} \mathrm{H}_{4}$ side (Fig. 5). It was apparent that had exposure been extended only slightly longer, the material would have been degraded completely through to the $\mathrm{N}_{2} \mathrm{O}_{4}$ side. A tentative evaluation indicated that the damage was caused by $\mathrm{N}_{2} \mathrm{O}_{4}$ permeating the Teflon material and reacting with $\mathrm{N}_{2} \mathrm{H}_{4}$ either at or slightly beneath the surface. This reaction caused severe blistering and disruption of the Teflon material, either from the generated heat, gas pressure, or both. It was felt that the damaging effect to the Teflon is

\footnotetext{
"Most of the Teflon materials mentioned in this report as being produced from dispersions by spraying and sintering were fabricated by Dilectrix Inc., Farmingdale, New York.
} 
mechanical or thermal rather than chemical in nature. This phenomenon has serious implications as far as the use of Teflon for a bladder material in any $\mathrm{N}_{2} \mathrm{O}_{4}-\mathrm{N}_{2} \mathrm{H}_{4}$ system where both propellants, either as liquids or vapors, can contact opposite sides of the bladder material. Aside from the explosion hazard, this condition would make the use of permeable Teflon bladders not feasible simply because of the loss in mechanical integrity.

Laminates of FEP Teflon film in thicknesses down to 0.001 in., and aluminum foil down to 0.0002 in., either adhesive or heat bonded, were found (in conventional permeation tests) to be an effective barrier to $\mathrm{N}_{2} \mathrm{O}_{4}$ so long as the aluminum foil was free from pinholes. Adhesive bonding is not acceptable because pinholes do occasionally occur in the aluminum and this allows the $\mathrm{N}_{2} \mathrm{O}_{4}$ to pass through and to chemically attack the adhesives resulting in a constantly spreading area of delamination. The heat-bonded laminates composed of 0.0005 - to 0.002-in. aluminum foil and 0.001- to 0.005-in. FEP Teflon seemed to be both tough and flexible, but resistance to delamination was variable. One of the best samples of heat-bonded laminate, submitted by Dixon Corp., Bristol, Rhode Island, was subjected to a tensile test of the bond. It failed at $600 \mathrm{lb} / \mathrm{in}^{2}{ }^{2}$, with the failure occurring at the bond between the Teflon and the etched aluminum. This laminate was prepared from 5-mil aluminum sheet, which had been etched in some undivulged manner, and onto which about 2 mils of Teflon was fused. This laminate was found to have zero permeability after 96-hr exposure to liquid nitrogen tetroxide, regardless of whether the $\mathrm{N}_{2} \mathrm{O}_{4}$ was in contact with the aluminum or Teflon surface and no delamination occurred.

Another material tested during the ALPS program was a multiple laminate of TFE-FEP Teflon sandwiched with several layers of chemically applied gold plate. This fabrication process was developed under JPL contract by Joclin Manufacturing Company of Wallingford, Conn. The combination laminate reduced permeability rates from those of cast TFE film by a factor of 10 . This material was built up by a series of spraying and plating operations so it could readily be fabricated into seamless bladders.

Single layer laminates of other metals plated on Teflon, whether the metal plate was homogeneous or composed of various combinations of metals, proved unsatisfactory. Results indicated that platings thick enough to be impermeable to $\mathrm{N}_{2} \mathrm{O}_{4}$ are too stiff for use as a bladder material. Also, the plate tended to crack and separate when flexed. Nickel plate was attacked by $\mathrm{N}_{2} \mathrm{O}_{4}$ and thin layers of nickel were removed from the Teflon film. This action was probably due to the $\mathrm{HNO}_{3}$ formed by combining $\mathrm{N}_{2} \mathrm{O}_{4}$ with moisture in the atmosphere. Vapordeposited gold and aluminum were removed from Teflon by $\mathrm{N}_{2} \mathrm{O}_{4}$ and appeared to offer little resistance to $\mathrm{N}_{2} \mathrm{O}_{4}$ penetration.

A process for applying lead plate to Teflon has been developed at JPL (see Ref. 20 and 21). It involves etching the Teflon surface to be plated, ultrasonically vibrating the plating bath and peening or rolling the plated metal between the plating cycles. A 0.010 -in.-thick sample of TFE Teflon film plated with $0.003 \mathrm{in}$. of lead by this process was exposed to $\mathrm{N}_{2} \mathrm{O}_{4}$ in permeation test that lasted for 366 days. During this time no measurable quantity of $\mathrm{N}_{2} \mathrm{O}_{4}$ was detected as having permeated through the test sample. Post-test examination of the plated lead indicated some etching of the exposed surface but less than $0.0005 \mathrm{in}$. loss of material thickness. It was also found possible to fuse seams between leadplated sheets of Teflon by application of a soldering iron.

This plating technique was later applied to another material called Armalon developed by duPont. Armalon is a composite material consisting of TFE Teflon fabric heat-bonded to FEP sheet. A sample of this material supplied supposedly etched, was re-etched on the fabric side, coated with silver, and then lead-plated. A permeability test of this material resulted in no apparent permeation until after $598.6 \mathrm{hr}$ of exposure. The test was carried out with liquid nitrogen tetroxide contacting the unplated surface, which is a drastic test since the solubility of the nitrogen tetroxide in the FEP sheet and the TFE fabric is certain to adversely affect the bond between the Teflon fabric and the metal plate. In actual use, the liquid nitrogen tetroxide would contact the bladder material at the metal surface. Inspection of the permeability test specimen after failure revealed a microscopic hole in a small bubbled region of the metal surface.

Comparison tensile strength tests show that re-etching of the Teflon fabric on Armalon is required for adequate adherence of the composite plate. A sample made without re-etching failed at only $2.4 \mathrm{lb} / \mathrm{in} .^{2}$, revealing a very weak bond between the composite metal plate and the Teflon fabric in the Armalon. With re-etching, failure occurred at $270 \mathrm{lb} / \mathrm{in} .{ }^{2}$. In this case the bond failing was that between the TFE fabric and the FEP sheet. (Lead plate applied to 10 -mil skived Teflon film, treated by a process developed at JPL, gave a tensile strength of $920 \mathrm{lb} / \mathrm{in} .{ }^{*}$ ) 
A special nitroso rubber compound made by Reaction Motors Division, Thiokol Chemical Corporation, was the only true elastomer tested which showed good resistance to chemical attack by $\mathrm{N}_{2} \mathrm{O}_{4}$ but unfortunately it was quite permeable. This material incorporates a special terpolymer and oxidation resistant crosslinking. (Earlier tests of the more common copolymer resulted in oxidizing the crosslinkages and return of the material to the monomer gum.) The terpolymer is at a very early stage of development at this writing and in extremely short supply.

Mylar, Kynar, and Aclar were also tested but found to be unsatisfactory either from the standpoint of compatibility, permeability, or both.

Because no polymers were found to be impermeable, it was suggested that composite structures be built up which would internally absorb the permeating propellant. Redel, Inc., of Anaheim, Calif., undertook the investigations of composites which might be expected to absorb $\mathrm{N}_{2} \mathrm{O}_{4}$ (Ref. 22). Two concepts were tested:

1. The reduction of permeation by filling fluorocarbonbase (FEP) with reactants which would leave an impermeable residue.

2. The development of fluorocarbon laminates (FEP) with liquid fluorocarbon and nonfluorocarbon cores.

The first concept examined was of films produced from Teflon (FEP) filled with unconventional fillers which might be expected to reduce permeability to $\mathrm{N}_{2} \mathrm{O}_{4}$ if the filler, on contact with $\mathrm{N}_{2} \mathrm{O}_{4}$, would swell, fill the molecular structure of the FEP, and thus reduce permeability. Fillers were chosen from materials known to react with $\mathrm{N}_{2} \mathrm{O}_{4}$ to form solid compounds without significant gaseous products. These compounds included cuprous oxide, finely divided nickel, ferric chloride, sodium tetraborate, urea, sodium metasilicate, aluminum oxide, and aluminum flake. It was shown that FEP dispersions containing the above mentioned materials could be sprayed and cured to yield well consolidated films. These films, however, were not significantly less permeable than FEP dispersion alone.

The second concept studied under this contract involved multiple laminates of 0.005 - and 0.010 -in.-thick FEP Teflon film sandwiched with thin liquid or waxy fluorocarbon or nonfluorocarbon base materials. These core materials were of two types. The first included components known to be inert to $\mathrm{N}_{2} \mathrm{O}_{4}$ and/or to have a physical character which could restrict the intermolecular passage of $\mathrm{N}_{2} \mathrm{O}_{4}$ or $\mathrm{NO}_{2}$ through the laminate. These included Arochlor 1254 (Monsanto Chemical), sodium orthosilicate (40 deg $\mathrm{Be}^{\prime}$ water glass) and Kel F No. 80 Grease (Minnesota Mining and Manufacturing Co.), plus such additives as Cab-O-Sil (colloidal silica, Cabot Corporation), graphite, bentonite clay, titanium oxide, and finely divided silica. The second type was represented by glacial acetic acid (plus thixotropic additives) which was chosen because $\mathrm{N}_{2} \mathrm{O}_{4}$ has been shown to retain its bimolecular mode in this acid.

The laminates were formed by sealing two pieces of FEP together quilt-fashion and then sealing a third piece to one of the first two in such a manner as to minimize the coincidence of seal areas. Total thickness of a typical three-layer laminated quilt was 0.025 to 0.030 in., yet a fair degree of flexibility was retained. Permeability rates for all of these combinations of Teflon film and fillers were below $0.2 \mathrm{mg} / \mathrm{in} .^{2} / \mathrm{hr}$; some combinations, particularly those containing sodium orthosilicate and graphite, gave rates as low as $0.004 \mathrm{mg} / \mathrm{in} .{ }^{2} / \mathrm{hr}$ for a period of $46 \mathrm{hr}$.

Althouch this approach to bladder construction has not been reduced to practice, it may be promising for applications where greater flexibility is required than is obtainable with the Teflon-metal laminates. It is probably significant that both Astro Research, because of the folding problem, and Redel, from the standpoint of permeability, arrived at similar conclusions for an optimum practical bladder material for use with $\mathrm{N}_{2} \mathrm{O}_{4}$. Both companies recommended a multiple laminate material of TFE or FEP Teflon and aluminum foil combined with absorbing and lubricating fillers.

While most of the foregoing description of the search for impermeable bladder materials was devoted to describing permeability test results with $\mathrm{N}_{2} \mathrm{O}_{4}$, some tests were made with $\mathrm{N}_{2} \mathrm{H}_{4}$, nitrogen gas, and helium gas. Insufficient data were collected, however, to draw any firm conclusions. Teflon TFE seems to be 100 to 1000 times less permeable to $\mathrm{N}_{2} \mathrm{H}_{4}$ than to $\mathrm{N}_{2} \mathrm{O}_{4}$. Both of the gases permeate Teflon quite readily, but not at exactly the same rate.

In addition to screening materials for permeation, a considerable number of crease damage tests were made using the apparatus described in Section III. Table 3 summarizes the results of these tests." Many of the samples listed were supplied by the Dilectrix Corp. of

'See footnote $a$ of Table 3, pp. 15-16. 
Farmingdale, New York. Some of these materials, particularly the "co-dispersions" and "redundant" films, show remarkable resistance to crease damage compared to ordinary Teflon. On the average, these materials are 10 to 20 times as resistant to failure from creasing as the common sprayed-and-sintered TFE-FEP bladder material, TFE skived film, etc. Dilectrix describes their "codispersion" material as TFE-FEP Teflon sprayed and sintered together into a uniform film, and the "redundant" films as discreet layers of TFE Teflon, built up to about $0.003 \mathrm{in}$. in thickness, interspersed with 0.0002 - to 0.0003-in.-thick layers of TFE mixed with some other material such as "AquaDAG" (a finely dispersed graphite) or aluminum flakes. The company says this film is adaptable to a diversity of structures since any reasonable number of layers, layer thicknesses, and interspersing layers with additives can be assembled. FEP Teflon can also be added to reduce permeation although the samples reported on herein did not contain FEP.

The samples of Teflon-aluminum foil laminates were made by Raybestos-Manhattan, Inc. Material No. L.S. 12.018 was tested both with the aluminum foil on the inside (touching the blades) and on the outside (away from the blades). None of the samples of this material proved to be very durable. As noted in the Table 3, in some samples the aluminum foil was noticeably broken beneath the Teflon film before the film developed pinholes through which the dye penetrant could pass. For cases like the ALPS bladder where near absolute impermeability is required, it appears that a continuous metal foil barrier will be necessary. Therefore, when the foil is ruptured but the film is intact, the failure detecting method presently being used may give misleading data.

Two other laminates made by Raybestos-Manhattan were tested. These had Teflon cloth on both sides of aluminum foil. The data indicate poor durability.

Several samples of sprayed and sintered FEP Teflon gave variable results. These were specimens prepared at JPL to serve as datum points in an investigation of the effects of additives on Teflon's crease durability. None of the samples with additives are listed; all gave less than 40-cycles before failure. (These results are reported in Ref. 11 and 23.)

An interesting result was obtained with commercial skived Teflon. The durability seems to be a function of the thickness. Over the range tested (10 to 20 mils) the durability improves as the thickness increases.
Mylar was tested for comparison purposes only, since Mylar's incompatibility with nitrogen tetroxide and hydrazine eliminates it from consideration.

Based on the results of compatibility and permeability testing, the materials left for consideration were TFE Teflon, FEP Teflon, and metal films, either singly or in various combinations. Certain newer elastomeric polymers, which are currently available only in laboratory quantities, may eventually prove better than any of these-particularly with respect to resistance to crease damage.

\section{B. Bladder Development}

To evaluate the state of the art, some model-size bladders of conventional sprayed and sintered Teflon were tested for expulsion durability early in the program (see Fig. 27). These 18-in.-diameter hemispheres were fabricated by Dilectrix Corporation, Farmingdale, New York (see section on Bladder Fabrication for a brief description

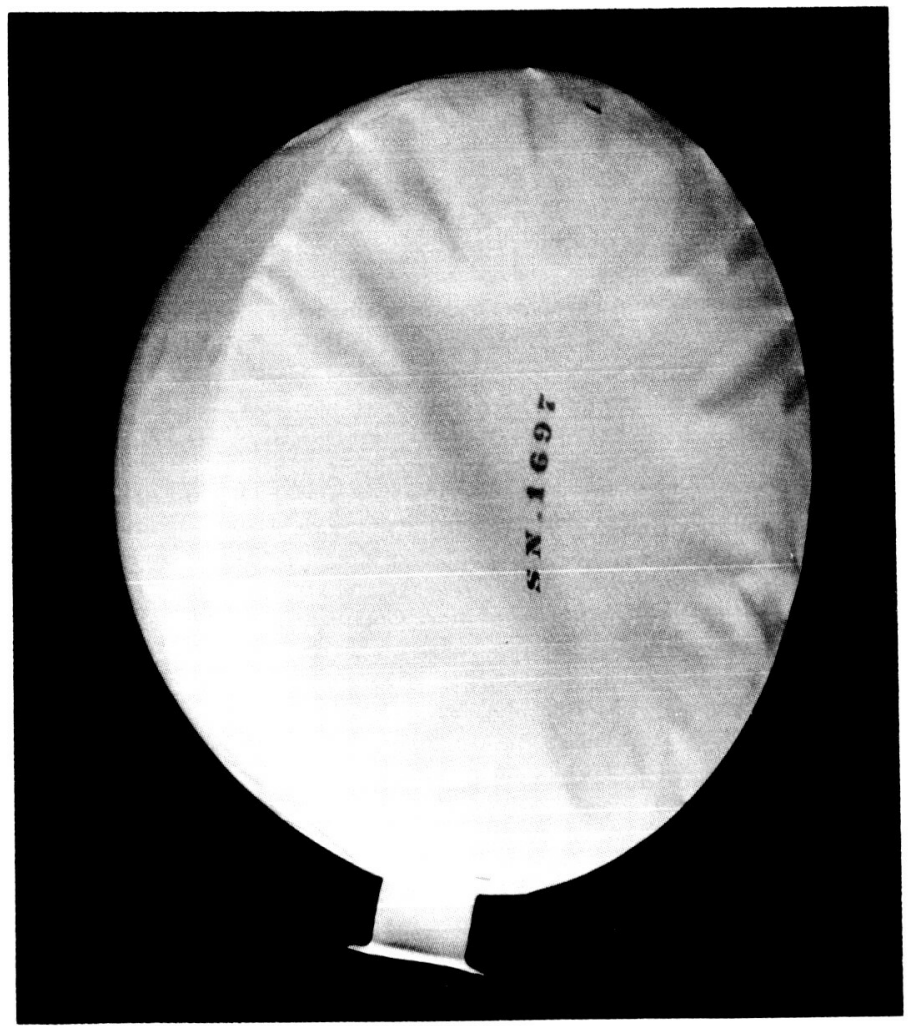

Fig. 27. Seamless hemispherical bladder of the conventional sprayed and sintered Teflon construction 
of the process and Ref. 8 for a more complete description). Expulsion efficiencies exceeding 99\% were measured in tests. The shape of the bladders, however, resulted in uncontrolled folding patterns with sharp creases. Noticeable leaks developed after one to four cycles at room temperature even though the expulsion pressure was less than 40 psig in all cases. Furthermore, the measured permeability of this material to the propellants was of many orders of magnitude greater than the ALPS system could tolerate.

The same contractor then supplied similar bladders with tapered wall thickness, which it was thought might help to control the folding pattern; these bladders displayed a slight improvement. Later, the contractor fabricated more bladders using a new composite material consisting of aluminum flakes distributed in the TFEFEP codispersion in order to stiffen the material and reduce its permeability. The bladders were made by spraying and sintering alternate layers of the conventional and the aluminum-containing codispersion. As before, folding control was sought by tapering the wall thickness from 0.005 to 0.020 in. The topmost area, where folding was supposed to begin first, was a single, flexible layer of the conventional material. Further down the side, the bladder was made stiffer by more and more layers. The bottom half consisted of four layers of the metal composite sandwiched between five layers of the conventional Teflon.

Results of permeability tests made of the aluminumfilled Teflon were not promising. The presence of the aluminum flakes decreased permeability only by a factor of 3 , in comparison with sprayed, unfilled TFE-FEP. This level of permeability, from 0.2 to $0.3 \mathrm{mg} / \mathrm{in} .{ }^{2} / \mathrm{hr}$., is still prohibitive.

Two bladders were subjected to repeated expulsions at ambient temperature. All tests were made with the outlet downward. Water was the test fluid and nitrogen gas was used as the pressurant. Although the tapered wall of the upper half of the bladder controlled the collapsing somewhat, the folding fell short of the desired "rolling" collapse. Double folds, three-cornered folds and creases occurred as in the previous tests of plain Teflon bladders of equal thickness, but they were not as severe as before. Using tank pressures of $30 \mathrm{psig}$, the volumetric expulsion efficiency of both aluminized bladders was $99.8 \%$. The expulsion characteristics is shown in Fig. 11. The bladders were repeatedly filled and evacuated to determine their cycle life. Fifty and sixty-five expulsion cycles were imposed, respectively, on the two aluminized bladders without causing a noticeable leak, and then the testing was terminated. The resistance of this material to damage by creasing was later verified by tests of patch samples in the JPL crease tester (see Fig. 7). Although the aluminum filler did not produce the desired decrease in permeability of Teflon or correctly control the folding of the collapsing bladder, its effect on the crease resistance of Teflon was particularly noteworthy.

It was determined early in the permeability test phase of the program that to be completely impermeable to $\mathrm{N}_{2} \mathrm{O}_{4}$ for any length of time, the bladder wall would have to contain, or consist of, a metal barrier. A concept of this nature that has advanced to the stage of fabrication is FEP Teflon laminated by heat bonding to aluminum foil. An impermeable barrier to $\mathrm{N}_{2} \mathrm{O}_{4}$ was obtained with this material, but fabrication into the hemispherical shape required of ALPS bladders was not state of the art. Swedlow Inc., of East Los Angeles, Calif., produced hemispherical bladders using Teflon aluminum laminate of 0.003 aluminum foil and 0.005 FEP Teflon film (see Fig. 28).

Testing was difficult, for the bladders did not fit readily into the existing test tanks because of the heavy seam joining the hemispherical and flat side of the bladders. In the expulsion tests that could be run, however, pinholes developed during the first cycle of expulsion due to creases and three-cornered folds formed by the random folding pattern. From these results, it is obvious that if this material is to be used, a method of folding control must be developed that will prevent the formation of random folds.

To further investigate folding control, two sintered Teflon bladders were fabricated over quarter sphere mandrels in such a way that, in the as-fabricated condition, the upper half of the hemispherical bladder was inverted into the lower half (see Fig. 29). The fold radius at the equator was approximately $1 / 8-\mathrm{in}$. OD and the wall thickness was 0.015 in. Conceptually, it was hoped that after liquid filling extended them to full hemispheres, there would be a built-in tendency to return to the involute shape during the expulsion cycle. Leaks developed during the initial extension of both bladders so it was not possible to accurately measure expulsion efficiency. Both did, however, return satisfactorily to the involuted position during the expulsion cycles except for some minor wrinkling at the corners where the flat and quarterspherical surfaces intersected. 


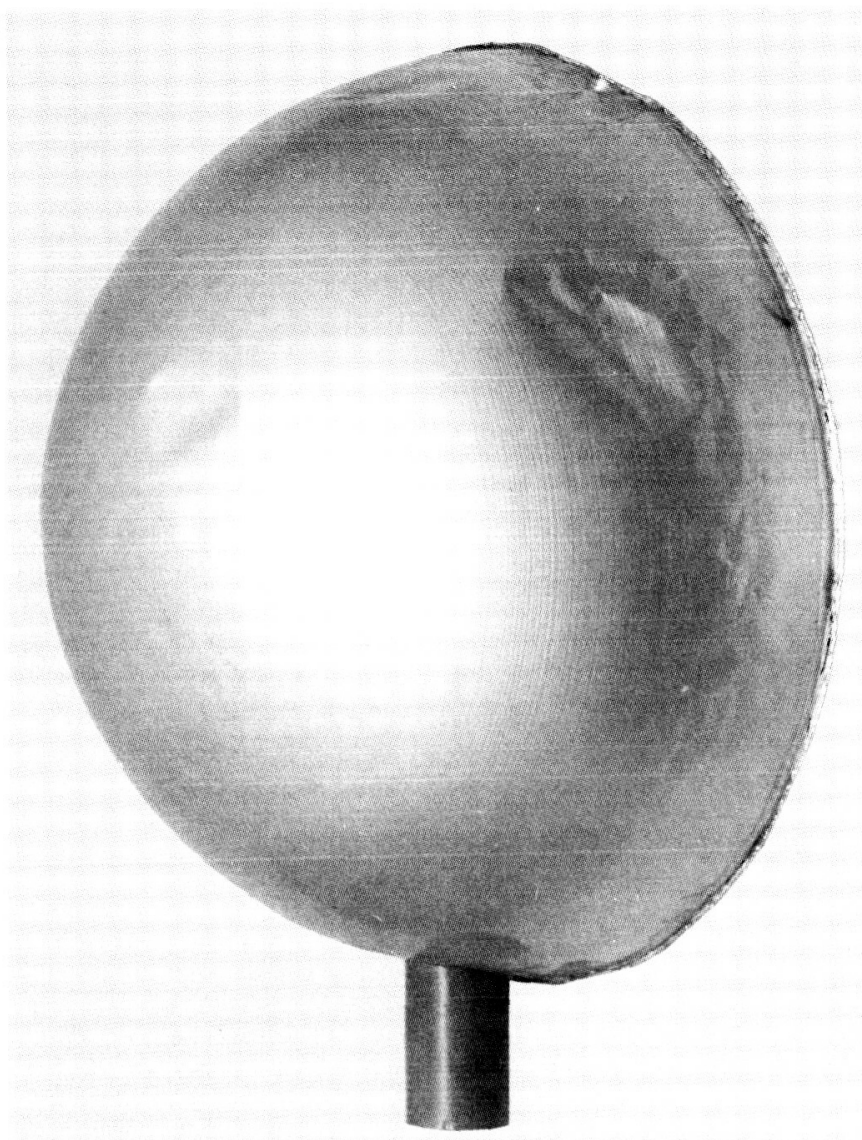

Fig. 28. Hemispherical bladder fabricated of Teflonaluminum foil laminate

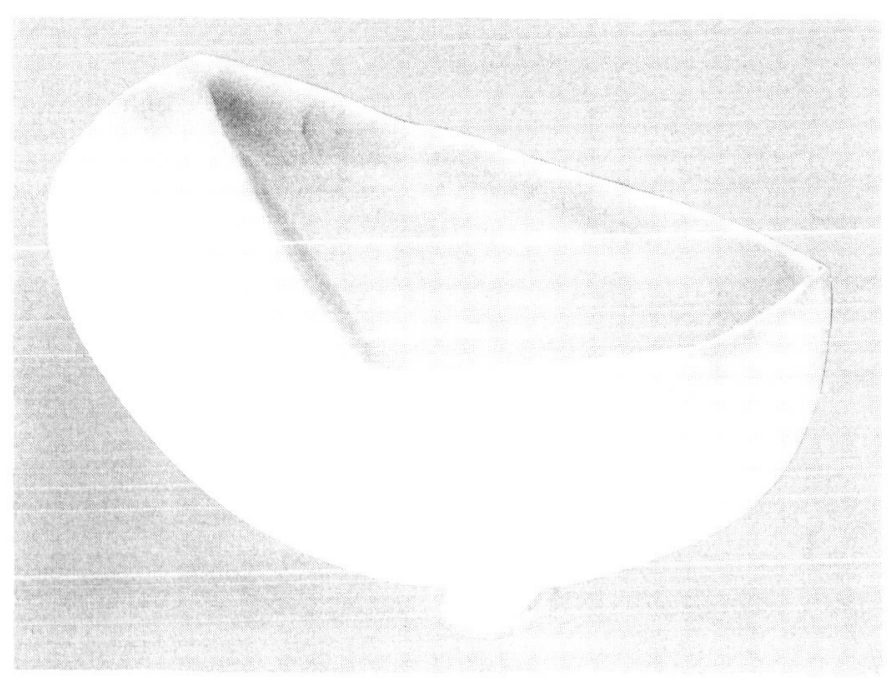

Fig. 29. Seamless hemispherical Teflon bladder fabricated with the top half folded down inside the bottom half
Still another method of folding control that was tried makes use of the fact that the hemispherical bladder is a portion of a surface of revolution. In this scheme, the flat surface of the bladder folds along the diameter perpendicular to the direction of propellant discharge (see Fig. 30). As the top half of the flat, circular surface rotates about its fold axis, it "sweeps" the inside of the hemispherical bladder wall. Ideally, the rotating flat surface pulls the hemispherical surface behind it in a continuous, rolling motion. A smooth, rolling motion is not nearly as destructive to bladder walls as random creasing, especially if the rolling radius is relatively large. The final configuration shows the upper half of the hemisphere inverted within the lower half, a position capable of high expulsion efficiency.

An 18-in., hemispherical, Teflon bladder was stiffened to induce the expulsion collapse control mentioned above. The lower half of the hemispherical surface was bonded to an aluminum shell with epoxy. The flat side of the bladder was stiffened with two semicircular plates, leaving an unstiffened "hinge" along the fold axis. Stiffening these surfaces prevents them from becoming distorted and interfering with the collapsing walls. The upper half of the hemispherical surface was left unstiffened to allow it to roll through $180 \mathrm{deg}$ during expulsion.

During expulsion tests with water, the upper semicircle rotated as desired, however, the upper half of the hemisphere collapsed and wrinkled ahead of the rotating semicircle instead of being pulled behind it. At the end of expulsion, the top half of the bladder was correctly inverted within the bottom half. A second expulsion test, with induced sloshing revealed that bladder motion was greatly reduced from that of unstiffened bladder expulsion tests. No practical means were found for solving the

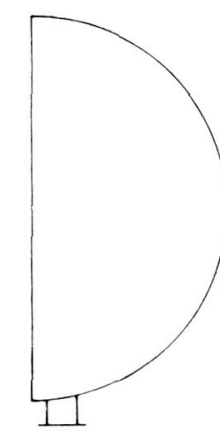

FILLED

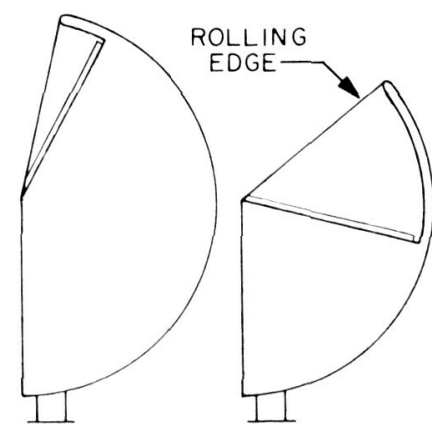

EXPELLING

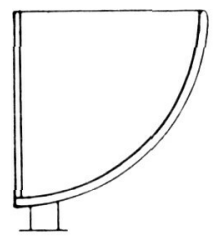

EMPTY
Fig. 30. Folding scheme for a hemispherical bladder involving hinging the flat side at the equator 
problems of installation and keeping the upper half of the hemisphere from wrinkling ahead of the flat rotating section.

A number of other folding concepts are being studied but no reproducible results have been obtained to date.

A severe storage problem is created by the current ALPS design which specifies that the oxidizer $\left(\mathrm{N}_{2} \mathrm{O}_{4}\right)$ and the fuel $\left(\mathrm{N}_{2} \mathrm{H}_{4}\right)$ be contained in bladders installed in a single spherical tank. A vertical partition between the two bladders serves to position the bladders but does not provide a hermetic seal between the two compartments. During the storage period of one year or longer, the propellant vapors which may have diffused through the bladder walls will be free to migrate throughout the ullage and to mix together; the resulting mixture of fuel and oxidizer vapors may or may not react in a catastrophic manner. The gradual buildup of propellant vapor in the ullage may also result in either permeation of oxidizer through the fuel bladder, or permeation of fuel through the oxidizer bladder.

Tests were made with model-size bladders to investigate the storage of propellant under these conditions. The bladders used in these tests were 18-in.-diameter hemispheres fabricated by Dilectrix, Inc., Farmingdale, New York. The seamless construction was current state of the art for sprayed and sintered Teflon. Nominal wall thickness was $0.010 \mathrm{in}$. In the first test, two bladders were installed in a steel tank; one bladder was filled with $\mathrm{N}_{2} \mathrm{O}_{4}$ and the other with distilled water (simulating the fuel). The tank was then pressurized to approximately 250 psig with nitrogen gas. The tank and contents were essentially at ambient temperature during the test so the fluids ranged between +40 and $+100^{\circ} \mathrm{F}$.

Data were to have been obtained by periodically sampling the pressurizing gas and measuring the acidity $(\mathrm{pH})$ of the water in the fuel bladder. Unfortunately the fuel bladder was cut during the filling process and some of the water spilled out of the bladder. Although this occurrence invalidated the gas sampling data, the $\mathrm{pH}$ data did yield results. Computations indicated that the diffusion rate through the oxidizer bladder averaged $2.06 \mathrm{mg} / \mathrm{in} .{ }^{2} / \mathrm{hr}$ during the first 10 days. An average rate of $1.37 \mathrm{mg} / \mathrm{in.}{ }^{2} / \mathrm{hr}$ was calculated for the full 91 -day test duration. These rates of $\mathrm{N}_{2} \mathrm{O}_{4}$ permeation are comparable with those obtained in laboratory tests of patches of similar TFE-FEP Teflon material.
A second storage test under similar conditions was conducted and continued for 64 weeks when it was concluded by rupture of the burst diaphragm on the tank. Ambient temperature during this period ranged from +15 to $+115^{\circ} \mathrm{F}$. The $\mathrm{N}_{2} \mathrm{O}_{4}$ crossover rate determination was accomplished by analyzing water samples periodically withdrawn from the water bladder. This information was used to compute the rate at which $\mathrm{N}_{2} \mathrm{O}_{4}$ permeated through the bladders and into the water. As can be noted in Fig. 31, this rate increased slightly over the test period, but averaged less than $0.2 \mathrm{mg} / \mathrm{in} .^{2} / \mathrm{hr}$ for the first 60 weeks. This rate of permeation is quite reasonable for two separated layers of 0.010 -in.-thick sprayed and sintered Teflon material.

At the end of 60 weeks both the $\mathrm{N}_{2} \mathrm{O}_{4}$ permeation rate and its accrual in the water-filled bladder increased rapidly. It is felt that at this time the water bladder was cut by movement of the divider panel. This would not only have reduced the separation between the $\mathrm{N}_{2} \mathrm{O}_{4}$ and the water to one layer of 0.010 in. of Teflon, but also would have allowed water vapor and $\mathrm{NO}_{2}$ to mix and form nitric acid $\left(\mathrm{HNO}_{3}\right)$. The acid then could have attacked the burst diaphragm and weakened it until the pressure caused it to rupture at the end of 64 weeks' total test time.

At the present time, the ALPS bladder development is still concentrated on folding studies and fabrication development. Most of the test facilities are operational and model-size bladders have been tested for expulsion efficiency, slosh loads, and storage. None of the bladders tested to date, however, are representative of the final ALPS construction.

\section{Convoluted Diaphragms}

The second or backup method of positive expulsion chosen for development in the ALPS program is the allmetal hemispherical diaphragm. Convoluted diaphragms were tried first. This device, although it currently lacks the ability to recycle, seems to possess definite advantages over most of the other known expulsion methods for leak-free, long-term space storage. The concept is not new (it was proven feasible several years ago by at least one commercial rocket firm). An opportunity remained, however, to improve the expulsion efficiency, to develop improved methods of fabricating large diaphragms and, if possible, to develop a recycling capability. The diaphragms fabricated for the ALPS program by the Aeronautical Division of Honeywell, Inc., were formed from 


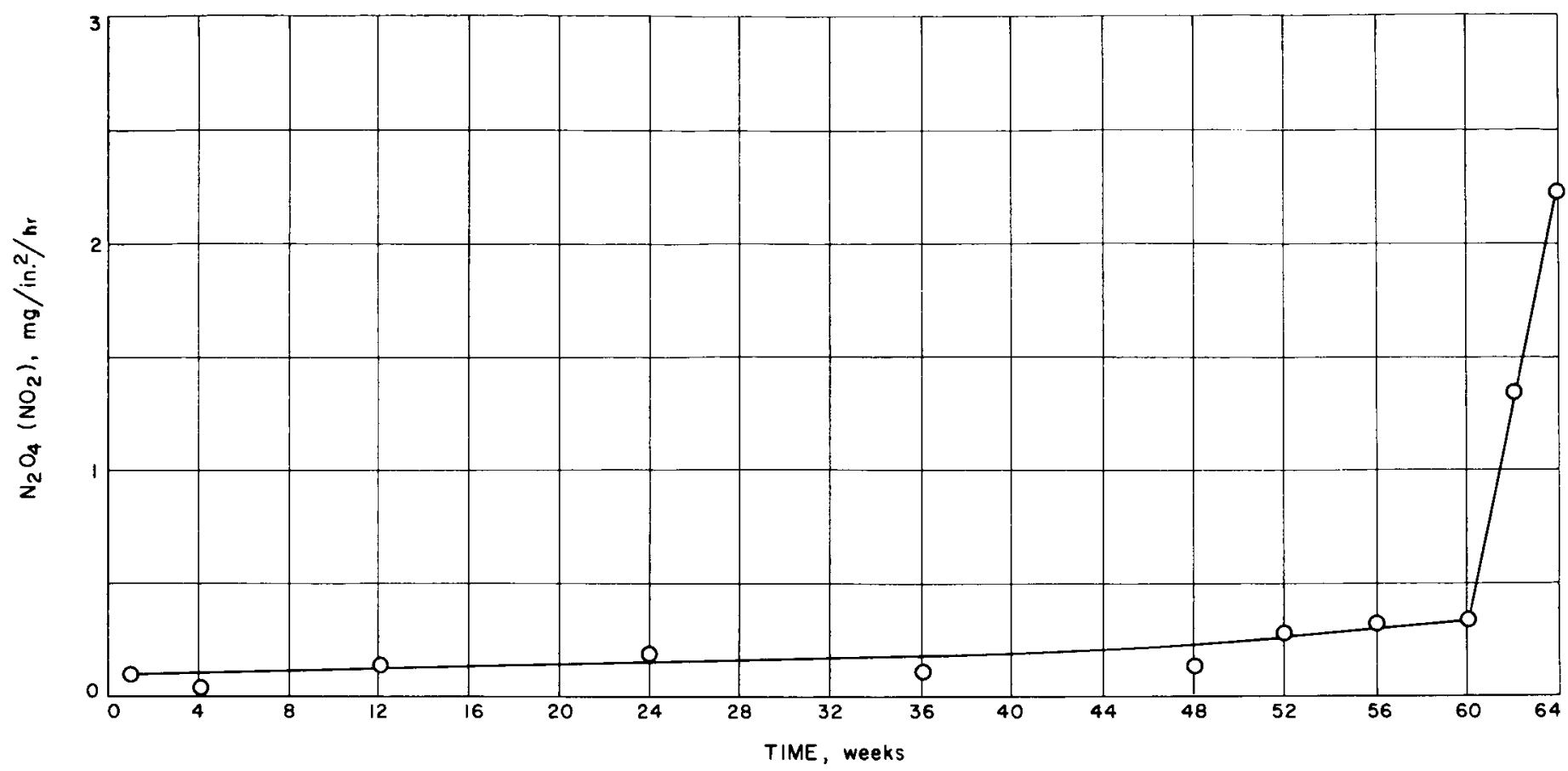

Fig. 31. Calculated permeation rate of $\mathrm{NO}_{2}$ from $\mathrm{N}_{2} \mathrm{O}_{4}$ bladder into water-filled bladder

hemispherical surfaces which were folded into concentrically convoluted surfaces lying about the equatorial plane (similar to Fig. 13d). Theoretically no metal stretching or shrinking would occur when the diaphragms were unfolded by pressure into a hemispherical shape during the expulsion cycle. This mode of flexure was chosen to keep the expulsion pressure low and the probability of damage to a minimum.

Many expulsion tests of these 18-in.-diameter diaphragms (made of type 1100 aluminum) have been made both with and without applied sloshing motion. The diaphragms ranged from 0.010 to 0.017 in. in thickness. Expulsion characteristics and efficiencies obtained in these tests are shown in Fig. 32. All of the diaphragms tested had expulsion efficiencies of $97 \%$ or above and some had efficiencies as high as $99 \%$ at an expulsion pressure of 30 psi.

In the initial tests performed at Honeywell, the diaphragms were held in the horizontal position (outlet in the middle of the top of the tank) with the gas pressure being applied to the under side. In these tests it was observed that the convolutions did not unfold by uniform circumferential rolling, but instead randomly located weak points allowed buckling which caused the convolutions to tilt.

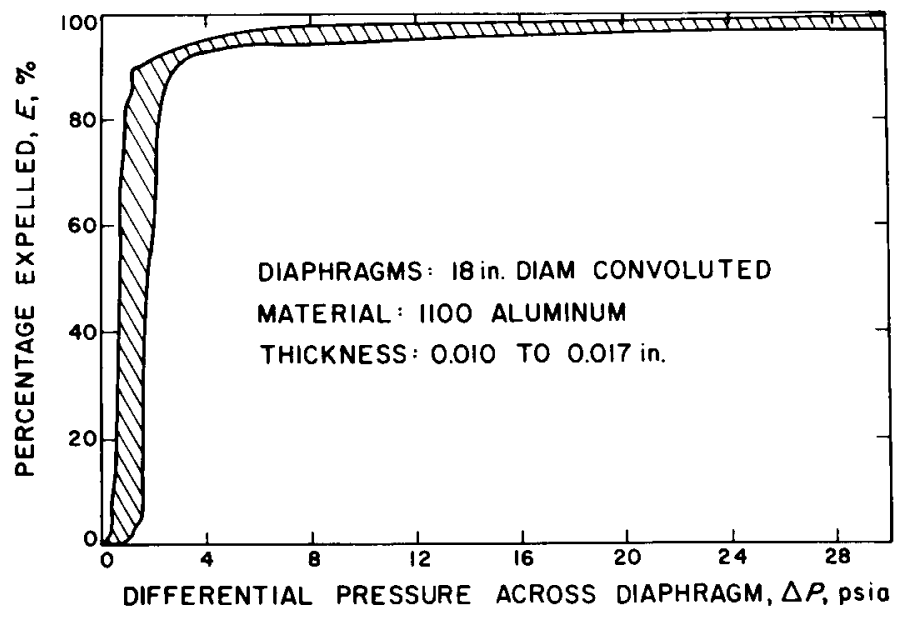

Fig. 32. Envelope containing the expulsion characteristics of seven convoluted metal diaphragms

Later, expulsion tests were made at JPL, on diaphragms of 0.015 to $0.017 \mathrm{in}$. in thickness, in which the tank outlets were located at the edge of the diaphragms and with the diaphragms in the vertical position (with the tank outlets at the bottom). Some tests were made under conditions of applied slosh loading with the diaphragms oriented with their equatorial planes perpendicular to and parallel to both the linear and rotational slosh modes. These tests, with one diaphragm used per test, were made at several amplitudes and frequencies of oscillation to de- 
termine the effect of these parameters on expulsion. In a preliminary test, the volume from which the water was to be expelled was filled to various levels with water, and sweeps were made through the available frequency range ( 0.5 to $13.0 \mathrm{cps})$ to find the resonant frequencies. The amplitudes of the free surface oscillations were used as a measure of resonance. ${ }^{10}$ The most violent oscillations occurred at $128 \mathrm{cpm}$, regardless of the water level. Two diaphragms were subjected to slosh oscillations at this resonant frequency and the maximum amplitudes permitted $\left( \pm 1^{7 / 16}\right.$ in. longitudinal, $\pm 4^{1 / 4} \mathrm{deg}$ angular), but there was no noticeable oscillation of the diaphragm during shaking; however, the pressure difference across the diaphragm exhibited low amplitude ( $0.4 \mathrm{psi})$ oscillations at a frequency equal to the slosh frequency. There was no damage caused by shaking.

Tank pressure for all of these expulsion tests was held constant at approximately $30 \mathrm{psig}$. The pressuredifferential across the diaphragms remained nearly constant at $2.0 \pm 0.8$ psi until approximately $90 \%$ of the fluid was expelled. Then the pressure difference increased sharply and approached a value near that of the tank pressure at the end of expulsion. Expulsion efficiencies seldom exceeded $99 \%$, incomplete expulsion being due partially to the nonspherical shape of the diaphragm after expulsion.

Expansion of the diaphragm was generally nonuniform with the upper side bulging first, probably due to the difference in hydrostatic pressure. Visual study of the diaphragms during and after expulsion indicated a nearly equally spaced 5-point buckling pattern on the outer convolutions which was reproduced on all of the diaphragms tested. These buckling points induced traveling creases up to $3 \mathrm{in}$. in length as the diaphragm distended. Although the metal was severely worked, apparently it was not breached for no leaks were noted.

Because it was thought desirable to be able to test these diaphragms (and larger ones) with actual propellants and with slosh loads applied, a special test facility with these capabilities was set up on Stand A at JPL's Edwards Test Station. Under contract to JPL, Lockheed Aircraft Services, (Ontario, Calif.) designed and fabricated a device for this facility which is capable of supporting and sloshing (oscillating) tanks up to 64 in. in diameter and weighing as much as $6,000 \mathrm{lb}$ (combined

\footnotetext{
${ }^{10}$ Actual peak resonance with a completely filled expulsion volume might have occurred at a different frequency, but a frequency scan was not made to define the peak resonance frequency.
}

weight of tank and propellant). The support structure is a cage of heavy construction which pivots at the lower end on a monoball joint and is laterally driven at the upper end by an eccentric arm from a controlled power source. This equipment is capable of oscillating at frequencies of 0 to $16 \mathrm{cps}$ with linear amplitudes up to \pm 4 in. (at the tank center) but is not intended to withstand acceleration forces in excess of $2 \mathrm{~g}$. Weight measurements for the determination of expulsion efficiency are obtained by means of a load cell mounted beneath the monoball joint.

A number of tests of 18-in. convoluted diaphragms have been made at this facility in which one or both propellants were expelled. Among the diaphragms tested were several fabricated of type 1100 aluminum for JPL by Phoenix Products Company (Milwaukee, Wisc.). These diaphragms were made by the spinning process and were of a design which allowed nesting as illustrated in Fig. 13e. They were received at JPL in the as-spun condition with thickness varying from 0.060 in. in the center to $0.020 \mathrm{in}$. at the outer convolution. The radii at the intersections of the surfaces of the convolutions were approximately 0.125 in. Expulsion tests under slosh conditions were conducted with these diaphragms first singly and then in pairs using the propellants $\left(\mathrm{N}_{2} \mathrm{O}_{4}-\mathrm{N}_{2} \mathrm{H}_{4}\right)$ as the test fluids. In some tests both propellants were expelled simultaneously from a single tank. Expulsion pressure was 250 psi which is high enough to overcome the increased stiffness of the thicker diaphragms and therefore the ultimate percentage expelled was the same as in previous tests with the thinner, drawn diaphragms. Pressure loss or differential pressure across the diaphragm, however, was noticeably higher for a given percentage expulsion.

One of the goals in the development of diaphragms is to make them capable of recycling. This capability is desirable in order to allow testing of components before flight. At least partial recycling is required to allow offloading propellant tanks ${ }^{11}$ and to compensate for changes of bulk density of the propellants with temperature. Figure 18 shows a typical convoluted diaphragm after an attempt was made to recycle it by pressurizing the liquid side with nitrogen gas after expulsion. The diaphragm collapsed with little relationship to the original convolutions. Under JPL contract, Honeywell is making

\footnotetext{
"The term "off-loading" refers to the act of removing part of the propellant from the tank. This capability, and the implied capability of also putting it back later, is desirable because it allows the propellant load to be optimized for the particular trajectory to be flown.
} 
studies of various stiffening methods to return diaphragms to their original convoluted shape during recycling.

Some in-house effort to obtain recycle capability has also been made. Several extra thick diaphragms were selectively "chem milled" so that the rolling or moving surfaces of the diaphragms were reduced to 0.010 to $0.015 \mathrm{in}$. in thickness. Occasional improvement in recycling capability was noted; one diaphragm survived three $20 \%$ overfills and two complete expulsion cycles before failure. To date this has not been repeatable. The most common failures have been tears in the thinned sections of the diaphragms due to creasing. Considerable difficulty was encountered in controlling the local thickness and avoiding pitting despite the best efforts by two different processors. Little difference was noted in the performance of opposite units of a nested pair. In addition to the chem milling approach, hard anodized and adhesively bonded reinforcing rings were used to selectively stiffen the nonrolling surfaces. On some diaphragms, thick rubber backing was applied. None of these methods materially improved the recycling ability of the diaphragms although serious problems with the quality of the workmanship makes final judgments on the worth of these approaches impossible.

Starting late in 1962 a brief series of hardware evaluation experiments was performed on convoluted hemispherical diaphragms fabricated from a cesium-resistant material in a size immediately useful in laboratory-scale ion motor integration testing. (These tests were not part of the ALPS program.) Six type 302 stainless steel convoluted diaphragms, $3 \mathrm{in}$. in diameter, $0.0056 \mathrm{in}$. in thickness, forming hemispheres containing approximately $100 \mathrm{ml}$ were fabricated for JPL by Honeywell. Tests were made to measure expulsion efficiency and to observe their mechanical operation. Nitrogen gas was used as the pressurant and water as the test fluid. Expulsion efficiencies of 93 to $96 \%$ were obtained with all but one diaphragm at $135 \mathrm{psig}$ differential pressure. The other diaphragm yielded only $88 \%$ efficiency.

Work on convoluted diaphragms is continuing. Most of the effort at present is directed toward making the diaphragms recyclable. Storage tests are also contemplated.

While the convoluted diaphragm concept meets the basic ALPS requirement for expelling two different propellants from the same tank, it is limited since two diaphragms are required to completely expel the contents of a spherical tank; this is true because it has not been possible to make a convoluted diaphragm reverse itself. All liquid propulsion systems require some ullage in the propellant tanks to allow for liquid expansion due to temperature changes. Systems to be heat sterilized must have up to $35 \%$ ullage. This fact means that the expulsion device will be more or less distended as the ullage requirements vary and that convoluted diaphragms, which must be positioned near the center plane of the tank when full, will be separated by a considerable space and supported only by the pressurizing gas. Whether they are oriented perpendicular or parallel to the axis of thrust, one or both of them will be subject to distortion by hydrostatic pressure exerted by the propellants during the high $g$ period of booster operation.

A recent development in metallic expulsion devices that seems to solve this problem is the thin walled, wirereinforced stainless steel fully-reversing hemisphere proposed and demonstrated in 6-in.-diameter size by Arde Inc., of Paramus, N.J. This idea conceptually satisfies the requirement for a single metallic device to completely expel the liquid from a spherical tank and, because of its mode of operation, (full reversal from one side of the tank to the other), it need not be placed in a position where it can be distorted by high-gravity loading during booster acceleration even though it is partially distended because of ullage requirements. In 1964 a contract was placed with Arde Inc. to demonstrate the feasibility of the concept in the ALPS 18-in.-diameter test size. As of the end of the period covered by this report, none of these hemispheres had been tested at JPL; results will be published in the JPL Space Programs Summaries after tests are performed.

\section{ALPS Generant Tank and Cell}

This assembly, which forms part of the generant feed system, contains both liquid generant (hydrazine) and pressurizing gas. The system operates on the "blowdown" principle. This means that the generant tank is partially filled with hydrazine and then gas-pressurized to $1300 \mathrm{psi}$. The pressure decays to approximately $600 \mathrm{psi}$ as the generant is expelled, since no more gas is added during expulsion. The tank system is expected to expel the generant under various vibrational environments as well as under steady accelerations ( $g$-loads) regardless of the direction.

A number of expulsion designs were considered, but all except the hemispherical diaphragm were discarded for various reasons. Earlier in the program a spherical bladder was also under development, but it was finally dropped. The bladder design had an inherent problem in that, unless restrained, sloshing was readily induced 
during any vibrational inputs to the tank. The bladder, being only about half the volume of the tank, could move from one side of the tank to the other in the manner of a boxer's punching bag. This problem was undoubtedly accentuated by the fact that the bladder when full occupied only about half the tank volume because of the ullage needed to store the pressurant gas. Sloshing may also be a problem with the diaphragm type of design, but it is not expected to be as severe as with the bladder.

Another problem, associated with both of these designs, was the tendency of the diaphragm or sphere to close off the outlet of the tank prior to complete expulsion of the liquid. Tests to investigate this were carried out with both bladders and diaphragms. A conventional bladder design (outlet similar to Fig. 2c) of thin (0.030-in. nominal thickness) butyl rubber was installed in a spherical transparent tank of $16^{1} \%$-in. ID and subjected to nine expulsion tests with the outlet upward and eight tests with the outlet downward in the facility shown in Fig. 10. Nitrogen gas pressures of 5 to 100 psig were used to expel water. Expulsion efficiencies greater than $99 \%$ in the downward position and greater than $98 \%$ in the upward position were obtained with differential pressures ranging from 1 to 4 psi across the bladder. In all tests the tank was held stationary.

A test diaphragm of thin (0.030-in. nominal thickness) butyl rubber was molded (by Stillman Rubber Co.) with segmented ribs on the external or liquid side. The ribs were thought to be necessary to avoid liquid entrapment due to the sealing effect of a smooth diaphragm surface against a smooth tank wall. The diaphragm (Fig. 33) was secured by clamping the flange between the two halves of the Plexiglas test tank.

The first tests were made using the fully ribbed diaphragm. During the program the seven rib segments were progressively removed, starting at the periphery and progressing to the center where the diaphragm contacts the tank outlet when expulsion is complete. Tests were made with seven, four, three, two, one, and finally no rib segments. Four to nine expulsions were made at tank pressures of 5, 10, 20, 50, and 100 psig. Expulsion efficiency of the diaphragm fell off at the higher pressures for all cases except the fully ribbed.

Additional tests were made with the smooth and the fully ribbed diaphragm to determine the effects of generant tank orientation on expulsion efficiency. These tests were made with the generant tank outlet in three posi-

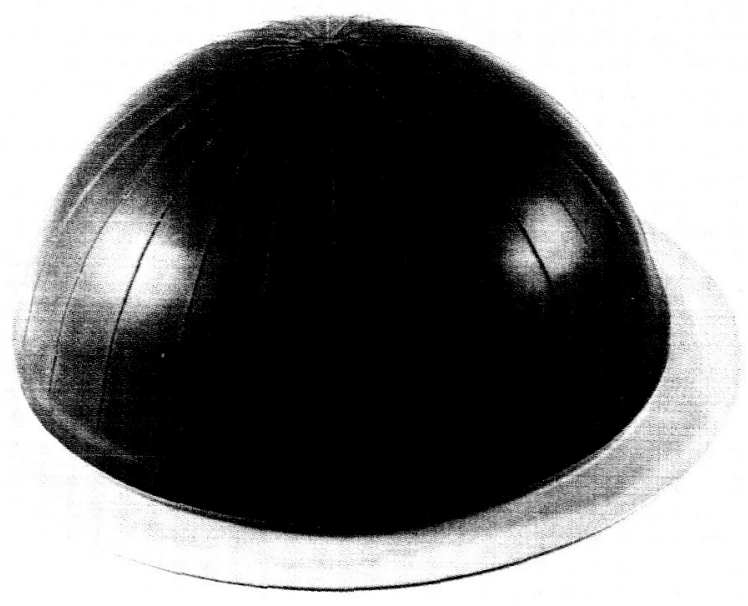

Fig. 33. Rubber hemispherical expulsion diaphragm with external ribs

tions: downward, upward, and sideward (horizontal). In each of the above positions, four to six tests were made at tank pressures of $5,10,20,50$, and 100 psig. The results are shown in Fig. 15. The smooth diaphragm performed consistently when upright but became erratic when horizontal or inverted. The ribbed diaphragm data show that this type of generant cell gives an expulsion efficiency ranging from 99.5 to $100.0 \%$. Also, the data indicate that expulsion efficiency is relatively independent of tank outlet position.

A trend of increasing expulsion efficiency with increasing pressure was apparent; this is just the reverse of the trend obtained using the smooth diaphragms and partially ribbed diaphragms. High pressure tests, using metal tankage, revealed that trend continued at pressures up to 700 psig (the highest test pressure used). These results substantiated the idea that the segmented ribs increase expulsion efficiency by preventing a sealing action between the diaphragm and the smooth tank wall which traps liquid away from the outlet port.

The final ALPS tank design, shown in cross section in Fig. 34, is a sphere, approximately $17 \mathrm{in}$. in diameter. A safety factor of 2.2 on the maximum working pressure of 1500 psig was chosen so that personnel could be in the vicinity while it is pressurized. The two halves, called the gas-side hemisphere and the liquid-side hemisphere, after the fluid contacted by each, are machined from $6 \mathrm{Al} 4 \mathrm{~V}$ titanium forgings which are welded together while kept in alignment by a backup ring. At one pole is an integral boss, housing a small valve through which the pressurizing gas is filled; at the other pole is 


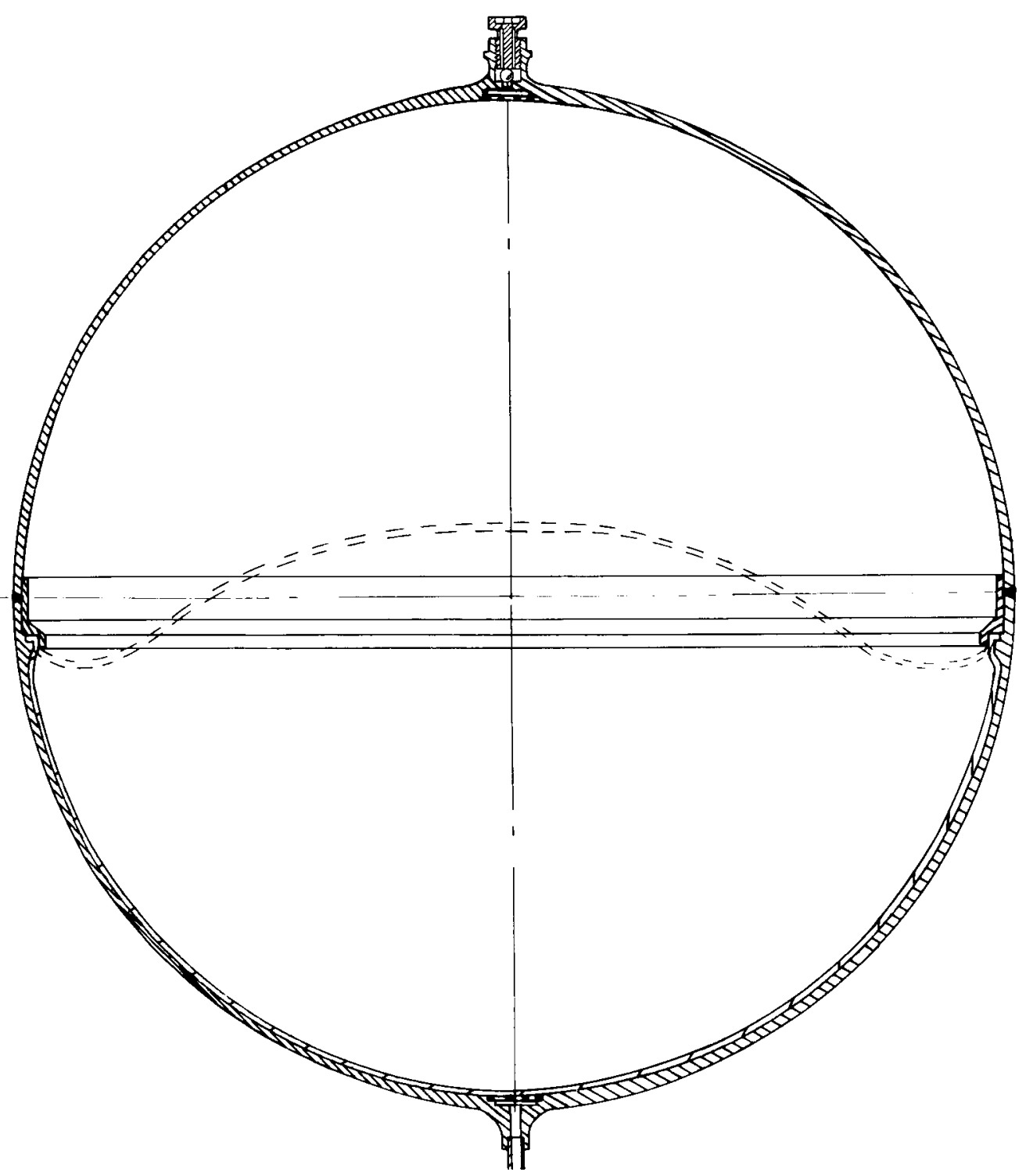

Fig. 34. Cross-section of the ALPS generant tank and expulsion diaphragm assembly

a small boss to which is welded a small outlet tube through which the generant is filled and expelled. The expulsion diaphragm is made of 0.035 -in.-thick ethylene propylene rubber of Shore A 80 hardness. It is anchored and sealed to the tank by an O-ring type of lip along its periphery which is clamped near the equator (or girth) of the tank between the backup ring and a sealing surface on the liquid-side hemisphere. This method of clamping the periphery was chosen in preference to a bolted flange in order to minimize the weight. When filled with the rated capacity of 1227 in. ${ }^{3}$ of generant, the diaphragm assumes a position which divides the tank into nearly equal volumes and after expulsion, its contour matches that of the lower half (or liquid-side hemisphere) of the tank. A segmented or interrupted rib pattern on the side contacted by the liquid serves to improve expulsion efficiency by preventing the diaphragm from being sealed tightly against the tank wall which might result in part of the liquid being trapped away from the outlet.

Small perforated plates cover both of the ports so that the diaphragm cannot be accidentally damaged by extrusion. In order to select the proper size holes for the perforated plates, a series of extrusion tests was carried out to investigate the required ratio of diaphragm thickness to hole diameter as a function of the final generant 
tank pressure. From the data it appears that for this application, holes with smooth entrances and with diameters approximately equal to or less than the diaphragm thickness are not likely to cause damage to the diaphragm. Therefore, the holes in the plates were made 0.040 in. in diameter with the entries rounded to a 0.020 -in. radius, and the diaphragm was locally thickened in the area that contacts the perforated plate. These plates prevent extrusion damage even when complete expulsion is achieved at final pressures as high as 700 psig (i.e., 700 psi differential pressure is allowed to develop across the diaphragm).

Four of the ALPS generant tank assemblies were fabricated for JPL by Pressure Systems, Inc. (City of Commerce, Calif.). The first was a special test assembly fitted with thermocouples to measure local temperatures during welding to be sure that the edge of the elastomeric diaphragm would not be overheated. These four tanks contained diaphragms molded by Parker Seal Co. of their ethylene propylene compound E515-8 and by Stillman Rubber Co. of their ethylene propylene compound 722-70. The total dry weight of each assembly was $20.8 \mathrm{lb}$; optimization of the tank might reduce this figure slightly.

The three operational tanks successfully passed proof, leak, and expulsion tests. One tank has been used with hydrazine in tests of the ALPS pressurization subsystem. Two of the diaphragms were inadvertently damaged at JPL, but the fabricator has successfully cut the tanks open, inserted new diaphragms, and welded them closed again.

This development has been completed except for slosh and long-term storage tests. Reference 24 is a detailed report on this project.

\section{E. ALPS Start Tank}

Concurrently with the investigations of bladders and convoluted metal diaphragms for the main ALPS tankage, a start tank was designed, fabricated, and tested. The start tank is not directly applicable to the current ALPS system but is an alternate to bladders and diaphragms as a solution to the general problem of starting a liquid rocket engine under zero-gravity conditions.

Start tanks (or "trap tanks") have been proposed as a means of using the main engine to accelerate the vehicle and settle the propellants. The start tank serves as a small auxiliary source of bubble-free propellant which the engine burns during the start and propellant settling period. Then, by appropriate valving, the engine is switched to propellant flowing from the main tanks. The dependence of this scheme upon smooth, uninterrupted flow during the switchover is obvious. Several approaches have been proposed by the industry and at least one device has been built. Unfortunately, all of the industrial designs examined to date have been mechanically complicated, have required electrical sequencing and power, or have involved the use of unacceptable operations such as overboard bleeding, etc.

The ALPS start tank concept was devised in an attempt to eliminate these disadvantages. It requires no external signals or actuation power, no source of pressurizing gas, and no engine sequencing. Apparently it can be installed in tanks of any conventional shape and be used with any earth-storable propellants.

The ALPS start tank operating sequence is shown schematically in Fig. 35. (Only one tank is shown for the sake of simplicity, but, of course, each propellant requires a separate tank.) The two basic parts are a nested-type bellows and a venturi valve. A spring holds the venturi valve closed at all times except during operation so that the propellant tank outlet ports are closed off. During the propellant tank filling operation, the volume between the propellant control valves on the engine and the top of the bellows (at its free, extended position) is completely filled with bubble-free liquid propellant. While coasting in zero-g ullage may be displaced from the top of the main tank so that bubbles of gas circulate throughout all parts of the tank (Fig. 35a); the tank outlet port seals prevent any of these gas bubbles from entering the feed line. The rocket engine is started in the conventional manner by opening the propellant valves and starting the flow of pressurizing gas into the main tanks. The venturi valve, held closed by the spring, prevents flow from the main tank while the pressure difference across the bellows causes the bellows to collapse and pump a predetermined volume of propellant into the engine. By proper sizing of the bellows volume, a sufficient engine burning time is obtained with this supply of propellant to settle the propellant in the main tank. At the point where the bellows has nearly reached the end of its stroke, it pushes the venturi valve open by overcoming the spring force (Fig. $35 \mathrm{~b}$ ). The venturi seals off the spring cavity as it descends, then uncovers the tank outlet port so propellant can flow out of the main tank through the venturi to the engine (Fig. 35c). The low static pressure in the venturi throat (caused by the increased local velocity) is transmitted to 


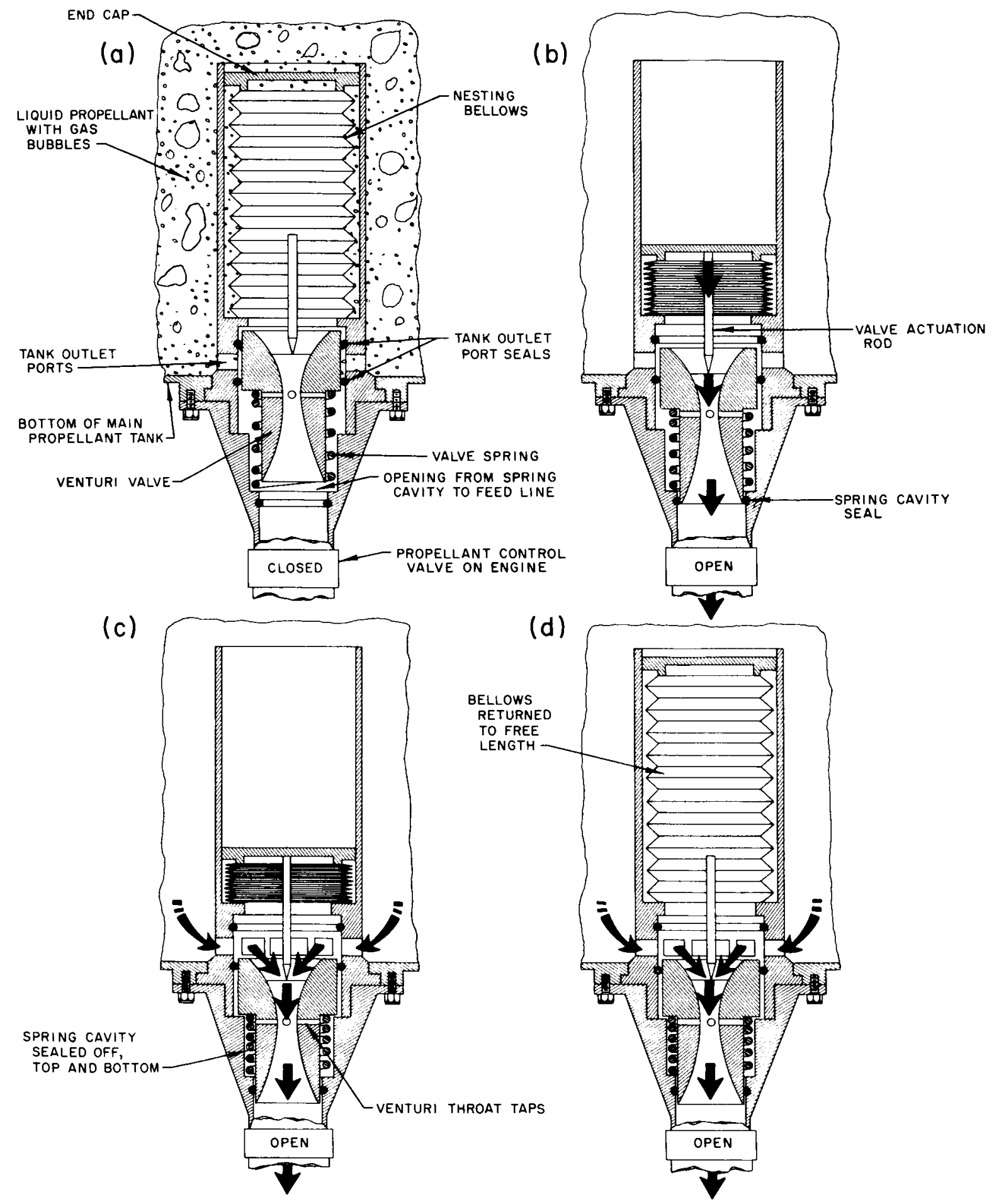

Fig. 35. ALPS start tank configuration and operating sequence 
the spring cavity through several small holes. (Low pressure cannot be obtained in the spring cavity before the valve opens because of the large opening between the cavity and the feed line below the valve.) An unbalance of pressure forces is created by the low pressure on the under side of the valve in the spring cavity and high pressure on the top of the valve; the resultant force is sufficient to hold the valve open against the spring force.

After the flow passage from the main tank is opened, the differential pressure across the bellows is greatly reduced so that the resilience of the bellows returns it to its free length (Fig. 35d); this action fills the bellows again with bubble-free propellant. The venturi valve remains open even after the bellows force is removed because of the resultant pressure force mentioned above, and it will remain open until the propellant valve stops flow to the engine. As flow stops, the pressure on all sides of the venturi equalizes and the spring returns the valve to the closed position (Fig. 35a). The start tank is now "recharged" and ready for another cycle.

Any number of cycles can be accomplished if each is completed. The necessity of completing each cycle is a drawback since the length of the cycle determines the minimum impulse bit a given installation can be called upon to deliver. Several different versions of this scheme can be used which shorten the cycle or even eliminate the need to cycle but these alternate plans complicate the device.

A Plexiglas model of essentially the same ALPS start tank design as shown in Fig. 35 was built and successfully tested with water. The range of flow rates over which the model would properly function, however, was quite limited. At low flows, the valve failed to open fully and the bellows did not refill. High flow rates caused the valve to open prematurely before the bellows had stroked. Later, analysis showed that design optimization would have greatly increased the operable flow range. No further work was done on the start tank since the feasibility had been adequately established.

\section{F. Additional Information}

Progress reports on the ALPS developments described above appear in the JPL Space Programs Summaries, Vol. IV (Unclassified). These reports are issued every other month.

\section{SUMMARY AND CONCLUSIONS}

The use of moving barrier-type positive expulsion devices can be advantageous for a number of reasons, particularly when the expulsion operation must be accomplished in free-fall. Choosing the optimum device for a given application can be difficult. The only rational procedure available to the designer is to methodically weigh the merits of each device against the needs of the mission; the constantly changing state of the art must be recognized and the latest data obtained to assure that a meaningful evaluation is performed.

Bladders, diaphragms, and pistons are three kinds of barriers that have potential application. Each of these has certain design and performance characteristics.
Starting in the middle 1940's, JPL has been involved in the development of all three kinds for use with the "earth-storable" liquid propellants. Both bladders and pistons have been used in Ranger and Mariner spacecraft with considerable success.

More stringent requirements will have to be satisfied in the future so advanced development programs at JPL are currently grappling with some of the more serious problems. Larger sizes, longer storage times, and wider temperature ranges (up to $+300^{\circ} \mathrm{F}$ if heat sterilization is used) are likely to pose major difficulties. Specific investigations now under way are aimed at finding more 
compatible materials for oxidizer service, means of using metals for reducing permeation, mechanisms for controlling the fold patterns in order to achieve multiplecycle operation with minimum deterioration, etc. Some new component designs, such as a small tank with integral rubber expulsion diaphragm and pressurant, have been developed.
At the present time, the only permeation-tight devices available for long-term storage of propellants in space are metal diaphragms and bellows-sealed pistons. Both devices require special tankage designs. The diaphragms, as yet, have not been proven reliable for multiple expulsion cycle service. The bellows, on the other hand, are heavy and susceptible to damage from vibration.

\section{REFERENCES}

1. Krivetsky, A., Research on Zero-Gravity Expulsion Techniques, Report No. 7129-933003, Bell Aerosystems Company, Buffalo, N.Y., March, 1962.

2. Study of Zero-Gravity Positive Expulsion Techniques, Report No. 8230-933004, Bell Aerosystems Company, Buffalo, N.Y., June, 1963.

3. Development of Expulsion and Orientation Systems for Advanced Liquid-Rocket Propulsion Systems, Report No. SSD-TDR-62-172, Rocket Research Laboratories, Edwards Air Force Base, Calif., November 1963.

4. Environmental Specification, Ranger Block-III, Flight Equipment Assembly Level Type Approval Test Procedures, JPL Specification 30277, Jet Propulsion Laboratory, Pasadena, Calif., February 18, 1963.

5. Mathematical Definition of Materials Strains During Folding of a Hemispherical Expulsion Bladder, Report ARC-R-61, Astro Research Corporation, Santa Barbara, Calif., May 10, 1962. (Available only from JPL, Re-order No. 62-320.)

6. Vango, S. P., Determination of Permeability of Cast TefIon Sheet to Nitrogen Tetroxide and Hydrazine, Technical Memorandum No. 33-35, Jet Propulsion Laboratory, Pasadena, Calif., August 25, 1961.

7. Stanford, H. B., The Measured Permeability to Nitrogen Tetroxide of Some Potential Bladder Materials, Technical Memorandum No. 33-123, Jet Propulsion Laboratory, Pasadena, Calif., March 24, 1963.

8. Porter, R. N., The Fabrication of Seamless Teflon Propellant Expulsion Bladders, Technical Report No. 32-919. Jet Propulsion Laboratory, Pasadena, Calif. July 1 , 1966.
9. MacGlashan, W. F., "Bladder Development," Space Programs Summary No. 37-34, Vol. IV, pp. 176-177, Jet Propulsion Laboratory, Pasadena, Calif., August 31, 1965.

10. Koch, E. F., et al, "Advanced Liquid Propulsion System," Space Programs Summary No. 37.15, Vol. IV, pp. 149155, Jet Propulsion Laboratory, Pasadena, Calif., June 30,1962 .

11. Porter, R. N., et al, "Advanced Liquid Propulsion System," Space Programs Summary No. 37-32, Vol. IV, pp. 151-162, Jet Propulsion Laboratory, Pasadena, Calif., April 30, 1965.

12. Densmore, J. E., Dual Generated-Gas System for Pumping Propellants, Progress Report No. 20-240, Jet Propulsion Laboratory, Pasadena, Calif., September 30, 1954. CONFIDENTIAL

13. Densmore, J. E., Bell, G. L., and Stanford, H. B., Generated-Gas System for Pumping Propellants, Report No. 20-93, Jet Propulsion Laboratory, Pasadena, Calif. April 3, 1957. CONFIDENTIAL

14. Lee, D. H., Development of the Midcourse TrajectoryCorrection Propulsion System for the Ranger Spacecraft, Technical Report 32-335, Jet Propulsion Laboratory, Pasadena, Calif., March 15, 1963.

15. Evans, D. D., et al, The Development of Ranger Block-III Spacecraft Propulsion System, Technical Report No. 32-829, Jet Propulsion Laboratory, Pasadena, Calif. March 15, 1966.

16. Smith, W. W., Development of a Trajectory-Correction Propulsion System for Spacecraft, Technical Report No. 32-205, Jet Propulsion Laboratory, Pasadena, Calif., December 8,1961 . 


\section{REFERENCES (Cont'd)}

17. Schmitz, B. W., and Groudle, T. A., Development of the Post-Injection Propulsion System for the Mariner-C Spacecraft, Technical Report No. 32-830, Jet Propulsion Laboratory, Pasadena, Calif. April 1, 1966.

18. Porter, R. N., and Evans, D. D., "Advanced Propulsion Systems for Unmanned Spacecraft," Astronautics and Aeronoutics, Vol. 3, No. 6, June 1965.

19. Dipprey, D. F., ef al, On the Evolution of Advanced Propulsion Systems for Spacecraft, Technical Report No. 32-735, Jet Propulsion Laboratory, Pasadena, Calif., July $15,1965$.

20. Vango, S. P., and Krasinsky, J. B., "Metal Plating of Teflon Sheet As a Means of Reducing Permeation," Space Programs Summary No. 37-21, Vol. IV, pp. 251252, Jeł Propulsion Laboratory, Pasadena, Calif., June $30,1963$.
21. Vango, S. P., and Krasinsky, J. B., "Continued Effort in Metal Plating of Teflon Sheet As a Means of Reducing Permeation," Space Programs Summary No. 37-23, Vol. IV, pp. 283-286, Jet Propulsion Laboratory, Pasadena, Calif., October 31, 1963.

22. Investigation of Unique Composite Fluorocarbon Type Material for Reduction of Nitrogen Tetroxide Permeability, Report No. 520-290, Redel Inc., Anaheim, Calif., August 15, 1962. (Available only from JPL; Reorder No. 62-319.)

23. Porter, R. N., ef al, "Advanced Liquid Propulsion System," Space Programs Summary No. 37-30, Vol. IV, pp. 120-122, Jet Propulsion Laboratory, Pasadena, Calif., December 31, 1964.

24. Keller, O. F., and Toth, L. R., ALPS Generant Tank and Cell Assembly, Technical Report 32-865, Jet Propulsion Laboratory, Pasadena, Calif. February 28, 1966. 


\section{ACKNOWLEDGMENTS}

It is not feasible to list all of the people, both at JPL and at contractors' plants, who did the work described herein and helped the writers in preparing this report. We hope they will accept, nevertheless, our grateful thanks for their contributions. To S. P. Vango and his associates in the Analytical Chemistry Section of JPL and to L. K. Jones of the Liquid Propulsion Section of JPL, we wish to express special gratitude for the accomplishment of much of the work described in the section on "Advanced Development" which was done within JPL. 